\begin{abstract}
Title of Thesis:

Degree Candidate:

Degree and year:

Thesis directed by:

REMEDIATION OF ABANDONED MINES USING

COAL COMBUSTION BY-PRODUCTS

Sowmya Bulusu

Master of Science, 2005

Dr. Ahmet H. Aydilek

Department of Civil and Environmental Engineering
\end{abstract}

Acid mine drainage (AMD) is a phenomenon that occurs when pyrite that is present in abandoned coal mines comes in contact with oxygen and water, forming acidic water rich in dissolved metals. Grout injection into mines is a popular technique that provides a permanent solution to control AMD. The main objective of this study was to investigate the effectiveness of coal combustion by-products (CCBs) in encapsulation of pyrite to remediate AMD. To meet this objective, CCB-based grouts were tested for spread, slump, bleed, and strength. Pyrite was coated with grouts and laboratory tests were performed to evaluate the encapsulation potential. Hydraulic conductivity was measured, and the leachate was analyzed for AMD- 
related parameters. Results indicated that flowability and strength of grout are related to the fly ash and free lime contents. High $\mathrm{pH}$, calcium and sulfate concentrations, and low concentrations of iron and aluminum in the leachate indicate that effective encapsulation has taken place. 


\title{
REMEDIATION OF ABANDONED MINES USING COAL COMBUSTION BY-PRODUCTS
}

\author{
by
}

\section{Sowmya Bulusu}
Thesis submitted to the Faculty of the Graduate School of the University of Maryland, College Park in partial fulfillment of the requirements for the degree of Master of Science
2005

Advisory Committee:

Dr. Ahmet H. Aydilek, Chair

Dr. Deborah J. Goodings

Dr. Dimitrios G. Goulias 
(C) Copyright by

Sowmya Bulusu

2005 
To Mummy, Pappa and Karti

I couldn't have done it without you all. 


\section{ACKNOWLEDGEMENTS}

I would like to thank a number of people who were vital to the completion of my thesis. First of all, I would like to thank my advisor, Dr. Ahmet H. Aydilek, for providing excellent guidance throughout this project. His enthusiasm and zeal in performing research inspired me to perform to the best of my ability. I would like to thank the members of my thesis committee, Dr. Deborah J. Goodings and Dr. Dimitrios G. Goulias, for their time and expertise.

My family and friends have motivated and supported me throughout and their contribution to this thesis is immense. I am forever indebted to my parents and brother for their understanding, endless patience, encouragement and advice when it was most required. I deeply appreciate the assistance provided by my colleagues Reagan, Ameya, Houng Li and all my other friends in conducting my experiments.

I gratefully acknowledge the financial support from the PPRP at the Maryland Department of Natural Resources and would especially like to thank Mr. Paul A. Petzerick for providing me the valuable opportunity of visiting a field site which provided great insight in conducting my research and experiments. 


\section{TABLE OF CONTENTS}

LIST OF FIGURES vii

LIST OF TABLES $\mathrm{X}$

1. INTRODUCTION 1

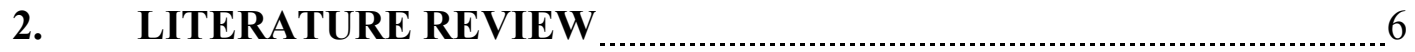

2.1 REMEDIATION OF ACID MINE DRAINAGE _............................... 6

2.2 ALKALINE ADDITION

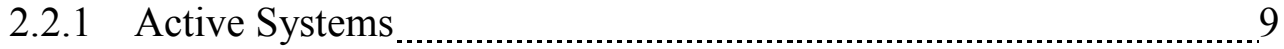

2.2.2 Passive Alkaline Addition Systems $\ldots$

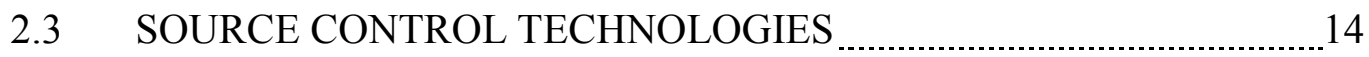

2.4 COAL COMBUSTION BY-PRODUCTS _..........................................

2.4.1 Fly Ash _ 16

2.4.2 Bottom Ash

2.4.3 Boiler Slag _ _ _ _ $\quad 19$

2.4.4 Flue Gas Desulfurization By-Product _...................................... 19

2.4.5 Fluidized Bed Combustion By-Product _.......................................... 21

2.5 LIME KILN DUST / CEMENT KILN DUST _ _

2.6 GROUT INJECTION 22

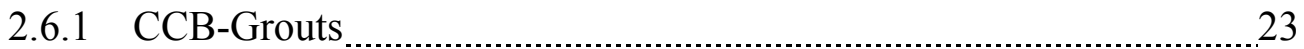

2.7 SYNTHESIS AND MOTIVATION FOR CURRENT RESEARCH $\ldots 24$

3. WINDING RIDGE DEMONSTRATION PROJECT _....................... 28

$3.1 \quad$ INTRODUCTION

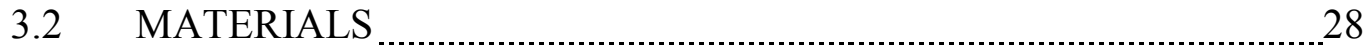

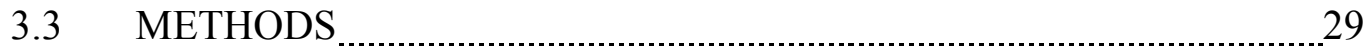

3.3.1 Laboratory Tests $\quad 29$

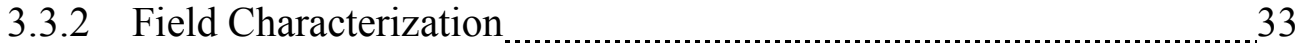


3.3.3 Sampling Locations

3.3.4 Injection Procedure and Post-Injection Monitoring _......................... 37

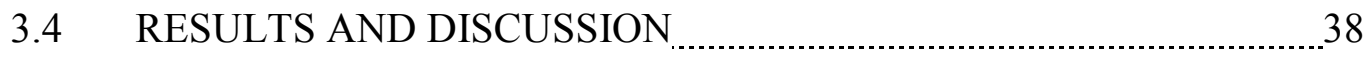

3.4.1 Laboratory Tests $\ldots$

3.4.2 Selection of the Optimal Field Grout Mix $\ldots$

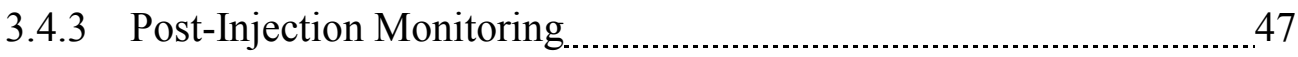

4. LABORATORY EVALUATION OF GEOMECHANICAL

PROPERTIES

4.1 MATERIALS 61

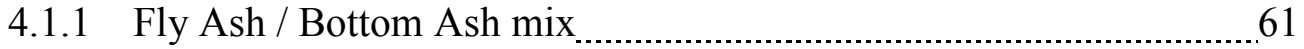

4.1.2 Fluidized Bed Combustion By-Product _....................................... 64

4.1.3 Lime Kiln Dust $\ldots$

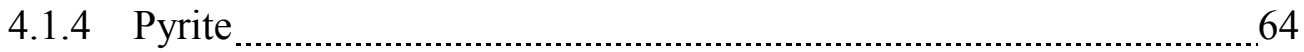

4.2 GEOTECHNICAL LABORATORY TEST PLAN _.............................. 65

4.3 SPREAD $\quad 71$

4.4 SLUMP $\quad 80$

4.5 BLEED _ 82

4.6 UNCONFINED COMPRESSIVE STRENGTH _ _ _............................ 84

5. LABORATORY EVALUATION OF HYDRAULIC

CONDUCTIVITY AND LEACHING BEHAVIOR

$5.1 \quad$ INTRODUCTION

5.2 HYDRAULIC CONDUCTIVITY _.............................................. 91

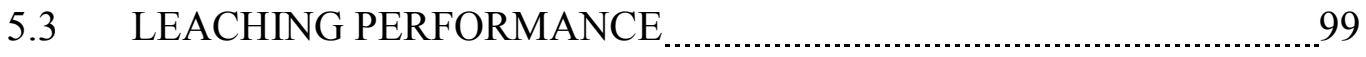

$5.3 .1 \mathrm{pH}_{1} \ldots$

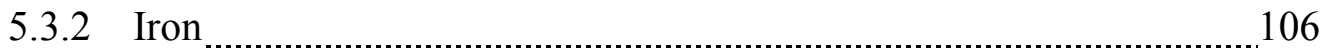

5.3.3 Aluminum

5.3.4 Sulfate $\quad 114$

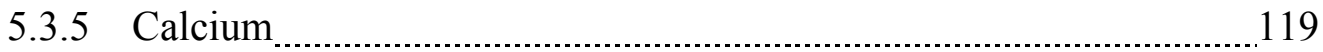




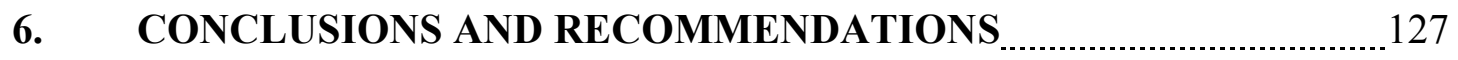

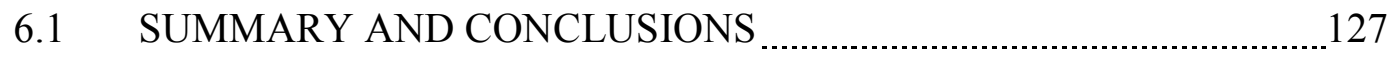

6.2 RECOMMENDATIONS 130

7. REFERENCES 


\section{LIST OF FIGURES}

Figure 1.1 AMD Pollution in Western Maryland 3

Figure 2.1 Abiotic and Biotic Remediation Systems _.................................. 8

Figure 2.2 Direct Alkaline Addition - Lime Doser $\ldots$

Figure 2.3 SEM images of (a) Fly ash and (b) Bottom ash $\ldots \ldots \ldots$

Figure 3.1 Schematic diagram of Mine Opening 2 35

Figure 3.2 Locations of mine openings, wells and coreholes

in the Frazee mine 36

Figure 3.3 Slump versus (a) Fly ash, and (b) Free lime content /

Fly ash for FBC-based and lime-based mixtures 39

Figure 3.4 Modified flow versus (a) Fly ash, and (b) Free lime

content / Fly ash for FBC-based and lime-based mixtures 40

Figure 3.5 Bleed versus (a) Fly ash, and (b) Free lime content /

Fly ash for FBC-based and lime-based mixtures

Figure 3.6 Strength versus (a) Fly ash and (b) Free lime content /

Fly ash for FBC-based and lime-based mixtures

Figure 3.7 Strength versus Curing time for FBC-based and

lime-based mixtures

Figure 3.8 Measured flow rates at Mine Opening 2 (MO2)

of the lower seep

Figure 3.9 Concentrations of various AMD parameters before

and after placement of the grout 52

Figure 4.1 Grain Size Distribution for FA-BA, FBC, and LKD 
Figure 4.2 Grain Size Distribution for Pyrite

Figure 4.3 Pyrite used in this study 67

Figure 4.4 FBC / FA-BA versus Spread for different water contents _................. 73

Figure 4.5 LKD / FA-BA mix versus Spread for different water contents _......... 75

Figure 4.6 Water content versus (a) Lime Activator /

FA-BA, and (b) FA-BA \%

Figure 4.7 Spread / Water Content versus (a) Lime Activator /

FA-BA, and (b) FA-BA \% 79

Figure 4.8 Slump / Water Content versus (a) Lime Activator /

FA-BA, and (b) FA-BA \%

Figure 4.9 Bleed / Water Content versus (a) Lime Activator /

FA-BA, and (b) FA-BA \%

Figure 4.10 Strength (at 7-day curing) versus (a) Lime Activator/

FA-BA, and (b) FA-BA \% 87

Figure 4.11 Strength versus Curing Time for (a) FBC-based, and

(b) LKD-based mixtures 88

Figure 5.1 Grout encapsulated pyrite in the mine pavement and shaft _............90

Figure 5.2 Pyrite/Grout column top and front view

Figure 5.3 Constant-head hydraulic conductivity set-up for pyrite-grout

columns 94

Figure 5.4 Hydraulic conductivity (k) versus time for FBC-based mixtures $\quad 95$

Figure 5.5 Hydraulic conductivity versus time for LKD-based mixtures _..........97

Figure 5.6 Hydraulic Conductivity versus (a) Free lime content / FA-BA, and

(b) FA-BA \% 100

Figure 5.7 $\mathrm{pH}$ versus time for FBC-based and LKD-based pyrite-grout columns

Figure 5.8 Average $\mathrm{pH}$ versus Free lime Content 105

Figure 5.9 Concentration of Iron versus time for different pyrite/grout 
mixtures

Figure 5.10 Concentration of Iron versus (a) FBC / FA-BA, and

(b) LKD / FA-BA

Figure 5.11 Concentration of Aluminum versus time for different

pyrite/grout mixtures

Figure 5.12 Concentration of Aluminum versus (a) FBC / FA-BA, and

(b) LKD / FA-BA

Figure 5.13 Concentration of Sulfate versus time for different

pyrite/grout mixtures 116

Figure 5.14 Concentration of Sulfate versus (a) FBC / FA-BA, and

(b) LKD / FA-BA

Figure 5.15 Concentration of calcium versus time for different

pyrite/grout mixtures

Figure 5.16 Concentration of calcium versus (a) FBC / FA-BA, and

(b) LKD / FA-BA

Figure 5.17 Concentrations of Calcium versus Concentrations of Sulfate for

(a) FBC-based, and (b) LKD-based grout mixtures 126 


\section{LIST OF TABLES}

Table 2.1 Chemical composition of bottom ash and boiler slag samples

Table 3.1 Physiochemical properties of CCBs 30

Table 3.2 Mixture proportions of FBC-based and lime-based mixtures .............. 31

Table 3.3 Cost Analysis

Table 3.4 Hydraulic conductivity and strength of exhumed grout specimens 50

Table 3.5 Water quality results for groundwater and surface 60

Table 4.1 Physical and chemical properties of materials used 62

Table 4.2 Legend and composition of grout mixture ratios 68

Table 4.3 Initial testing of FBC-based grout mixtures

Table 4.4 Initial testing of LKD-based grout mixtures for water contents $\quad 70$

Table 4.5 Results of spread, slump, and bleed for "optimal" grout mixtures 76

Table 4.6 Results of unconfined compressive strength for "optimal" grout Mixtures

Table 5.1 Hydraulic conductivity of pyrite-grout columns 96 


\section{SECTION 1}

\section{INTRODUCTION}

Acid Mine Drainage (AMD) is a ubiquitous problem in areas where abandoned coal mines exist. It is a phenomenon that occurs when oxygen and water come in contact with sulfur bearing minerals like pyrite that are commonly present in coal seams and in rock layers overlying coal seams. A series of geo-chemical and microbial reactions oxidize the sulfide minerals forming mainly iron hydroxide, iron sulfate, and sulfuric acid. As a result, water with high acidity and dissolved metals is discharged into the environment causing severe damage to all forms of life.

Coal mining in Western Maryland began in the early 1800s with small deep mines, most of which were developed utilizing gravity drainage to avoid excessive water accumulation in the mines. As a result, acidic water that is rich in iron, sulfur,

and aluminum drained away from the mines into nearby streams (Rafalko and Petzrick 2000). Maryland has about 450 coal mines out of which only 50 are active and about 150 mines produce AMD (Rafalko and Petzrick 2000; Petzrick 2001). The combination of these factors has caused one of the most serious water pollution problems in the state. The AMD problem is also present in other states including the two neighboring states, Pennsylvania and West Virginia (Dolence and Giovannitti 1997; Petzrick 1997; Barton and Karathanasis 1999; Rudisell et al. 2001; Herr et al. 2003; Taerakul et al. 2004). These are the two most extensively mined states in Appalachian region, with both experiencing severe acid drainage pollution. Pollution caused by acid drainage that flows from abandoned coal mines is so severe in some 
parts of the Appalachian region that plant and animal life in many streams has not survived (Fig. 1.1). The U.S. Environmental Protection Agency has singled out acid drainage from abandoned coal mines as the major water quality problem in this region.

In the last few decades, many in-situ abiotic and biological remediation technologies have been developed to remediate abandoned mines producing AMD. Application of alkaline products, directly to the mine discharge or incorporation into soil as trenches or mine overburden, is a popular remediation technique. However, these methods pose various problems due to formation of metal precipitates and armoring of the alkaline products, and are not very cost effective.

Grout injection into abandoned coal mines is a popular technique that provides a permanent solution to control AMD. The injected grout penetrates into the pyritic rock present on the mine pavement and shaft, entombs the pyrite and forms a long-term barrier between the pyrite and water and oxygen, thus reducing the potential for acid formation.

Coal combustion by-products (CCBs) like fly ash, bottom ash, fludized bed combustion (FBC) ash, and flue gas desulfurization (FGD) sludge that are extensively produced by various coal burning power plants pose a great disposal problem in the U.S. Grouts consisting of alkaline CCBs such as FBC and FGD, have great potential to neutralize AMD. 


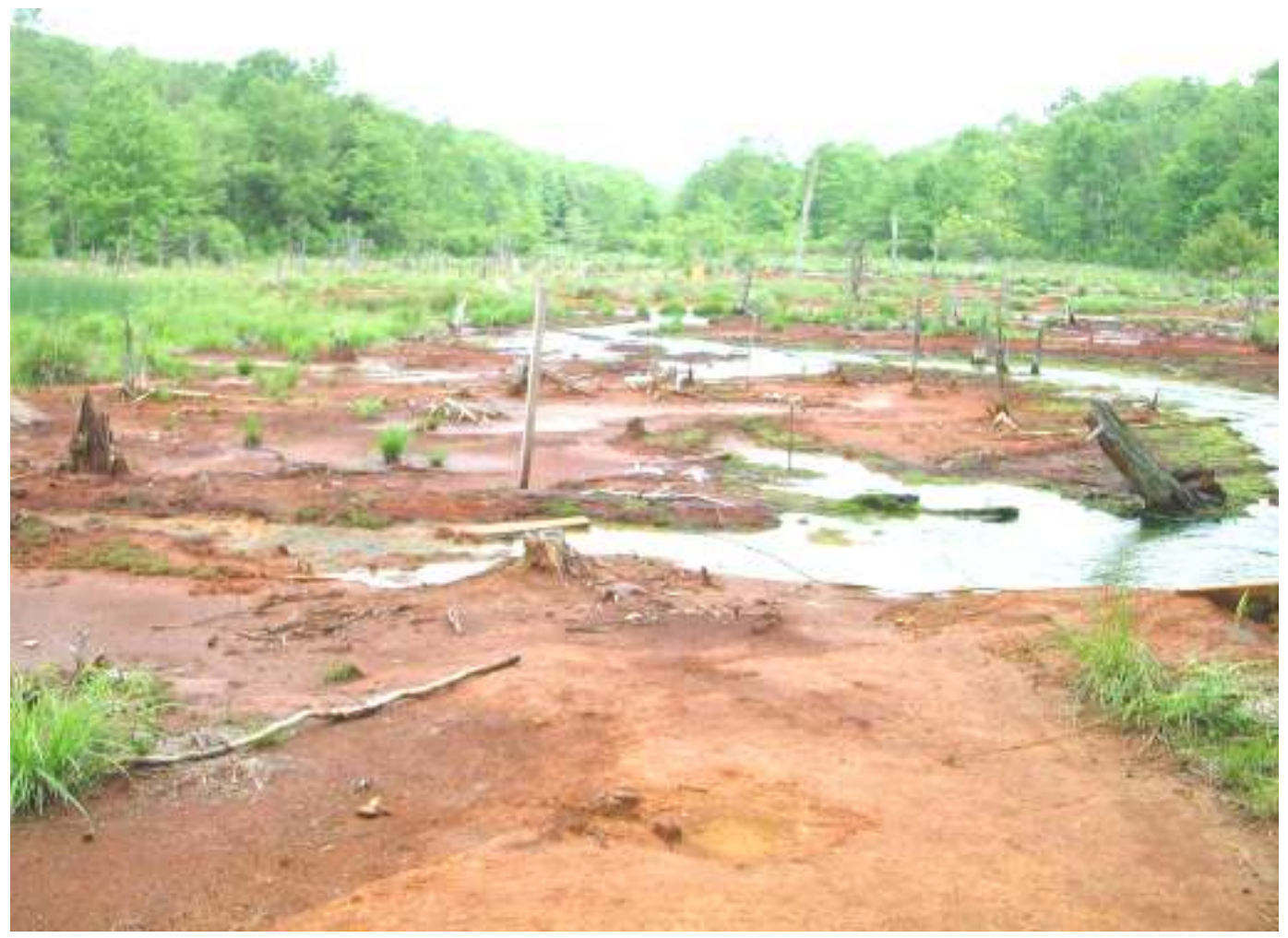

Figure 1.1. AMD Pollution in Western Maryland 
The main objectives of this study were:

- To determine if CCBs collected from Maryland's power plants have suitable geomechanical and environmental properties needed for use in remediation of abandoned coal mines,

- To study the encapsulation of pyrite with CCB-grouts, and

- To determine the long-term effectiveness of a field remediation application initiated in Western Maryland in abating AMD.

To meet these objectives, laboratory tests were conducted on various grouts with different proportions of CCBs collected from Maryland power plants, and lime kiln dust (LKD) to evaluate their geomechanical properties and leaching behaviour. Spread, slump, bleed, and unconfined compressive strength tests were performed in order to arrive at optimal grout mixtures. These mixtures were then evaluated for their potential to encapsulate the pyrite rock in mine pavements and shafts. As part of the study, the data collected from the Frazee mine, a four hectare abandoned underground coal mine in Western Maryland, remediated using CCBs, were analyzed to evaluate the long-term effectiveness of the encapsulation process.

A literature review of various in-situ AMD remediation techniques, including grout injection, is presented in Section 2. This section also provides information about the origin and properties of various coal combustion by-products such as fly ash, bottom ash, FBC, FGD, and high lime-content by-products such as LKD and cement 
kiln dust (CKD). Section 3 presents the results of the Winding Ridge Project, a demonstration project conducted to investigate the long-term effectiveness of CCBbased grout mixtures in abating acid mine drainage. Section 4 discusses the results of the laboratory geomechanical tests. Section 5 discusses the hydraulic conductivity and leaching behavior of pyrite after encapsulation by selected grout mixtures. The summary and conclusions obtained from the current work and recommendations for further research are given in Section 6. 


\section{SECTION 2}

\section{LITERATURE REVIEW}

\subsection{REMEDIATION OF ACID MINE DRAINAGE}

Acid mine drainage (AMD) is the most severe environmental pollution problem in the Appalachian region in Eastern U.S. AMD kills fish and aquatic insects, stunts plant growth, and leaches toxic concentrations of metals like iron, and aluminum from mine rocks, causing further contamination of creeks, rivers, and ground water.

The chemical reactions that characterize various stages of pyrite oxidation and formation of AMD are as follows (Singer and Stumm 1970):

$$
\begin{aligned}
& \mathrm{FeS}_{2}+7 / 2 \mathrm{O}_{2}+\mathrm{H}_{2} \mathrm{O} \rightarrow \mathrm{Fe}^{2+}+2 \mathrm{SO}_{4}{ }^{2-}+2 \mathrm{H}^{+} \\
& \mathrm{Fe}^{2+}+1 / 4 \mathrm{O}_{2}+\mathrm{H}^{+} \rightarrow \mathrm{Fe}^{3+}+1 / 2 \mathrm{H}_{2} \mathrm{O} \\
& \mathrm{Fe}^{3+}+3 \mathrm{H}_{2} \mathrm{O} \rightarrow \mathrm{Fe}(\mathrm{OH})_{3}+3 \mathrm{H}^{+} \\
& \mathrm{FeS}_{2}+14 \mathrm{Fe}^{3+}+8 \mathrm{H}_{2} \mathrm{O} \rightarrow 15 \mathrm{Fe}^{2+}+2 \mathrm{SO}_{4}{ }^{2-}+16 \mathrm{H}^{+}
\end{aligned}
$$

In the above reactions, $\mathrm{Fe}^{3+}$ and oxygen are the major pyrite oxidants. In Eq. 2.1, the pyrite is oxidized by atmospheric oxygen and water to form sulfuric acid and soluble ferrous ions, which are then oxidized to ferric ions (Eq. 2.2). The reaction shown in Eq. 2.2 is $\mathrm{pH}$ dependant and occurs very slowly at a $\mathrm{pH}$ of about 3 . However, the presence of iron-oxidizing bacteria Thiobacillus ferrooxidans can accelerate the oxidation of $\mathrm{Fe}^{2+}$ by a factor of $10^{6}$ (Singer and Stumm 1970). The next reaction is a 
major reaction in the release of acid to the environment (Eq. 2.3). During this reaction, hydrolysis of ferric ion occurs at $\mathrm{pH}$ values of above 3.5 and the ferric hydroxide is formed. In the last reaction, pyrite is then oxidized by the ferric ions.

AMD prevention and/or remediation are essential in order to reclaim the areas of land and water that is plagued by the AMD problem. AMD treatment can be generally classified into two main areas: passive treatment and active treatment methods. The traditional and most common method to control AMD is active treatment i.e., direct alkaline addition to AMD to neutralize the acidity and cause metals to precipitate out into their insoluble form. Passive treatment refers to the use of natural or constructed wetland ecosystems that rely on biological, geochemical and gravitational processes to remediate AMD. The latter does not require constant operation and maintenance as in active systems. Active and passive treatment technologies remediate AMD through biotic or abiotic processes. Biotic systems rely on biological processes to treat AMD, where as the abiotic systems utilize chemical and neutralization processes (Johnson and Hallberg 2005). A good summary of the various remediation options for AMD is shown in Figure 2.1.

\subsection{ALKALINE ADDITION}

Alkaline addition involves using alkaline products such as sodium hydroxide $(\mathrm{NaOH})$, sodium carbonate $\left(\mathrm{Na}_{2} \mathrm{CO}_{3}\right)$, calcium oxide $(\mathrm{CaO})$, calcium carbonate $\left(\mathrm{CaCO}_{3}\right)$, or calcium hydroxide $\left(\mathrm{Ca}(\mathrm{OH})_{2}\right)$, directly or indirectly to treat AMD. For instance lime and limestone, which comprises of $\mathrm{CaO}$ and $\mathrm{CaCO}_{3}$ respectively, are commonly used in AMD remediation. 


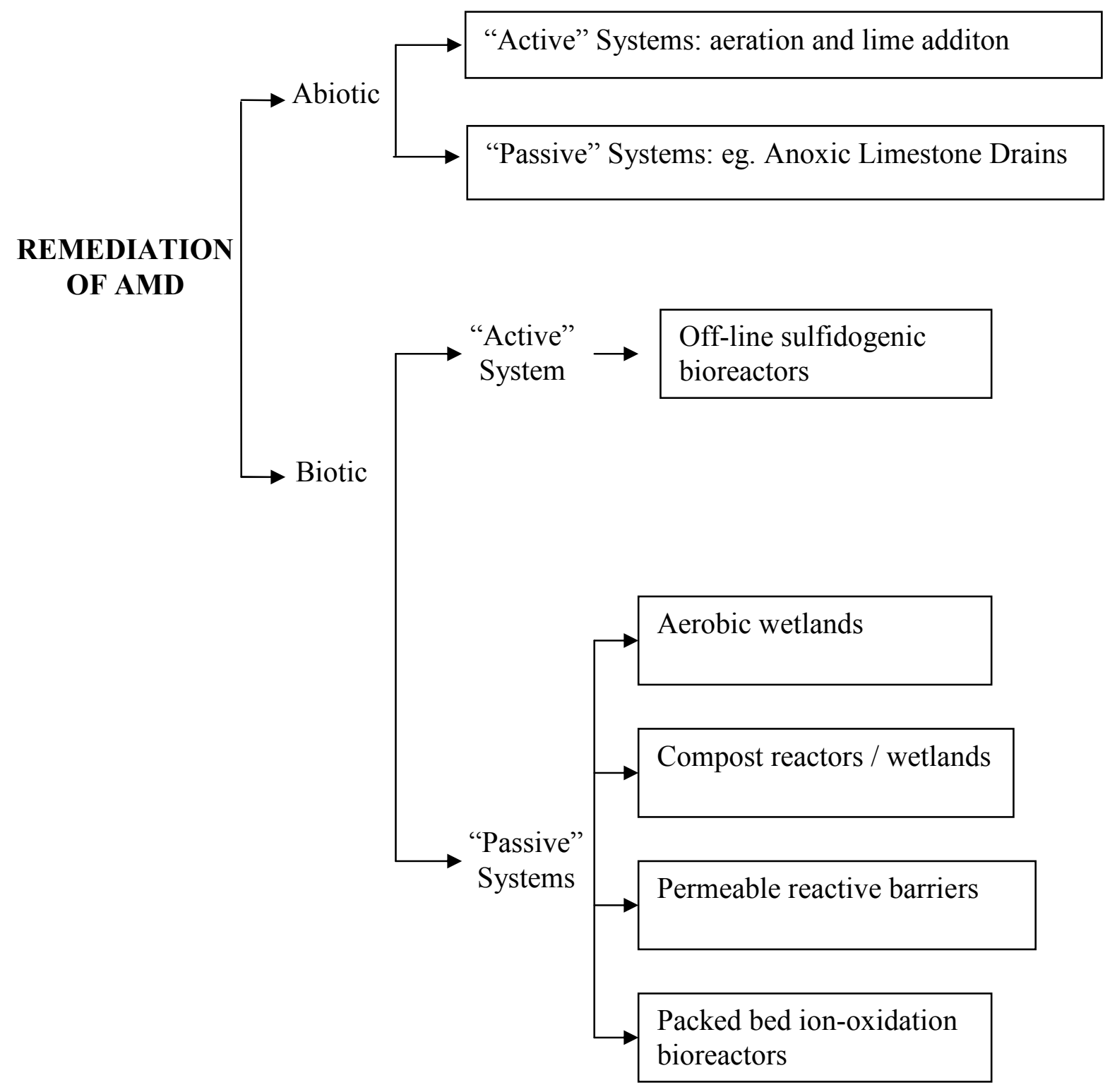

Figure 2.1. Abiotic and Biotic Remediation Systems

(After Johnson and Hallberg, 2005) 
These strong bases act as $\mathrm{pH}$ buffers and neutralizers, and cause metals to precipitate. Alkaline products can be applied to treat AMD in many ways:

1. Active systems which refers to direct addition of alkaline materials to AMD to neutralize the acidity.

2. Passive treatment systems such as open limestone channels, and anoxic limestone drains.

\subsubsection{Active Systems}

Direct addition of alkaline materials to a stream affected by AMD is one of the simplest and most widely used methods to treat AMD. The injected alkaline material neutralizes the acidity of the stream raising the $\mathrm{pH}$ and precipitates the metals out. Most active treatment systems consist of an inflow pipe, a storage tank or a bin to hold the treatment chemical, a means of controlling the chemical application, a settling pond to capture precipitated metal precipitates, and a discharge point. Dosers are generally used to add the alkaline material into the acidic stream. A photo of lime doser system is given in Figure 2.2.

The amount and type of alkaline material to be added depends on the flow rate of the stream, acidity of the AMD, types and concentrations of metals in the water, and desired final water quality. The selection of the alkaline chemical also depends on other factors such as transportation, labor, and equipment costs. Limestone is a popular methodology for treatment of AMD due to its low cost, and easy handling of the metal sludge formed. However it has a tendency to get armored by formation of 

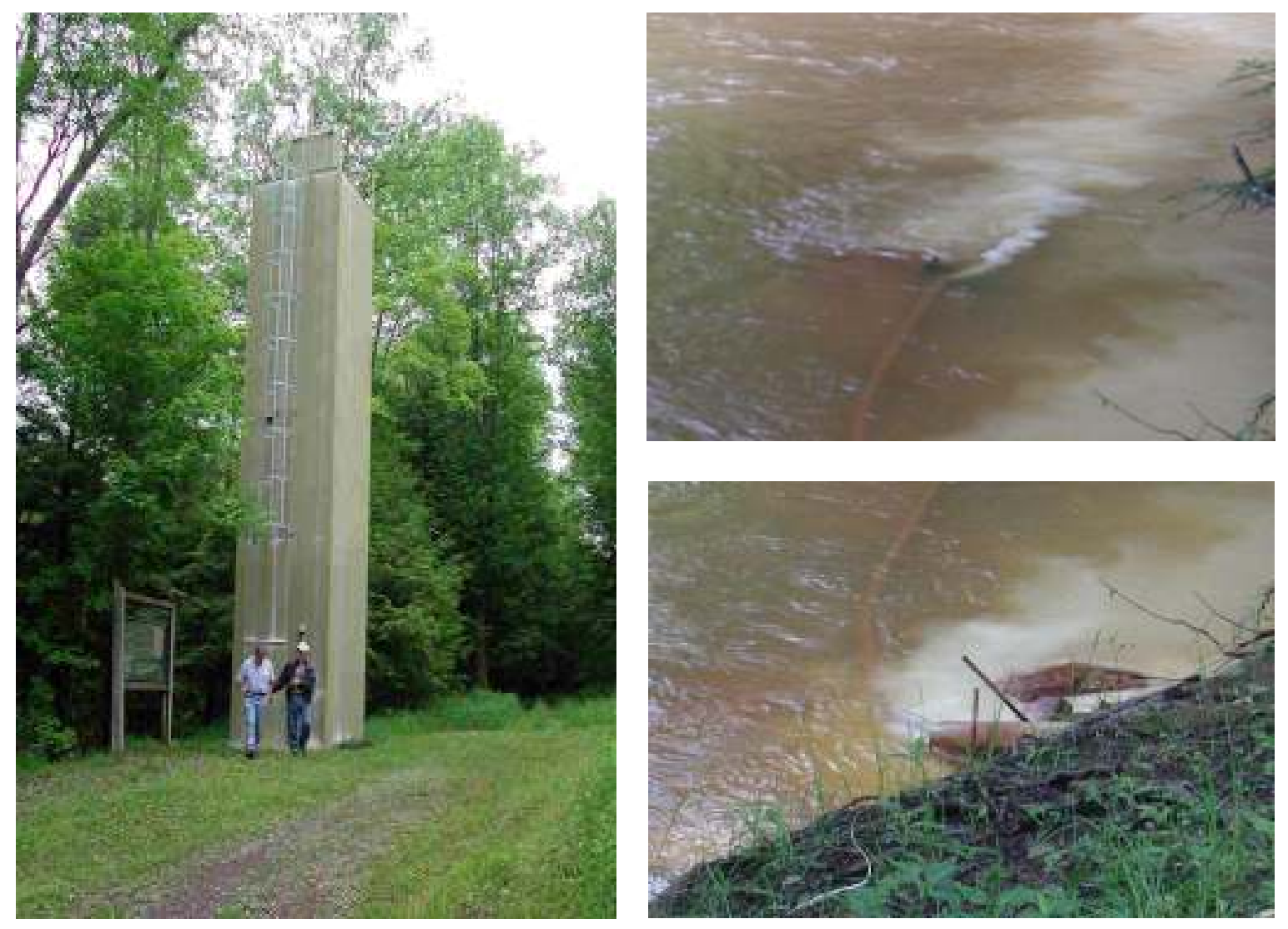

Figure 2.2. Direct Alkaline Addition - Lime Doser 
ferric hydroxide on its surface, which limits its solubility and reduces alkalinity available for treatment.

Crushed limestone was used to reclaim $22 \mathrm{~km}$ of acidic water in the Blackwater River in West Virginia (Zurbuch 1984). Rotary drum stations were used to grind the limestone into a powder form before introducing into the streams. The $\mathrm{pH}$ of samples collected from the stream was around 6.0. In another study sand-sized limestone, which is known as limestone sand, was introduced into the Middle Fork River along 41 sites, including 27 tributaries (Zurbuch 1996). The pH of collected samples from the site was around 6.0 as well. Limestone sand is usually added into the banks of the stream and is gradually washed downstream, neutralizing the acidity as it carried through the stream bed. Addition of limestone sand is most effective for streams with low $\mathrm{pH}$ and relatively low concentrations of metals.

Hydrated lime $\left(\mathrm{Ca}(\mathrm{OH})_{2}\right)$ is also commonly used for treating AMD. It is particularly useful and cost effective in areas where the flow rate and acidity of the AMD are high. In these areas, treatment plant with a mixer/aerator is generally constructed to help aerate the water and mix the chemical with the water (Skousen and Ziemkiewicz 1996).

Active treatment systems are effective only if they are monitored and maintained on a regular basis. However, they are very expensive to operate and maintain, and disposal of the metal-laden sludges can be a problem. They are also impractical for many remote abandoned mine sites. 


\subsubsection{Passive Alkaline Addition Systems}

Another approach for treating AMD by alkaline material addition is through passive treatment methods. Alkaline material may be placed in stratified layers in the overburden, as ditches or channels in the stream bed, or as buried trenches to impart alkalinity by coming in contact with the AMD.

Open Limestone Channels (OLCs) impart alkalinity to AMD in open channels or ditches lined with limestone (Ziemkiewicz et al. 1994). OLCs can be constructed in two ways: dropping large, high-quality limestone in existing stream channels, or constructing a diversion channel parallel to the stream and rerouting the contaminated water through the new channel. In time, the limestone fragments become armored (coated) by metal hydroxide, and cease to dissolve, which decreases their effectiveness at neutralizing the acidity of the water. However, a study conducted by Ziemkiewicz et al. (1997) showed that armored limestone was only 2 to $45 \%$ less effective than unarmored limestone in neutralizing acid, depending on the $\mathrm{pH}$ of the solution. In a field study conducted on seven armored limestone open channels, they observed that acid concentrations of AMD were reduced by 4 to $62 \%$. Ziemkiewicz et al. (1997) concluded that OLCs work best on steep slopes (> $20 \%)$ and where flow velocities are high enough to keep the metal hydroxide in suspension, thereby limiting their precipitation on the channel bed.

A method to prevent armoring of limestone is the use of Anoxic Limestone Drains (ALDs). A typical ALD consists of crushed limestone of uniform size in a buried trench or pit into which acidic AMD is channeled before its exposure to atmospheric oxygen. The trenches are usually covered using a geomembrane to 
reduce or eliminate the presence of oxygen and aerated water to prevent armoring of the limestone. ALD for treatment of mine water was first introduced by Turner and McCoy (1990) and have been effectively used to remediate AMD since then. They are often used as a pre-treatment methodology to increase alkalinity and raise $\mathrm{pH}$ before the water is routed into a wetland or pond, where the metals are oxidized and removed (Hedin et al. 1994, Whitehead et al. 2005a). At the Howe Bridge and Morrison ALDs in Pennsylvania, alkalinity in effluents increased by 128 and 248 $\mathrm{mg} / \mathrm{L}$, respectively, over influent water (Hedin et al. 1994). At both sites, the ALDs precede ponds and wetland systems.

The $\mathrm{pH}$ of effluent dissipating from an ALD typically ranges from 6 to 7 , and ferrous hydroxide generally does not precipitate at such values, even though the precipitation of aluminum hydroxide is very likely to occur. Thus, longevity of treatment is also a concern for ALDs in the presence of $\mathrm{Fe}^{+3}$ and $\mathrm{Al}^{+3}$. These ions, if present in the AMD, have the potential to significantly reduce the permeability due to clogging of the drain with their hydroxides, resulting in early failure. For instance, in a study, Whitehead et al. (2005b) observed that ALD was effective in increasing the $\mathrm{pH}$ of the mine water. However, as the $\mathrm{pH}$ increases, aluminum hydroxide was precipitated as a gel which blocked flow within the drain, since Al concentration in the mine water was around $100 \mathrm{mg} / \mathrm{L}$. As a result, the ALD pretreatment method was abandoned. The results of the study showed that the sole function of an ALD is to convert net acidic mine water to net alkaline water by adding bicarbonate alkalinity, and the method should not be considered for removal of metals. 
Alkaline material may also be incorporated in the mine overburden as a trench or a pit to provide an induced alkaline recharge zone. The infiltrating water will provide an alkaline front that migrates through the backfill neutralizing acidity and increasing the $\mathrm{pH}$. The alkalinity may also cause the acid-producing reactions to slow down, which in turn decreases the acidity. Caruccio et al. (1984) studied the performance of 15 in-situ recharge trenches of $3 \mathrm{~m}$ width, $1 \mathrm{~m}$ depth, and 23 to $220 \mathrm{~m}$ length. It was seen that the acidity (expressed as $\mathrm{mg} / \mathrm{L}$ of $\mathrm{CaCO}_{3}$ ) decreased from 600 $\mathrm{mg} / \mathrm{L}$ to $100 \mathrm{mg} / \mathrm{L}$, which was accompanied by a decrease in sulfate concentrations.

\subsection{SOURCE CONTROL TECHNOLOGIES}

AMD treatment methods are employed when AMD formation has already taken place or is anticipated to occur. However, methods that treat the pyrite directly to prevent or retard formation of AMD are source-control methods. Both oxygen and water are required for the formation of AMD. Therefore, by limiting the intrusion of either oxygen or water (or both), it is possible to minimize AMD production. One proposed method of source control is permanent inundation and sealing of the mine. The dissolved oxygen present in the water will be consumed by oxidation reactions of pyrite and replenishment of the oxygen will be impeded by the top seal (Johnson and Hallberg 2005). In the Broken Aro mine in Ohio, groundwater was sealed inside the underground mine to inundate the mine voids with water so that AMD can be minimized (Rudisell et al. 2001). The seal was made from a coal combustion byproduct called flue gas desulfurization (FGD) sludge. The low permeability FGD seal limited the seepage of water out of or into the mine. This method improved water 
quality inside the mine, and reduced flow rate of water seeping from the mine, since the contaminant load to Simmons Run decreased up to about $98 \%$.

Mine sealing method is effective if all mine shafts and voids are known and there is no influx of oxygen-rich water. Unfortunately, this is not possible in all cases since detailed maps may not be available for old abandoned underground mines. The mine configurations are approximately estimated by drilling exploratory boreholes or groundwater monitoring wells. Hence, the mine is generally not entirely sealed off in a remediation application and may still continue to form AMD. Another approach to source-control is to mix acid-producing material with acid-consuming material to obtain an environmentally safe material (Mehling et al. 1997). In general, it is difficult to inhibit the formation of AMD at source as there are many factors that have to be satisfied to cause significant reduction in its formation. Thus, active or passive treatment technologies are generally employed in the field to mitigate the problem after formation. However, at-source technologies may prove to be more cost effective if details of site conditions are known.

\subsection{COAL COMBUSTION BY-PRODUCTS}

Mined coal is used for electric power generation in most of the power plants in the United States. As a result, the power plants produce vast quantities of coal combustion by-products (CCBs). The type of $\mathrm{CCB}$ produced at a plant depends on the type of coal burnt, type of boiler, and combustion technology used. The most common types of CCBs include fly ash, bottom ash, boiler slag, fluidized bed combustion by-product, and flue gas desulfurization by-product. The latter two are 
results of new technologies for burning coal, minimizing the production of $\mathrm{SO}_{2}$ gas. Hence they are rich in lime content $(\mathrm{CaO})$.

In 1999, approximately 1.2 million tons of CCBs were generated in Maryland and this total is expected to grow to 2 million tons by 2009 (Hodges and Keating 1999). A majority of these CCBs are placed in landfills, which consume valuable space and may affect the terrestrial and aquatic resources. Thus, beneficial use of these $\mathrm{CCBs}$ is necessary.

\subsubsection{Fly Ash}

Fly ash is defined as "the finely divided residue resulting from the combustion of ground or powdered coal, which is removed from the stack gasses with various types of air quality control equipment" (ACI Committee 116 1985). Unburned particles of coal are carried from the boiler in flue gases. These particles solidify while suspended in the flue gases to form fly ash, which is then collected from the flue gas by means of electrostatic precipitators, baghouses, or mechanical collection devices such as cyclones. Fly ashes collected using mechanical collection devices are usually coarser than those collected using electrostatic precipitators (Tolle et al. 1982). Fly ash particles are primarily solid or hollow glassy spheres (Figure 2.3a) which vary in size from 1 micron $(0.001 \mathrm{~mm})$ to 100 microns $(0.1 \mathrm{~mm})$ (Federal Highway Administration 1986). The specific gravity of fly ash varies from source to source but usually ranges from 2.1 to 2.6 (Adriano et al. 1980). The major constituents of fly ash are aluminum, iron, magnesium, silicon, and calcium. 

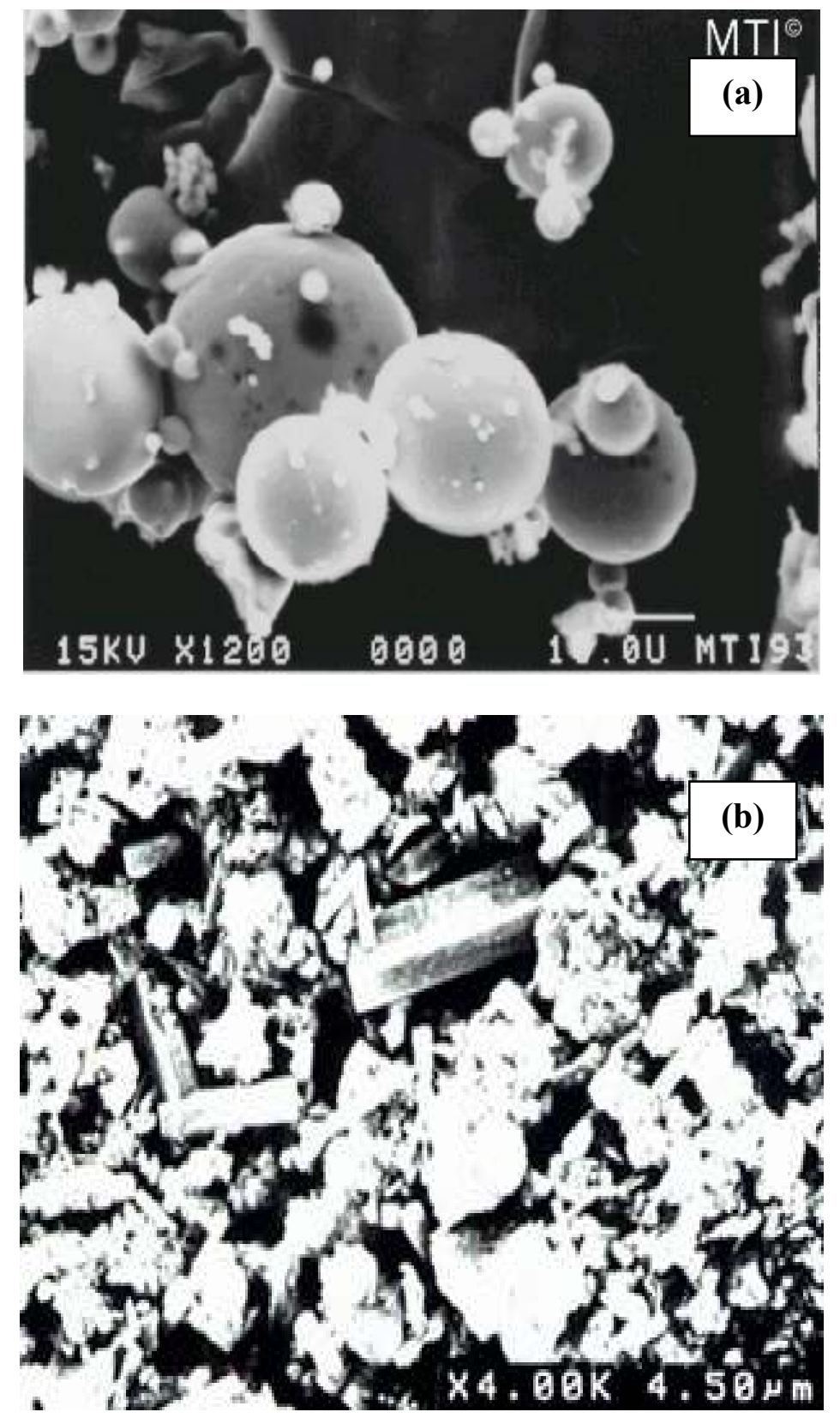

Figure 2.3. SEM images of (a) Fly ash and (b) Bottom ash 
However, the chemical composition of fly ash varies widely, depending on the type of coal burned, the particle size of the ash, and the efficiency of the collectors. ASTM C 618 classifies fly ash as Class F and Class C based on their chemical composition and the type of coal they are produced from. Class C fly ash is produced from burning lignite or sub-bituminous coal, and Class F fly ash is produced from anthracite or bituminous coal. Class C fly ash is self cementitious where as Class F fly ash possesses little or no self-cementing properties. Class F fly ash is a pozzolan: a siliceous material which in the presence of water will combine with lime $(\mathrm{CaO})$ to produce a cementitious material with good structural properties. Class F fly ash is typically associated with eastern and midwestern U.S. coals and Class C is associated usually with western U.S. coals.

The color of fly ash ranges from tan to gray to black depending on the carbon content of the ash. Lighter color indicates lower carbon content. Fly ash obtained from lignite or sub-bituminous coal is lighter in color indicating lower carbon content and presence of calcium, whereas anthracite or bituminous fly ashes are shades of gray.

\subsubsection{Bottom Ash}

When coal is burned in a dry bottom boiler, about $80 \%$ of the unburned residue is carried by the flue gases and is captured as fly ash. The remaining $20 \%$ is a coarse, non-combustible, fused residue that falls to the bottom of the boiler and is called bottom ash. Bottom ash is typically gray to black in color. Bottom ash particles are angular (Figure 2.3b), have a porous surface texture, and range in size from fine 
gravel to fine sand. Specific gravity of bottom ash is a function of its carbon content, with higher carbon content resulting in lower specific gravity. Specific gravity ranges from 2.1 to 2.7 . Bottom ashes are primarily composed of silica and alumina, and smaller percentages of oxides of iron, magnesium, calcium, sodium, potassium, and sulfate. Ash derived from anthracite or bituminous coals has lower calcium than ashes derived from lignite or sub-bituminous coal.

\subsubsection{Boiler Slag}

Wet-bottom boilers contain quenching water in their ash hoppers. When molten slag comes into contact with the water it immediately crystallizes and forms pellets. The large fused particles of ash thus formed are called boiler slag. Boiler slags are usually coarse to medium sand-sized within the range of $5.0 \mathrm{~mm}$ to $0.5 \mathrm{~mm}$ (Moulton 1973). Boiler slag obtained from burning lignite or sub-bituminous coal is more porous than the ash from anthracite coals (Majizadeh et al. 1979). Specific gravity of boiler slag ranges from 2.3 to 2.9 . The chemical composition of boiler slag is very similar to that of bottom ash. Typical chemical compositions of bottom ash and boiler slag are given in Table 2.1.

\subsubsection{Flue Gas Desulfurization By-Product}

The burning of pulverized coal in electric power plants produces sulfur dioxide $\left(\mathrm{SO}_{2}\right)$ gas emissions. The Clean Air Act Amendments promulgated in 1990 mandated the reduction of $\mathrm{SO}_{2}$ emissions from power plants. Flue Gas Desulfurization (FGD) by-product is the solid residue generated from the treatment of 
Table 2.1 Chemical composition of bottom ash and boiler slag samples

(After Moulton, 1973)

\begin{tabular}{|c|c|c|c|c|c|}
\hline \multirow{3}{*}{$\begin{array}{c}\text { Chemical } \\
\text { Constituents }\end{array}$} & \multicolumn{3}{|c|}{ Bottom Ash } & \multicolumn{2}{|c|}{ Boiler Slag } \\
\hline & \multicolumn{2}{|c|}{ Bituminous Coal } & \multirow{2}{*}{$\frac{\text { Lignite Coal }}{\text { Texas }}$} & \multirow{2}{*}{$\begin{array}{c}\text { Bituminous Coal } \\
\text { West Virginia }\end{array}$} & \multirow{2}{*}{$\begin{array}{c}\text { Lignite Coal } \\
\text { North } \\
\text { Dakota } \\
\end{array}$} \\
\hline & $\begin{array}{c}\text { West } \\
\text { Virginia }\end{array}$ & Ohio & & & \\
\hline $\mathrm{SiO}_{2}(\%)$ & 53.6 & 47.1 & 70 & 48.9 & 40.5 \\
\hline $\mathrm{Al}_{2} \mathrm{O}_{3}(\%)$ & 28.3 & 28.3 & 15.9 & 21.9 & 13.8 \\
\hline $\mathrm{Fe}_{\mathrm{s}} \mathrm{O}_{3}(\%)$ & 5.8 & 10.7 & 2 & 14.3 & 14.2 \\
\hline $\mathrm{CaO}(\%)$ & 0.4 & 0.4 & 6 & 1.4 & 22.4 \\
\hline $\mathrm{MgO}(\%)$ & 4.2 & 5.2 & 1.9 & 5.2 & 5.6 \\
\hline $\mathrm{Na}_{2} \mathrm{O}(\%)$ & 1 & 0.8 & 0.6 & 0.7 & 1.7 \\
\hline $\mathrm{K}_{2} \mathrm{O}(\%)$ & 0.3 & 0.2 & 0.1 & 0.1 & 1.1 \\
\hline
\end{tabular}

Note: All percentages are by weight 
these emissions. FGD systems are designed to introduce an alkaline sorbent consisting of lime or limestone (primarily limestone) in a spray form into the exhaust gas system of a coal-fired boiler. The alkali reacts with the $\mathrm{SO}_{2}$ gas and is collected as calcium sulfite or calcium sulfate. FGD by-product is usually thixotropic in nature unless stabilized with fly ash or other dry materials. It has a specific gravity between 2.25 to 2.6 .

The physical nature of FGD by-product varies from a wet sludge to a dry powdered material depending on the process by which it is produced. The material consists of fine silt to clay sized particles. The calcium sulfate FGD is usually used as an embankment or road base material, whereas FGD with calcium sulfite can be used as a replacement for gypsum in cement manufacture.

\subsubsection{Fluidized Bed Combustion By-Product}

Fluidized Bed Combustion (FBC) by-product is the ash produced when coal with high sulfur content is burned with limestone in the fluidized bed boiler. Dry sorbents such as lime or limestone $\left(\mathrm{CaCO}_{3}\right)$ are added to the fluidized bed to generate $\mathrm{CaO}$ that removes sulfur dioxide $\left(\mathrm{SO}_{\mathrm{x}}\right)$ emitted from the burning coal. $\mathrm{FBC}$ byproduct has physical and chemical properties similar to Portland cement. It typically contains 25 to $30 \%$ free lime. The spent bed material (removed as bottom ash) contains reaction products from the absorption of gaseous sulfur oxides $\left(\mathrm{SO}_{2}\right.$ and $\mathrm{SO}_{3}$ ) and is generally known as FBC bed ash. 


\subsection{LIME KILN DUST / CEMENT KILN DUST}

Lime kiln dust (LKD) and cement kiln dust (CKD) are very fine particulates trapped in air pollution control systems of rotary kilns used to manufacture lime and Portland cement respectively. They are extremely fine materials with about $85 \%$ passing U.S. No. 200 mesh sieve size. The specific gravity of LKD and CKD ranges from 2.6 to 3.0 and from 2.6 to 2.8 , respectively. CKD has a chemical composition similar to Portland cement. The principal constituents are compounds of lime, iron, silica and alumina. LKD can vary chemically depending on whether high-calcium lime (chemical lime, hydrated lime, quicklime) or dolomitic lime is being manufactured. The free lime content of LKD can be significantly higher than that of CKD (up to about 40 percent), with calcium and magnesium carbonates as the principal mineral constituents.

\subsection{GROUT INJECTION}

Previous studies indicate that grout injection into abandoned coal mines provides a permanent solution to control land subsidence (Wilbert 1997, Stump 1998). Grouting of mines using alkaline binders has also been a popular method to reduce acid production (Harshberger and Bowders 1991, Gray et al. 1998, Siriwardane 2003, Taerakul et al. 2004). The injected grout penetrates into the fractures of the pyritic rock, entombs the debris from roof walls and collapsed chimneys, and provides structural support to the mine roof and walls to avoid further subsidence. Overall, the grout forms a long-term barrier between the pyrite in the mine and water and oxygen, thus reduces the potential for acid formation. 
In a study conducted by Siriwardane (2003), a grout consisting of a mixture of fluidized bed combustion (FBC) ash, bentonite, and water was used as a hydraulic backfill to control mine subsidence and acid mine drainage in an abandoned coal mine in West Virginia. After grouting, it was observed that flow rate of mine water dropped from a pre-backfilling value of $12.6 \mathrm{~L} / \mathrm{s}$ to less than $0.63 \mathrm{~L} / \mathrm{s}$. The acid concentrations did not change significantly, but the total acid production or acid load reduced significantly. In another study, a flue gas desulfurization (FGD) grout was injected into the Roberts-Dawson mine in central-eastern Ohio, and its effects on surface and groundwater impacted by AMD was studied (Taerakul et al. 2004). It was seen that the injection of FGD grout did not have any deleterious effect on the water quality in the vicinity of the mine. Although no siginificant reduction in the concentration of major elements in the mine seepage was observed, the FGD material remained geochemically stable in the acidic mine water.

\subsubsection{CCB-Grouts}

Some of the CCBs, such as flue gas desulfurization (FGD) and fluidized bed combustion (FBC) by-products are highly alkaline in nature due to the presence of unreacted lime (calcium oxide). Alkaline CCBs or other additives rich in free lime can be mixed with another $\mathrm{CCB}$, Class F fly ash, and water to prepare a grout that upon curing hardens like cement. Such grouts typically have low hydraulic conductivities, which is necessary to fill mine voids and seal off the mine from any contact with water or oxygen in a field remediation application (Harshberger and Bowders 1991, and Gabr et al. 1996). This alkaline CCB grout when injected into a 
mine penetrates into the mine voids and hardens, encapsulating the pyrite and impeding its contact with oxygen and water. The high free-lime content of the alkaline CCBs may also help in neutralizing the AMD.

CCBs have traditionally been used in flowable fill applications as they improve the flowability and reduce bleeding, shrinkage, and hydraulic conductivity of

grouts (Ayers et al. 1994, Naik and Ramme 1994, Butalia et al. 2001, Gabr and Bowders 2000); however, limited information exists about their applicability in mine grouting and long-term effectiveness in abating the acid mine drainage. In many ways, flowable fill is a construction method that could be applied to remediation of abandoned mines, since good flowability is essential for the grout to fill the pores of the acidic pyrite material. However, recent advancements in mine grouting suggested that the remediation of the abandoned mines could be highly different than flowable fills, due to requirement of relatively higher strengths to avoid mine subsidence, and potential contamination of groundwater and surface water by AMD (Haefner 2002, Murarka et al. 2002, Loop 2004, Taerakul et al. 2004).

\subsection{SYNTHESIS AND MOTIVATION FOR CURRENT RESEARCH}

Active treatment seems to be the most straightforward method for treating AMD, in which treatment can be warranted in the short-term. However, active treatment may prove to be not only very expensive but also ineffective in the long run due to formation of metal precipitates and sludge (Johnson and Hallberg 2005). Therefore, extensive research and field studies have been conducted for developing successful passive treatment technologies. 
Passive technologies such as open limestone drains and anoxic limestone drains are efficient in treating AMD only under certain conditions. Both work well only with waters that have low metal concentrations. However, past field experience has provided sufficient evidence that, at high metal contents, the limestone becomes armored with metals and is rendered ineffective (Hedin et al. 1994, and Cravotta 2003). ALDs are also ineffective when the mine water is aerated and contains high dissolved oxygen content. Alternative technologies, such as biological treatment have been developed; however, they are relatively expensive to install and usually require large areas of land. Furthermore, they are less predictable than chemical processes.

Of the many available technologies to treat AMD and limit its formation, grout injection is a popular and effective method. Low permeability grouts are injected into underground mines to displace mine water and seal the mines, so as to prevent contact of the acid producing pyrite with water and oxygen. Coal combustion by-products like fly ash, bottom ash, FBC ash, and FGD sludge that are extensively produced by various coal burning power plants pose a great disposal problem in the U.S. Lime activators such as FBC and FGD can be added to Class F fly ash to prepare grouts that have good flowable characteristics and reasonable strength. These grouts are alkaline in nature due to the lime activators and therefore neutralize the acidity of mine water.

In spite of the fact that extensive research and field applications exist for $\mathrm{CCB}$ grouting of underground mines, the emphasis is usually on filling all the mine voids with impermeable grout. However, as reported by Taerakul et al. (2004) as well as through the observations made in the Winding Ridge Demonstration Project (Section 
3), total filling of mine is not possible in most cases due to unknown voids that exist, and/or limited penetration of the grout into deep mine voids and pyritic rock on the mine pavement. It is more practical to aim at proper "encapsulation" of the pyritic rock in the mine pavements and shafts than to expect entire filling of mine voids.

The motivation for the current research was to investigate the effectiveness of $\mathrm{CCBs}$ to abate the acid mine drainage by studying the encapsulation process described above.

The three main objectives of the research program were:

- to determine if CCBs collected from Maryland power plants have suitable geotechnical and environmental properties needed for use in remediation of abandoned coal mines

- to study how the encapsulation of acid-leaching pyrite occurs with the CCBs, and

- to determine the long-term effectiveness of a field remediation application initiated in Western Maryland in abating the AMD and to make further recommendations for improving the future remediation strategies.

In order to satisfy these objectives, grouts with different proportions of CCBs collected from Maryland power plants, and quicklime were analyzed for geotechnical properties such as modified flow, slump, bleed, strength, and hydraulic conductivity in order to arrive at optimal mixtures. The optimal mixtures were then evaluated for 
their potential for encapsulating the pyrite rock in mine pavements and on the walls of the mine shafts. As part of the study, the data collected from the Frazee mine, a four hectare abandoned underground coal mine remediated in 1996 using CCBs, were analyzed to evaluate the long-term effectiveness of the encapsulation process. 


\section{SECTION 3}

\section{WINDING RIDGE DEMONSTRATION PROJECT}

\subsection{INTRODUCTION}

The Winding Ridge Project was a demonstration project conducted to investigate the effectiveness of CCB-based grout mixtures in abating acid mine drainage. The study included two phases: laboratory and field phase. In the laboratory phase, grouts with different proportions of Class F fly ash, FBC byproduct, FGD by-product, and quicklime were analyzed for geotechnical properties such as slump, modified flow, bleed, and strength in order to arrive at an optimal mixture. The second phase of this study entailed the injection of this optimal mixture into the Frazee mine, four hectare abandoned underground coal mine located in Western Maryland. An extensive set of pre- and post-injection water quality data was collected to analyze and assess the effectiveness of grout injection in reducing acid mine drainage. Hence, the demonstration project focuses not only on presenting a CCB-based optimal grout mixture, but also on assessing the long-term effect of the in-situ mine grouting operation.

\subsection{MATERIALS}

Class F fly ash, FGD by-product, FBC by-product, and quicklime were used in the laboratory tests. Natural spring water and mine water $(\mathrm{pH}=3)$ were used during grout preparation. The fly ash was obtained from pulverized bituminous coal used in the Mt. Storm Power Plant located in West Virginia. Atterberg limits tests 
conducted on the fly ash indicated that the liquid limit and plastic limit of fly ash were $29 \%$ and $27 \%$, respectively, indicating non-plastic nature of the material. Nonplastic FGD by-product was also obtained from the Mt. Storm Power Plant. The FBC by-product consisted of a blend of non-plastic fly ash and bed ash supplied by the Morgantown Energy Associates Power Plant located in West Virginia. The fly ash and bed ash in the case of FBC by-product refer to the ash obtained from the top and bottom, respectively, of the combustion chamber during the fluidized bed combustion process. The physiochemical properties of the Class F fly ash, FGD by-product, and FBC by-product are shown in Table 3.1.

\subsection{METHODS}

\subsubsection{Laboratory Tests}

In the laboratory study, specimens were prepared using different proportions of fly ash, FGD by-product, and an activator (free lime source). Two types of activators were used, FBC and lime. A series of geotechnical tests were performed on 16 FBC-based and lime-based specimens. The mixture designs for the laboratory tests are listed in Table 3.2. The amount of each by-product in a specimen was selected considering the widely used percentages in grout mixture design (Gabr et al. 1996, Huang 2001, Mirza et al. 2002, United Kingdom Quality Ash Association 2002). Eight of the specimens were prepared using spring water and the other eight were prepared with mine water to more closely represent the field conditions. For lime-based mixtures, the lime content in the entire mixture was varied between 5 and $10 \%$, and non-prehydrated lime was used for one of the mixtures. 
Table 3.1. Physiochemical properties of CCBs

Physical Properties

\begin{tabular}{c|c|c|c}
\hline Property & Fly Ash & FGD by-product & FBC by-product \\
\hline $\mathbf{D}_{\mathbf{1 0}}(\mathbf{m m})$ & 0.0035 & 0.0017 & 0.0095 \\
\hline $\mathbf{D}_{\mathbf{3 0}}(\mathbf{m m})$ & 0.0086 & 0.0026 & 0.0148 \\
\hline $\mathbf{D}_{\mathbf{8 5}}(\mathbf{m m})$ & 0.0375 & 0.0182 & 0.0771 \\
\hline $\begin{array}{c}\text { Fines content } \\
(\%)\end{array}$ & 99 & 100 & 81.7 \\
\hline $\mathbf{C}_{\mathbf{u}}$ & 5.36 & 4.2 & 4.3 \\
\hline $\mathbf{C}_{\mathbf{c}}$ & 1.14 & 0.58 & 0.56 \\
\hline
\end{tabular}

Chemical Constituents

\begin{tabular}{c|c|c|c}
\hline Chemical & Fly Ash & FGD by-product & FBC by-product \\
\hline $\mathbf{K}_{\mathbf{2}} \mathbf{O}(\%)$ & 2.4 & 0.2 & 1.6 \\
\hline $\mathbf{M g O}(\%)$ & 1.1 & 0.67 & 2.3 \\
\hline $\mathbf{F e}_{\mathbf{2}} \mathbf{O}_{\mathbf{3}}(\%)$ & 5.6 & 0.56 & 6.2 \\
\hline $\mathbf{A l}_{\mathbf{2}} \mathbf{O}_{\mathbf{3}}(\%)$ & 28.5 & 2.6 & 11.5 \\
\hline $\mathbf{S O}_{\mathbf{3}}(\%)$ & 0.59 & 47.1 & 12.3 \\
\hline $\mathbf{S i O}_{\mathbf{2}}(\%)$ & 52.4 & 3.4 & 24.7 \\
\hline $\mathbf{C a O}_{\mathbf{2}}(\%)$ & 1.6 & 35.4 & 24.8 \\
\hline \hline
\end{tabular}


Table 3.2. Mixture proportions of FBC-based and lime-based mixtures

\begin{tabular}{|c|c|c|c|c|c|c|c|c|c|c|c|c|}
\hline \multicolumn{6}{|c|}{ FBC - based Mixtures } & \multicolumn{7}{|c|}{ Lime - based Mixtures } \\
\hline $\begin{array}{c}\text { Mix } \\
\text { ID }\end{array}$ & $\begin{array}{c}\text { Fly } \\
\text { ash } \\
\% \\
\end{array}$ & $\begin{array}{c}\text { FGD } \\
\text { by- } \\
\text { product } \\
\%\end{array}$ & $\begin{array}{c}\text { FBC } \\
\text { by- } \\
\text { product } \\
\%\end{array}$ & $\begin{array}{c}\text { Average } \\
\text { water } \\
\text { content } \\
\% \\
\end{array}$ & $\begin{array}{c}\text { Water } \\
\text { type }\end{array}$ & $\begin{array}{c}\text { Mix } \\
\text { ID }\end{array}$ & $\begin{array}{c}\text { Fly } \\
\text { ash } \\
\text { \% }\end{array}$ & $\begin{array}{c}\text { FGD } \\
\text { by- } \\
\text { product } \\
\%\end{array}$ & $\begin{array}{c}\text { Lime } \\
\%\end{array}$ & $\begin{array}{c}\text { Average } \\
\text { water } \\
\text { content } \\
\%\end{array}$ & $\begin{array}{c}\text { Water } \\
\text { type }\end{array}$ & $\begin{array}{c}\text { Lime } \\
\text { pre- } \\
\text { hydrated } \\
?\end{array}$ \\
\hline $\mathrm{F}-1$ & 30 & 40 & 30 & 39 & Mine & L-1 & 50 & 40 & 10 & 41 & Mine & No \\
\hline $\mathrm{F}-2$ & 38 & 32 & 30 & 39 & Mine & L-2 & 50 & 40 & 10 & 41 & Mine & Yes \\
\hline $\mathrm{F}-3$ & 44 & 36 & 20 & 39 & Mine & L-3 & 40 & 50 & 10 & 41 & Mine & Yes \\
\hline $\mathrm{F}-4$ & 20 & 20 & 60 & 56 & Mine & L-4 & 40 & 55 & 5 & 41 & Mine & Yes \\
\hline F-5 & 40 & 40 & 20 & 39 & Spring & L-5 & 55 & 40 & 5 & 41 & Spring & Yes \\
\hline F-6 & 25 & 55 & 20 & 39 & Spring & L-6 & 40 & 55 & 5 & 41 & Spring & Yes \\
\hline F-7 & 30 & 40 & 30 & 39 & Spring & L-7 & 50 & 40 & 10 & 41 & Spring & Yes \\
\hline $\mathrm{F}-8$ & 15 & 55 & 30 & 39 & Spring & L-8 & 35 & 55 & 10 & 41 & Spring & Yes \\
\hline
\end{tabular}

Note:

Each FBC-based mixtures consisted of three specimens prepared by varying the water content from $38 \%$ to $40 \%$. Each lime-based mixtures consisted of three specimens prepared by varying the water content from $40 \%$ to $44 \%$. All the percentages are by weight. 
Similar initial water contents were intended during preparation of each mixture; however, due to hydration of lime and possible evaporation it was difficult to control the water content during the mixing process. As a result, the average initial water content was approximately $39 \%$ for FBC-based mixtures and $41 \%$ for limebased mixtures. A separate mixture with relatively low fly ash and high FBC content (F-4) was also included in laboratory tests and, considering these CCB percentages, the initial water content of this mixture was kept high $(\mathrm{w}=56 \%)$ to ensure good flowability. Triplicate specimens were tested from each mixture, and the average of the values was reported. The laboratory test data were interpreted to decide on the optimal mixture for field grouting.

The mixing was conducted as recommended in ASTM C 192 using a low shear mixer. Most of the lime-based mixtures were prepared using pre-hydrated quick lime, in which the lime was hydrated with spring or mine water in a steam chamber for about 12 hours. For the mixtures that did not use pre-hydrated lime, the lime was directly added to the dry mixture, and water was added subsequently. The slump of each grout was determined following the standard procedures in ASTM C 143/C 143M. The modified flow (i.e., spread) tests were conducted on the mixtures following the procedures outlined in ACI 229. The intention of using both slump and modified flow tests was to investigate whether a particular mixture had good flowability i.e., slump between 200 to $250 \mathrm{~mm}$, and good spread, i.e., at least 200 $\mathrm{mm}$. Bleed of the freshly prepared grout was determined following the procedures outlined in ASTM C 940. Unconfined compressive strength tests were conducted on cylindrical specimens with 75-mm diameter and 150-mm length using a compression 
machine with a loading capacity of $13,500 \mathrm{~N}$ and following the procedure summarized in ASTM C 39/C 39M. The FBC-based grouts were demolded after 24 hours, and the lime-based grouts were demolded after 40 to 50 hours. All specimens were cured for 7 days at $100 \%$ relative humidity and constant temperature $\left(\sim 21^{\circ} \mathrm{C}\right)$ before the strength tests. Additional unconfined compression strength tests were conducted on selected mixtures after 14 and 28 days of curing.

\subsubsection{Field Characterization}

The Frazee mine is located atop of Winding Ridge, a mountainous region located about $1.6 \mathrm{~km}$ east of Friendsville, Maryland. It was selected as the experimental area since the mine was perched high on an isolated ridge, the recharge area was well-defined, and the mine entries were known. Unfortunately, the internal mine geometry was not well known. As a small mine abandoned 35 years ago, a map of the mine was not available, and the mine geometry had to be established by interviewing miners who worked in the mine, exploratory drilling, and some downhole camera observations (Petzrick 1999).

The mine is overlain by about $30.5 \mathrm{~m}$ of shale and sandstone, $2 \mathrm{~m}$ thick Upper Freeport coal layer, and 0.15 to $0.45 \mathrm{~m}$ continuous rider coal seam. The strike of the face and butt cleats of the Upper Freeport coal are $\mathrm{N} 40^{0} \mathrm{E}$ and $\mathrm{N} 50^{0} \mathrm{~W}$, respectively. The floor of the mine consists of dense, dry weathered shale and a low hydraulic conductivity clay layer. Preliminary analysis indicated that the rider coal seam is the only other source of acid producing rock besides Upper Freeport coal layer (Rafalko and Petzrick 2000). 


\subsubsection{Sampling Locations}

The mine consists of four mine openings designated as MO1 through MO4, located along the south of the mine. Acid mine drainage (AMD) discharges only from a lower seep and upper seep at Mine Opening 2 (MO2), which is a collapsed entry (Figure 3.1) and water samples were collected from this opening. The flow from the lower seep is continuous, while the upper seep flows intermittently depending on the elevation of the mine pool. The mine pool elevation is around $660 \mathrm{~m}$ above the mean sea level. The combined discharge (from both seeps) varies between 0.13 and 0.32 $\mathrm{L} / \mathrm{s}$, and the acidic mine seepage is adsorbed into the underlying soil located $60 \mathrm{~m}$ below the MO2.

Six groundwater monitoring wells (designated as MW-1 through MW-6) were installed before grouting in 1995 to monitor the first water bearing zone commensurate with the elevation of the Frazee mine (Figure 3.2). These wells were completed at depths of about 24 to $30 \mathrm{~m}$. A seventh monitoring well, MW-7, was installed after grout injection to a depth of $100 \mathrm{~m}$ to monitor deep groundwater. Groundwater level measurements from four monitoring wells, MW-1 through MW-4, indicated that these wells have been dry since they were installed in 1995 and the Frazee mine is located in unsaturated bedrock. Measurements from MW-7 indicated the deeper water table is about 17 to $20 \mathrm{~m}$ below the floor of the mine.

Nearly one year after grout injection, nine coreholes were drilled to obtain hardened grout samples and to confirm the grout integrity (Figure 3.2). Grout was encountered in only three of the nine coreholes. 


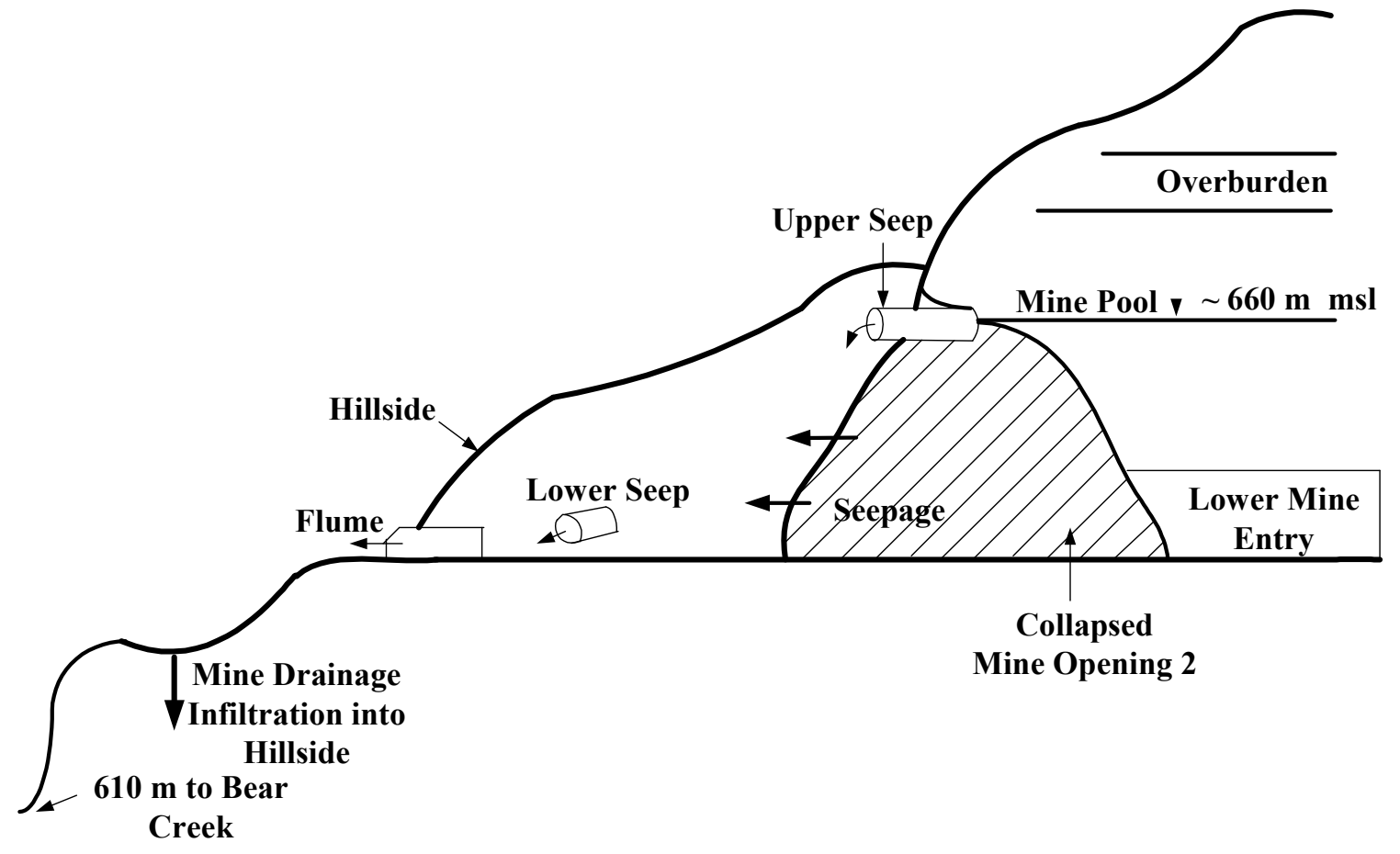

Figure 3.1. Schematic diagram of Mine Opening 2 (After Aljoe 1999) 


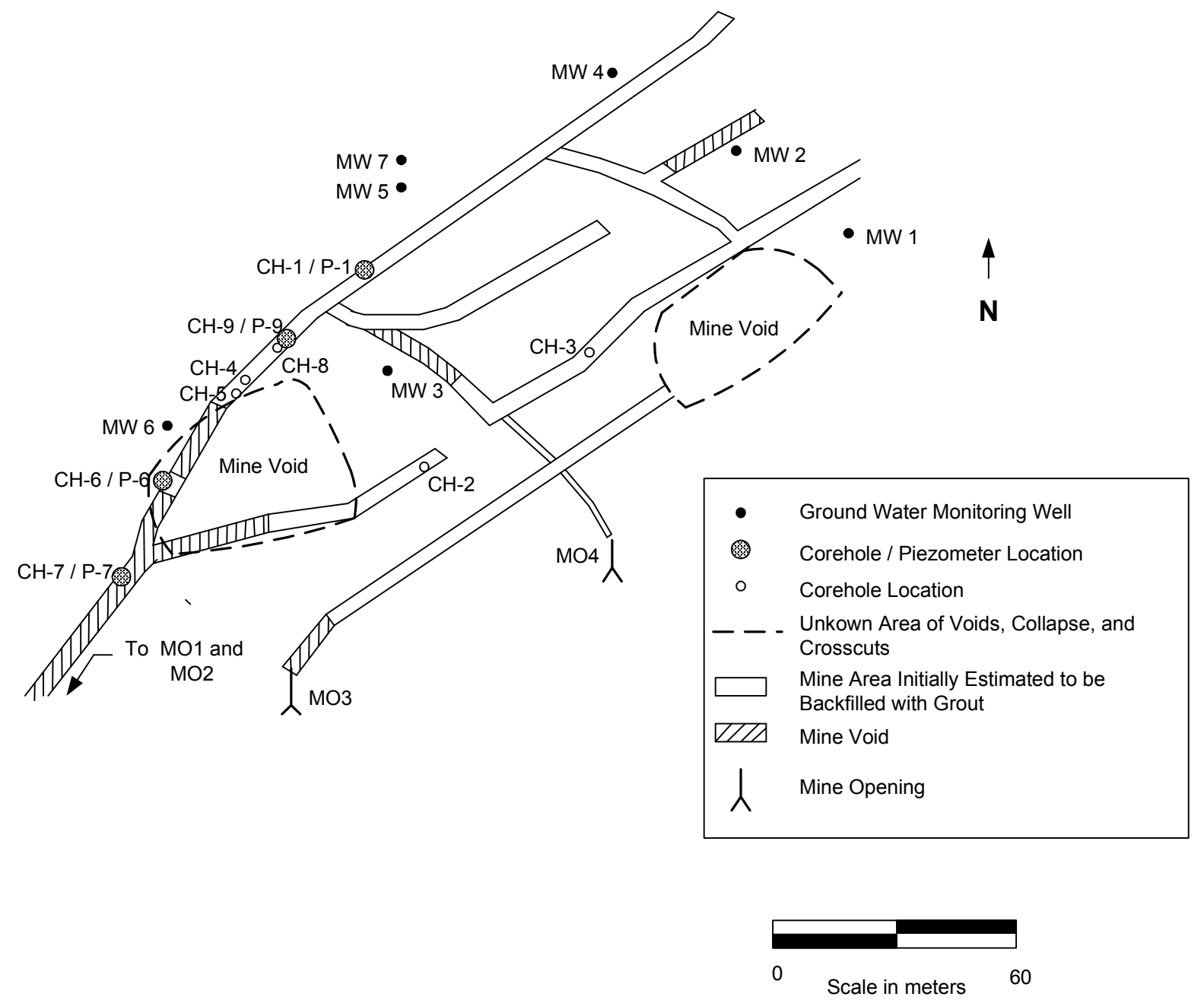

Figure 3.2. Locations of mine openings, wells and coreholes in the Frazee mine 
The hydraulic conductivity and unconfined compressive strength of the field grouts were determined in the laboratory. Piezometers were installed in five of the coreholes after grout cores were retrieved to monitor the mine pool elevation and water quality.

\subsubsection{Injection Procedure and Post-Injection Monitoring}

Preliminary calculations based on the mine dimensions indicated that about $3,000 \mathrm{~m}^{3}$ of grout was necessary to fill the abandoned Frazee mine. The grout mixture was formed within 24 hours of delivery of the materials to the field. A 125$\mathrm{mm}$ diameter Schedule $30 \mathrm{PVC}$ casing was hung into the boreholes and the grout was pumped into the mine. Standard concrete mixing equipment was used to set up a portable mixing plant at the site to mix the grout. The target injection rate was $240 \mathrm{~m}^{3}$ per day but only about $170 \mathrm{~m}^{3}$ over a 10 -hour workday was achieved due to daily setup and dismantlement of the equipment. Furthermore, the injection process required about $4,300 \mathrm{~m}^{3}$ of grout, as opposed to the initially estimated value of $3,000 \mathrm{~m}^{3}$, due to the presence of some additional void space (possible crosscuts and other voids) encountered during injection.

Pre- and post-injection water quality monitoring included measurement of various parameters that are indicative of AMD such as $\mathrm{pH}$, total acidity, iron, and aluminum. Also, the water was tested for trace elements such as nickel, zinc, arsenic, cobalt, copper, lead, and chromium. Mine water quality monitoring was conducted at the upper and lower seeps and at the piezometers installed in the coreholes. The water quality trends in the lower seep were selected to represent the long-term water quality conditions of the mine water in contact with the grout, since the upper seep was 
intermittent and frequently dry. Furthermore, the upper seep endured frequent drying and wetting cycles, which resulted in mine pool fluctuations and thus no reliable information about water quality.

Groundwater samples were collected from two monitoring wells (MW-5 and MW-6), a deep monitoring well (MW-7) and a residential well. Additionally, surface water samples were collected from the vicinity of the mine. The USEPA Method 9040 was used to measure $\mathrm{pH}$. Total acidity and total alkalinity were measured using the USEPA Methods 305.1 and 310.1, respectively. Analysis of total dissolved solids was conducted in accordance with the procedure of USEPA 160.1. The USEPA Method 300 was used to analyze anions, whereas cation concentrations (except mercury) were measured following the procedure outlined in SW 846 EPA 6010B. Mercury was analyzed according to the USEPA Method 7470A.

\subsection{RESULTS AND DISCUSSION}

\subsubsection{Laboratory Tests}

A total of eight FBC-based and eight lime-based mixtures were tested for slump, modified flow, bleed, and unconfined compressive strength in the laboratory. Preliminary observations indicated that the type of water (spring or mine) used in specimen preparation did not have a significant effect on these mechanical parameters. Figure 3.3 relates the measured slump to different percentages of fly ash and free lime content/fly ash ratios. The effects of the same parameters on modified flow are shown in Figure 3.4. 


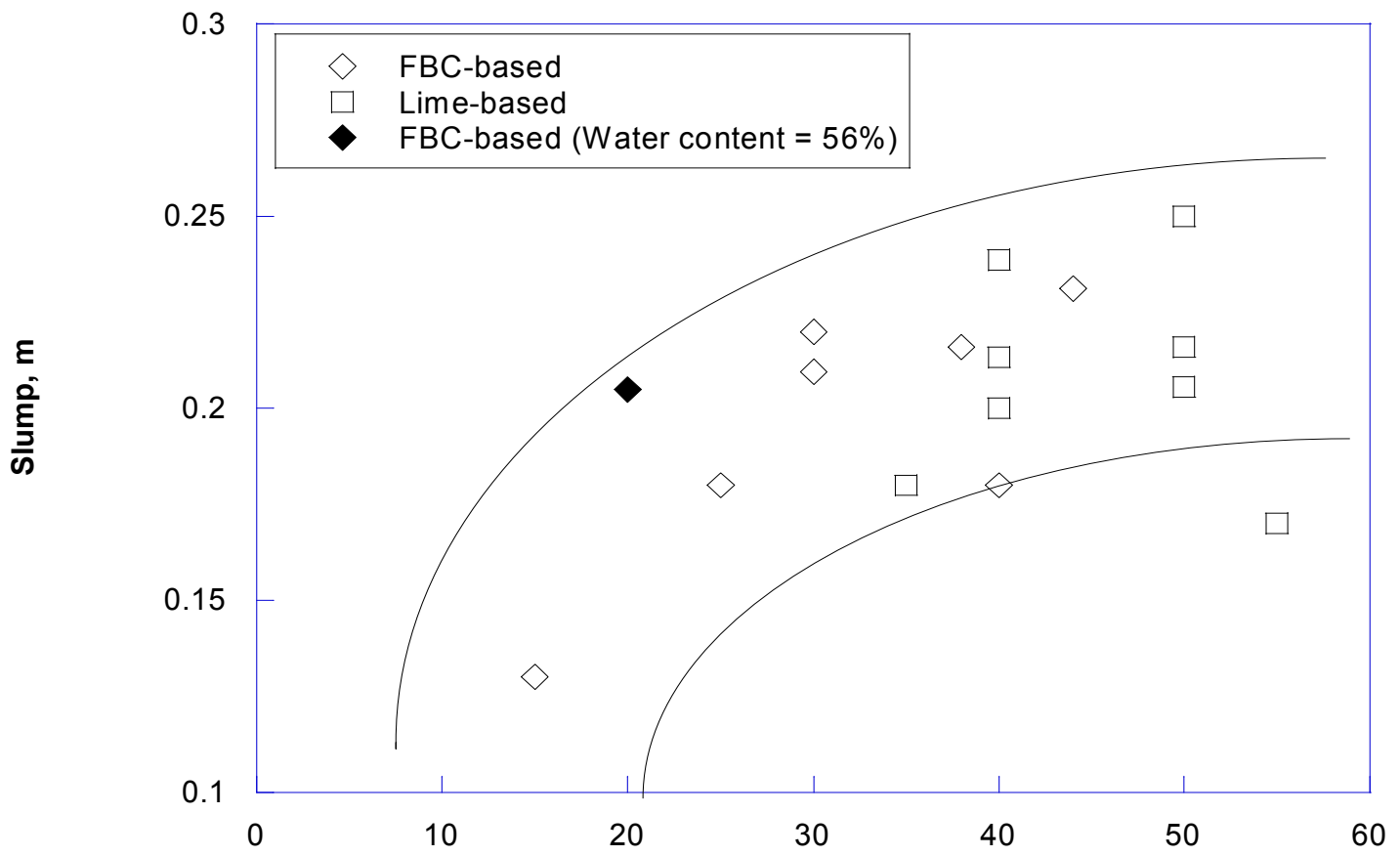

Fly ash, \%

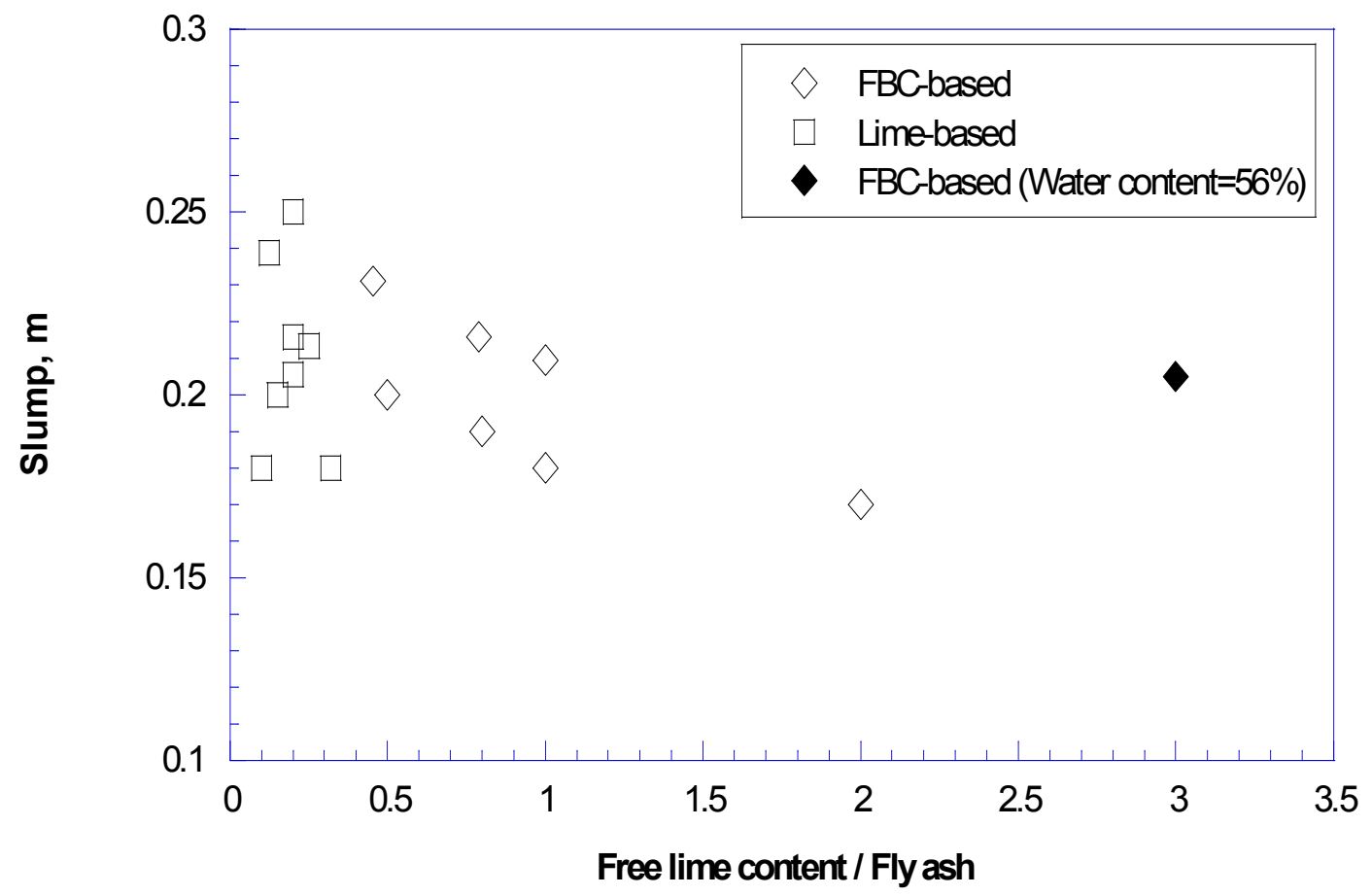

Figure 3.3. Slump versus (a) Fly ash and (b) Free lime content / Fly ash for FBC-based and lime-based mixtures 


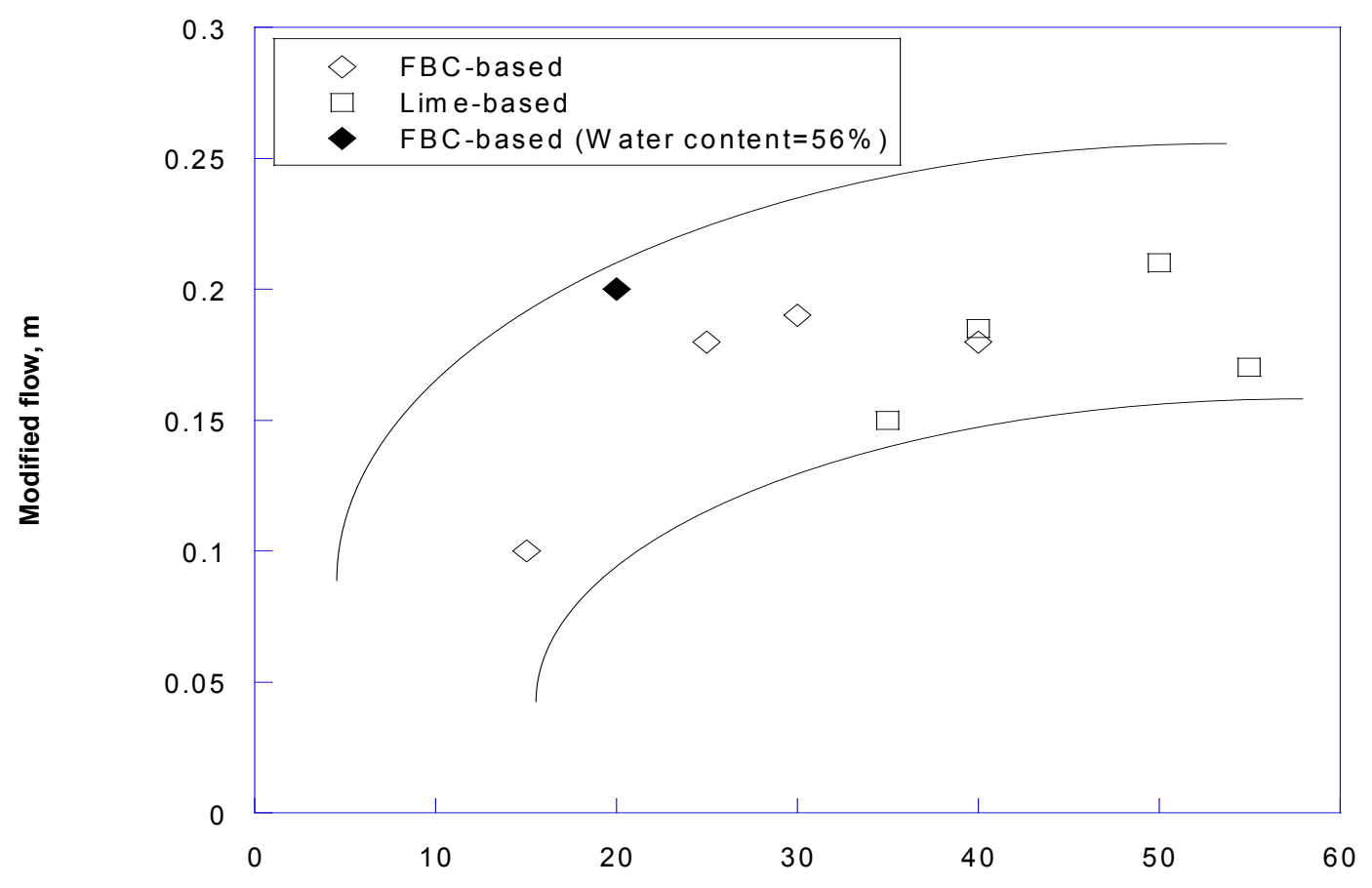

Fly ash, \%

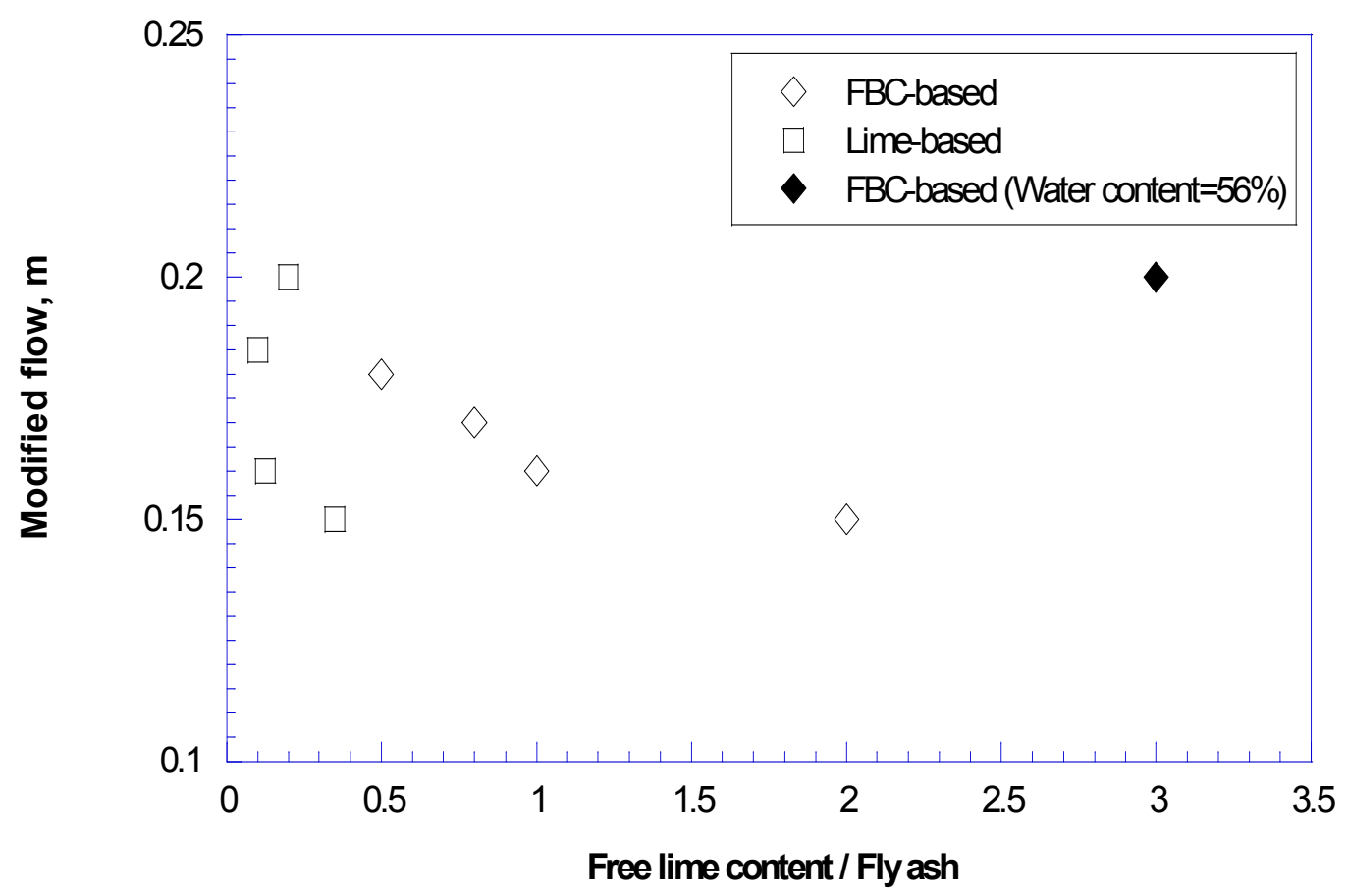

Figure 3.4. Modified flow versus (a) Fly ash and (b) Free lime content / Fly ash for FBC-based and lime-based mixtures 
For both categories of mixes, it is seen that the slump and modified flow initially increase with increasing fly ash content and then the curve levels off. With an increase in the percentage of fly ash, less free lime is available for hydration, and the presence of bulky fly ash contributes to the flowability, thereby increasing the slump. Conversely, slump and modified flow followed an approximate downward trend with increasing free lime/fly ash ratio, with the trend being more visible in FBC-based mixtures (Figures 3.3b and 3.4b). This is similar to the behavior observed by Gabr and Bowders (2000) for fly ash/cement/AMD sludge mixtures.

This decrease in slump and modified flow may be attributed to increased pozzolanic activity due to an increase in free lime content. Excess lime consumed the water for hydration; therefore the flowability decreased at high lime/fly ash ratios. An exception to this phenomenon was the mixture F-4, which exhibited high slump and modified flow due to its relatively higher water content.

Figure 3.5 shows the percentage of bleed, which is termed as the excess water not used in hydration. Bleed slightly increased with increasing fly ash content, since Class F fly ash is not self-cementing and the water is excessive for the activator (FBC or lime). Conversely, bleed water followed a decreasing trend with increasing free lime/fly ash ratio due to increased pozzolanic activity caused by higher free lime content using up the mixture water. Bleed tests were not conducted on mixture L-1 (non-prehydrated lime). Moreover, no bleed tests were conducted on F-4 since the fly ash content was only $20 \%$ by weight and bleed of excess water was not of concern. For the remaining mixtures, the bleed was small, being less than $2 \%$ in most cases. 

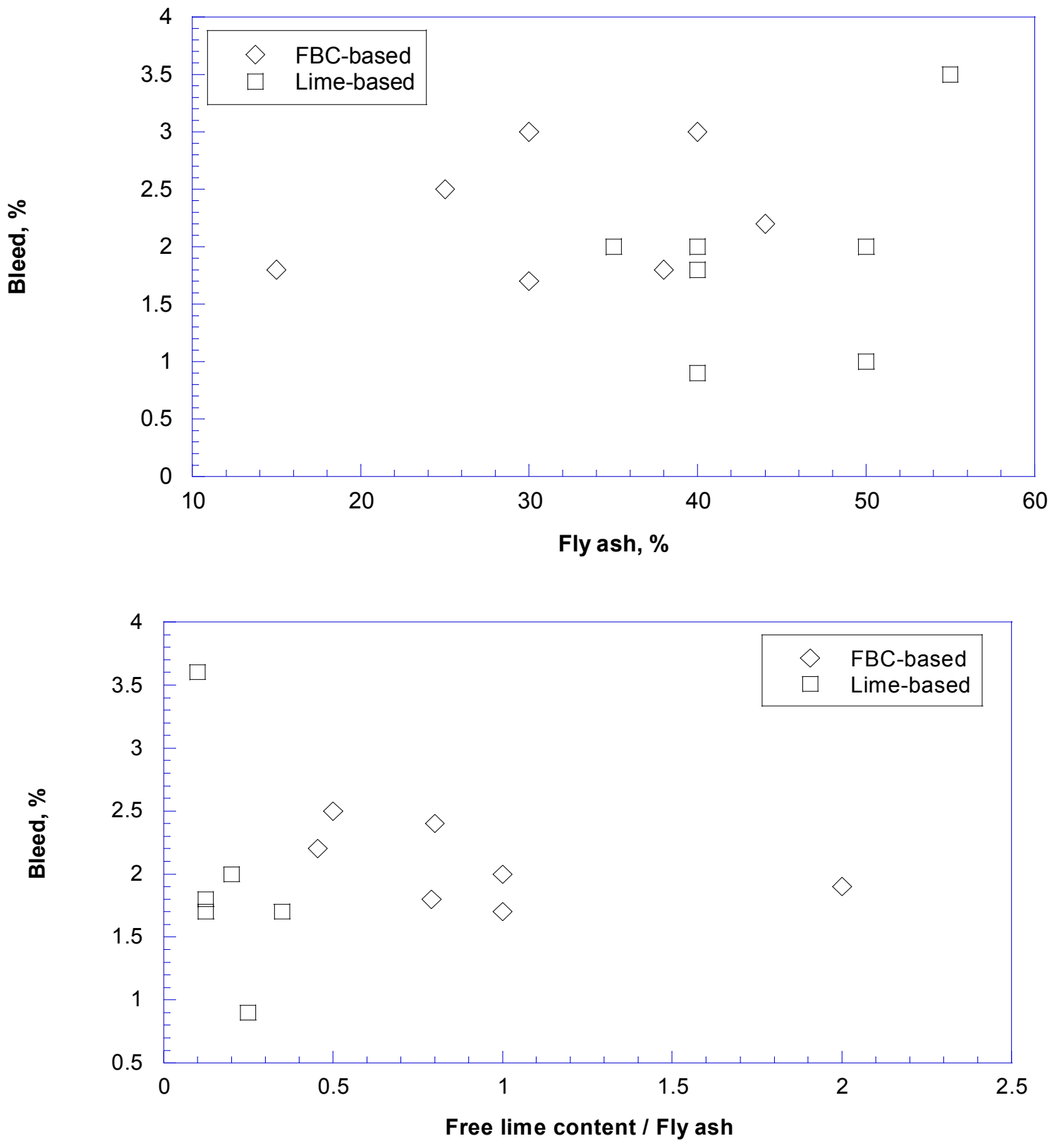

Figure 3.5. Bleed versus (a) Fly ash and (b) Free lime content / Fly ash for FBC-based and lime-based mixtures 

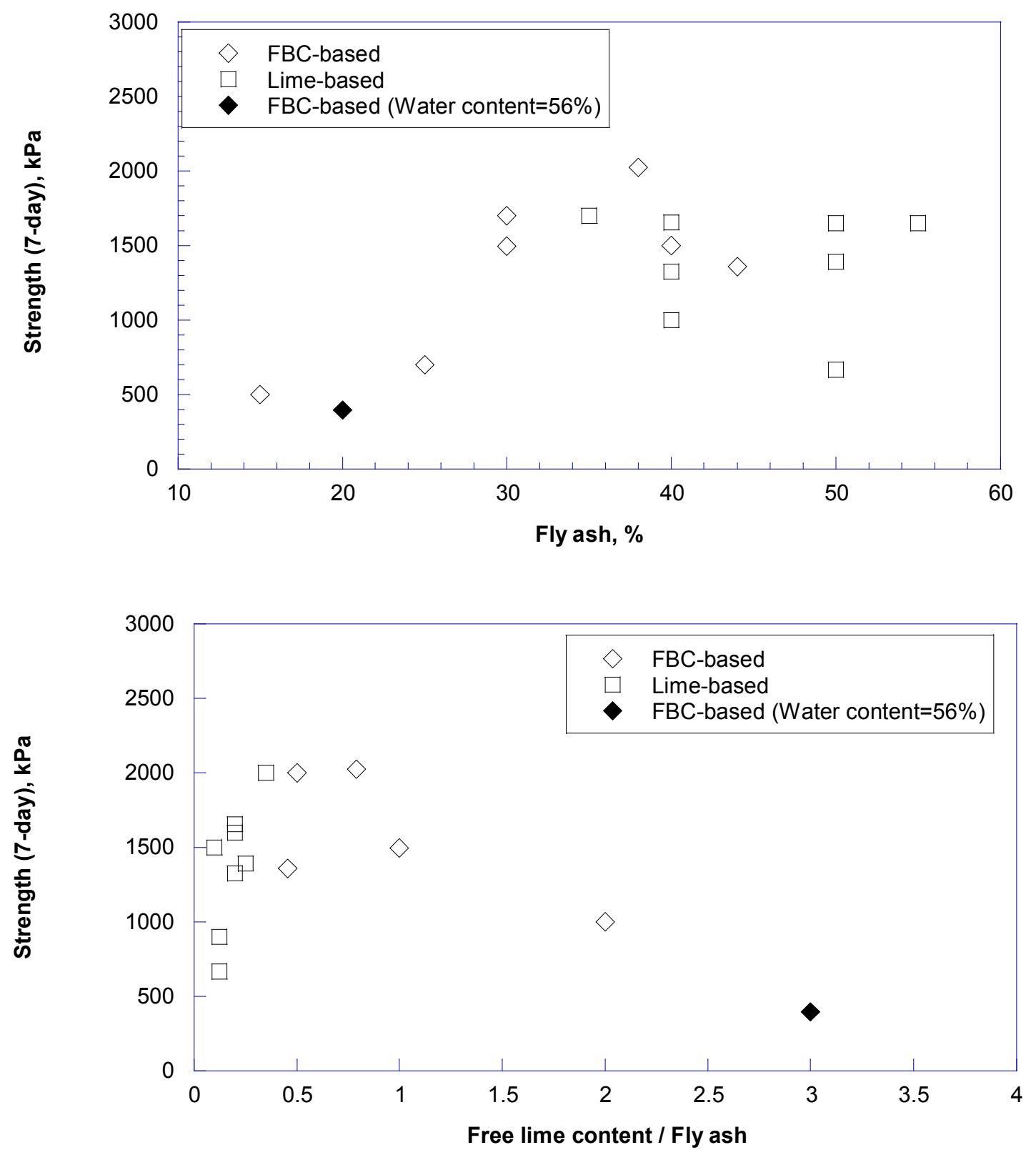

Figure 3.6. Strength versus (a) Fly ash and (b) Free lime content / Fly ash for FBC-based and lime-based mixtures 
As suggested by Figure 3.6a, strength increases with increasing fly ash content due to the formation of calcium silicate hydrates and calcium alumina hydrates, which in turn hardens the specimen. An increase in fly ash content beyond $40 \%$ does not seem to contribute to the strength, and the observed trend is highly consistent with the findings of previous research (Indraratna 1996, Han et al. 2003). Figure $3.6 \mathrm{~b}$ shows the effect free lime/fly ash ratios on the unconfined compressive strength. The compressive strength follows a downward trend; however, the data points are scattered.

The strength initially increases with increasing lime content; however, when all of the silica in fly ash is consumed, further increase in lime (i.e., calcium) does not result in an appreciable increase in strength (Hausmann 1990). These observations are in agreement with the suggestions of Conner (1990) that typical free lime-tofly ash ratio should be between 0.15 and 0.6 , and higher ratios do not generally contribute to strength. Lime stabilization is generally beneficial for clays with a PI greater than 10 (Department of the Army 1983). The fines of CCBs used in the current study were non-plastic, which is believed to be the reason for the observed detrimental effect of lime on strength. Nevertheless, lime-based mixtures gain considerable strength even beyond 14 days, as seen in Figure 3.7. Delayed strength gain in lime-stabilized mixtures has been reported in the previous studies as well (Conner 1990, Sharma and Lewis 1994). For FBC-based mixtures, on the other hand, the rate of strength increase with time is higher at the initial stages, and the strength does not increase significantly after 14 days probably due to relatively lower amount of free lime as compared to quicklime. 

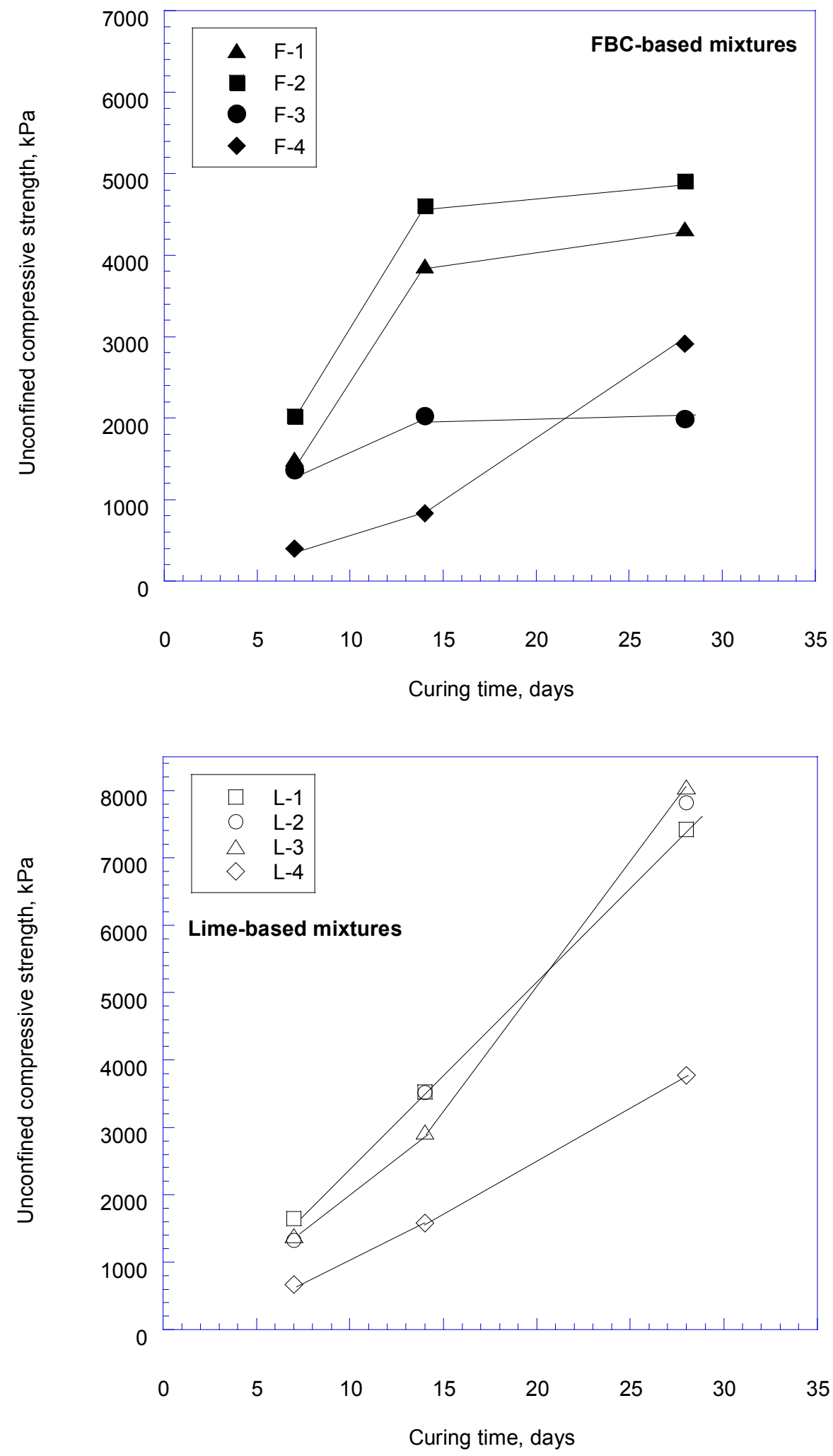

Figure 3.7. Strength versus Curing time for FBC-based and lime-based mixtures 


\subsubsection{Selection of the Optimal Field Grout Mix}

Based on flowability, strength and cost, the mixture F-4 performed the best in laboratory tests and was selected for grouting the Frazee mine. Although some of the other mixtures had similar slump and strength values as F-4, only mixture L-1 had a modified flow of around $200 \mathrm{~mm}$. However, considering the cost issues discussed below, F-4 was selected as the final grout mixture for field injection. The mixture F4 had a slump and modified flow of around $200 \mathrm{~mm}$, which indicates good flowability of the grout according to ACI (1999).

As mentioned before, no bleed tests were performed on this mixture due to low fly ash amount (20\%); however, Figure 3.5 confirms relatively low bleed values, i.e., $\sim 2 \%$, at this fly ash percentage. Even though the 7-day strength of this mixture was low, the 28-day values indicated promising long-term strength characteristics. In order to further confirm the long-term strength gain of this mixture, 26 additional unconfined compression tests were performed on 7, 14 and 28-day cured specimens of F-4. The average strength values plotted in Figure 3.7 verify this gain. The average strength increased to $2,914 \mathrm{kPa}$ after 28 days of curing and exceeded the generally required grout strengths against mine subsidence (Siriwardane et al. 2003, Taerakul et al. 2004).

A total of 3,800 tons of FBC by-product, and 1,200 tons each of Class F fly ash and FGD by-product were required to inject $4,300 \mathrm{~m}^{3}$ of grout into the mine. These CCBs were available at no cost. The Mt. Storm Power Plant, that supplied the Class F fly ash and FGD by-product, was located about 64 kilometers from the site, and the Morgantown Energy Associates Power Plant, that supplied the FBC by- 
product was located about 53 kilometers from the site. The overall cost of transportation of these materials to the site was $\$ 27,000$. However, if quicklime were used instead of FBC by-product, the total cost would increase considerably, as the cost of quicklime is approximately $\$ 75 /$ ton. Additionally, the closest quicklime plant is located at Pittsburgh, Pennsylvania, which is about 150 kilometers from the mine site Another alternative free lime source would be lime kiln dust (Wattenbach et al. 1999), which is available from the manufacturer for about $\$ 13 /$ ton. A detailed cost analysis provided in Table 3.3 indicates that using FBC in a mine grouting application has a clear advantage over using other free lime sources.

\subsubsection{Post-Injection Monitoring}

Monitoring of mine water at the lower seep, surface water and groundwater was conducted to study the long-term impact of AMD on water quality. As seen in Figure 3.8, the AMD from the Mine Opening 2 (MO2) has been continuous after grouting, at flow rates of about 1 to $7 \mathrm{~L} / \mathrm{min}$. The flow rate was seasonal, with high flow rates typically in January through April and lower flow rates during summer months. Grout injection did not impact the flow rates significantly as the grout may not have completely filled the mine voids due to the possible presence of additional unknown voids in the mine. The grout cores collected from the Frazee Mine were sound and did not show evidence of in-situ weathering or particle size segregation. Table 3.4 lists the hydraulic conductivity and strength of the grout core samples that were taken from the mine site. Strength of the grout increased almost 16 times as compared to 7-day strength of the specimens prepared in the laboratory. 
Table 3.3. Cost Analysis

\begin{tabular}{c|c|c|c}
\hline \hline Item & CCBs & Lime & Lime Kiln Dust \\
\hline Cost of Material & Free & $\begin{array}{c}\$ 285,000 \\
(\$ 75 / \text { ton })\end{array}$ & $\begin{array}{c}\$ 49,400 \\
(\$ 13 / \text { ton })\end{array}$ \\
\hline $\begin{array}{c}\text { Cost of } \\
\text { Transportation }\end{array}$ & $\$ 27,000$ & $\$ 41,820$ & $\$ 41,820$ \\
\hline Cost of Labor & $\$ 10,000$ & $\$ 10,000$ & $\$ 10,000$ \\
\hline Total Cost & $\$ 37,000$ & $\$ 336,820$ & $\$ 101,220$ \\
\hline \hline
\end{tabular}




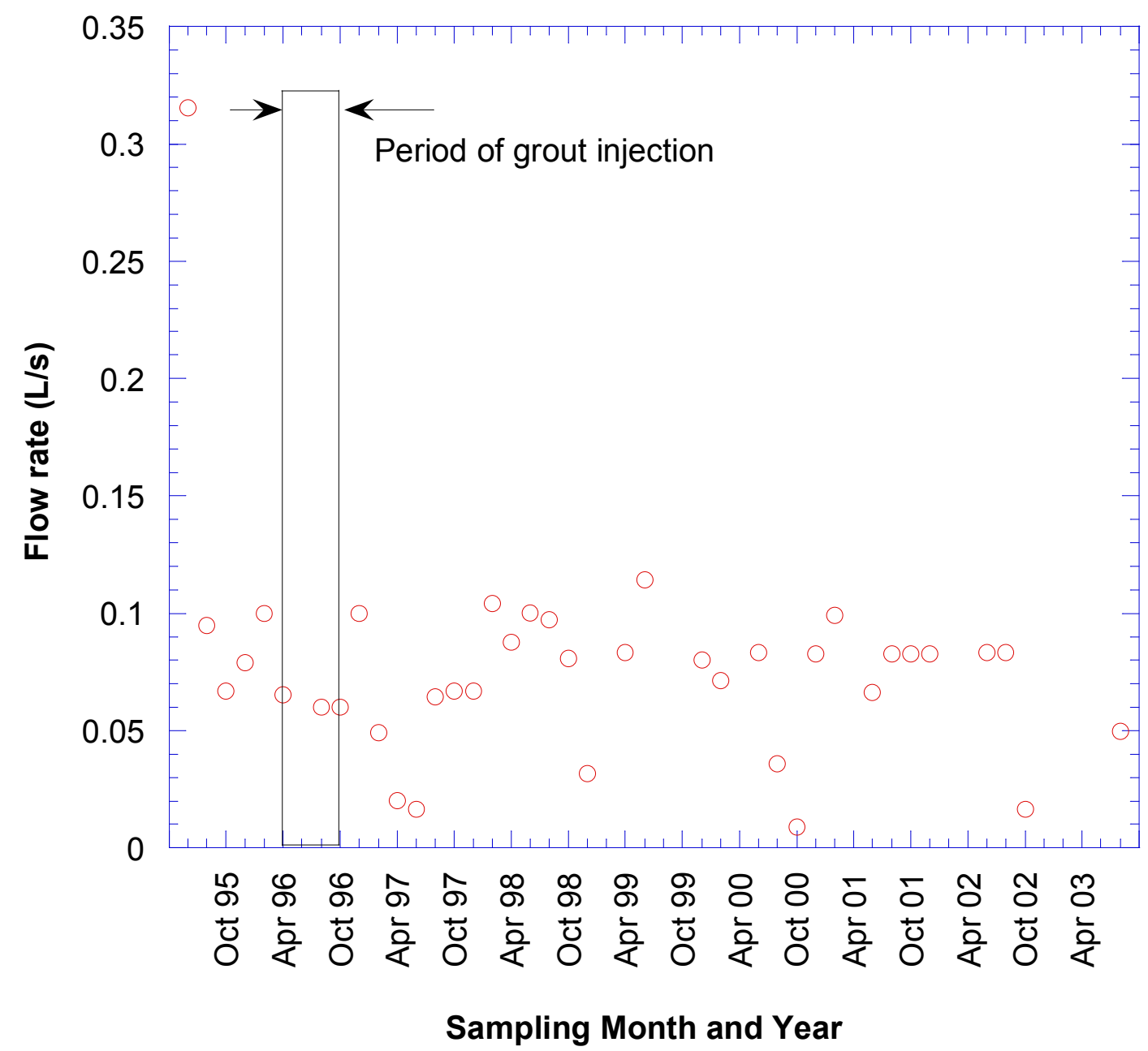

Figure 3.8. Measured flow rates at Mine Opening 2 (MO2) of the lower seep 
Table 3.4. Hydraulic conductivity and strength of exhumed grout specimens

\begin{tabular}{c|c|c|c}
\hline \hline Grout core ID & $\begin{array}{c}\text { Coring depth } \\
(\mathbf{m})\end{array}$ & $\begin{array}{c}\text { Hydraulic conductivity } \\
(\mathbf{m} / \mathbf{s})\end{array}$ & $\begin{array}{c}\text { Strength } \\
(\mathbf{k P a})\end{array}$ \\
\hline $\mathrm{CH}-1$ & 22.02 & $2.6 \times 10^{-9}$ & 8053 \\
\hline $\mathrm{CH}-2$ & 25.54 & $1.3 \times 10^{-9}$ & 9232 \\
\hline $\mathrm{CH}-4$ & 26.22 & $6 \times 10^{-10}$ & 9769 \\
\hline \hline
\end{tabular}


It is also evident from the values that the hydraulic conductivity decreases and the strength increases with coring depth; however, the number of field samples is too small to make conclusive statements at this point.

pH and Acidity in the Lower Seep

Figure 3.9 summarizes the water quality monitoring results for the lower seep at $\mathrm{MO}$ 2. The post-injection $\mathrm{pH}$ in the lower seep shows a slight increase from its preinjection value. During injection, a fluctuation of $\mathrm{pH}$ was observed; however, $\mathrm{pH}$ has exhibited an upward trend in the post-injection period.

Even though the $\mathrm{pH}$ of the mine water did not increase greatly after injection, the total acidity decreased considerably compared to its pre-injection values.

The chemical reactions that characterize various stages of pyrite oxidation and cause the formation of acidic water are as follows (Singer and Stumm 1970):

$$
\begin{aligned}
& \mathrm{FeS}_{2}+7 / 2 \mathrm{O}_{2}+\mathrm{H}_{2} \mathrm{O} \rightarrow \mathrm{Fe}^{2+}+2 \mathrm{SO}_{4}{ }^{2-}+2 \mathrm{H}^{+} \\
& \mathrm{Fe}^{2+}+1 / 4 \mathrm{O}_{2}+\mathrm{H}^{+} \rightarrow \mathrm{Fe}^{3+}+1 / 2 \mathrm{H}_{2} \mathrm{O} \\
& \mathrm{Fe}^{3+}+3 \mathrm{H}_{2} \mathrm{O} \rightarrow \mathrm{Fe}(\mathrm{OH})_{3}+3 \mathrm{H}^{+} \\
& \mathrm{FeS}_{2}+14 \mathrm{Fe}^{3+}+8 \mathrm{H}_{2} \mathrm{O} \rightarrow 15 \mathrm{Fe}^{2+}+2 \mathrm{SO}_{4}^{2-}+16 \mathrm{H}^{+}
\end{aligned}
$$




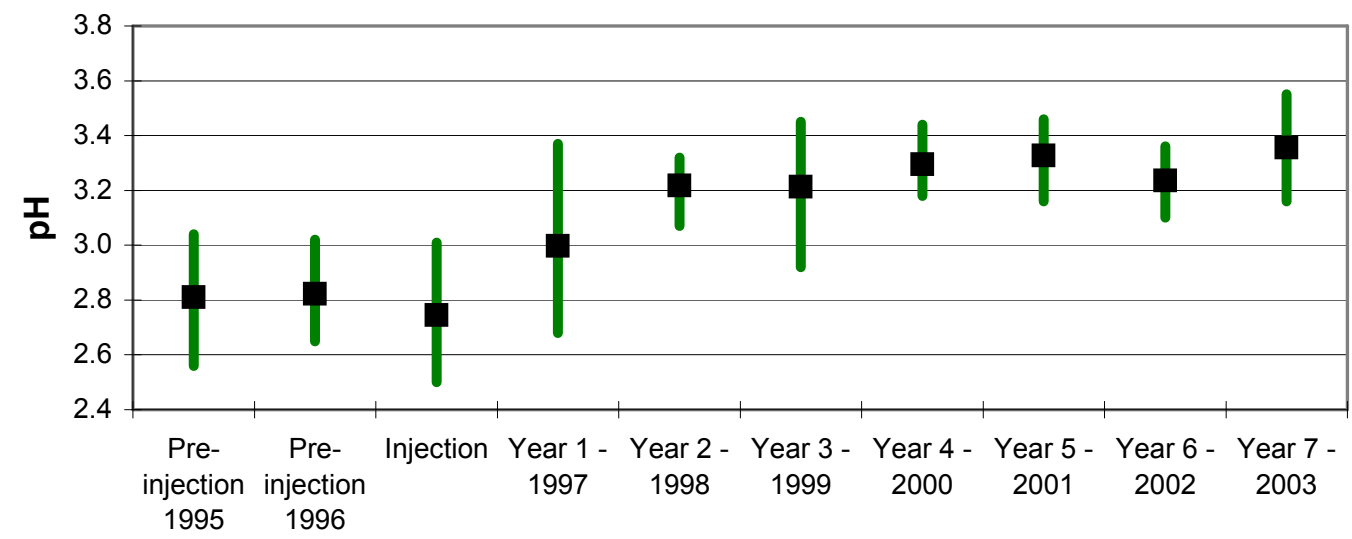

Sampling Interval

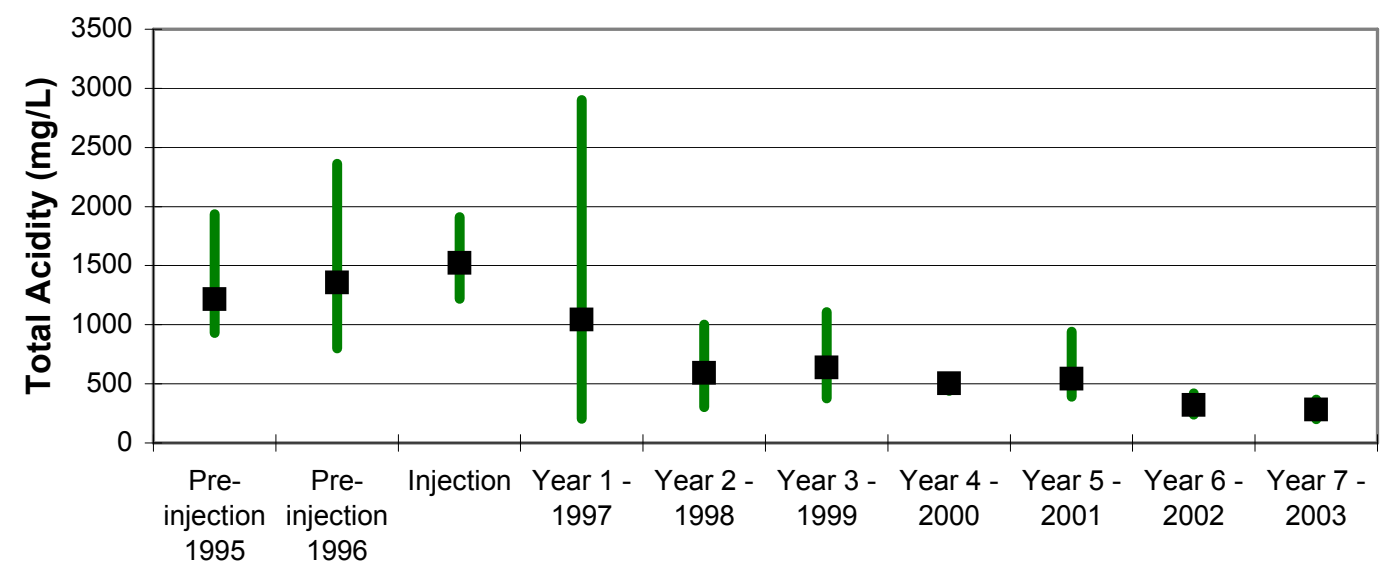

Sampling Interval

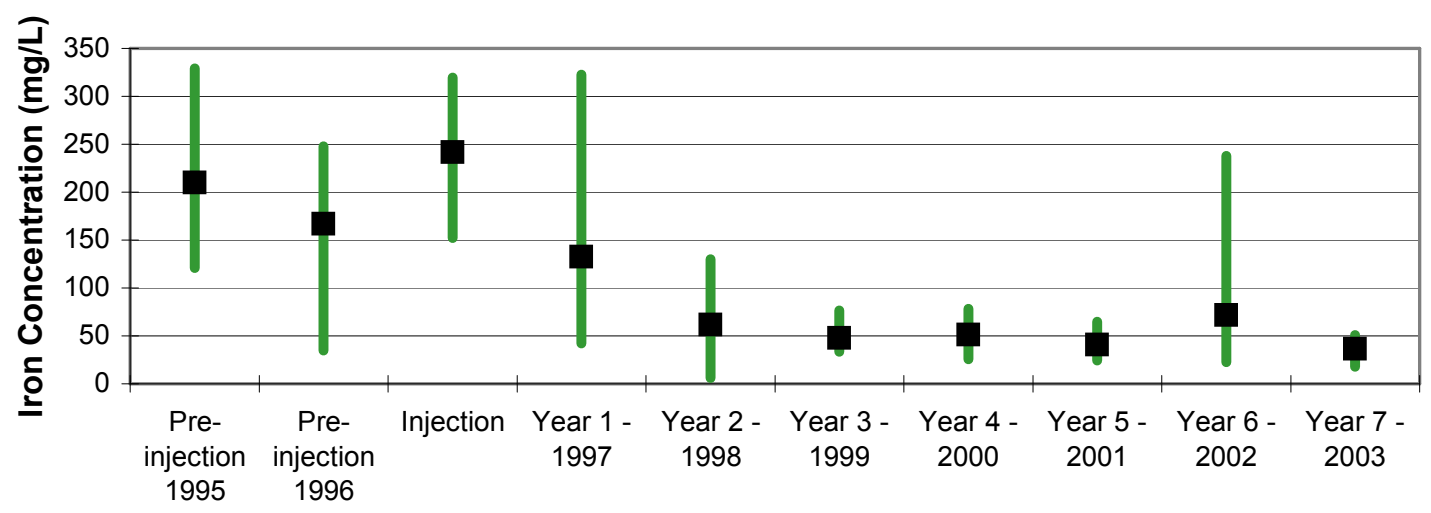

Sampling Interval

Figure 3.9. Concentrations of various AMD parameters before and after placement of the grout 


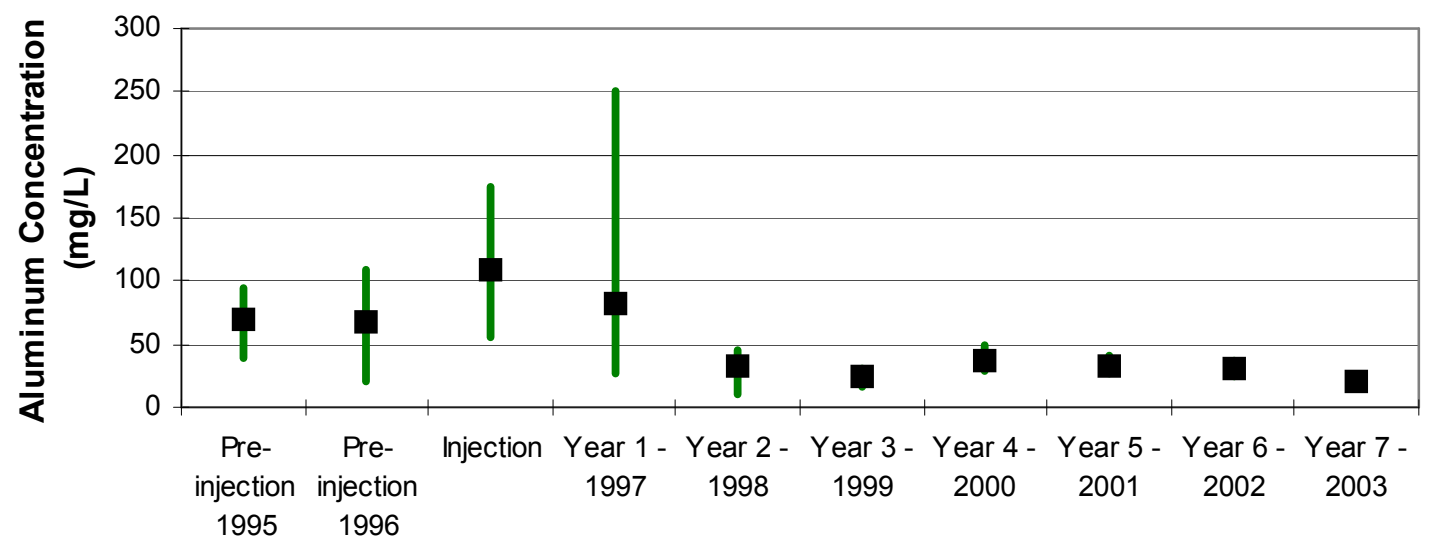

Sampling Interval

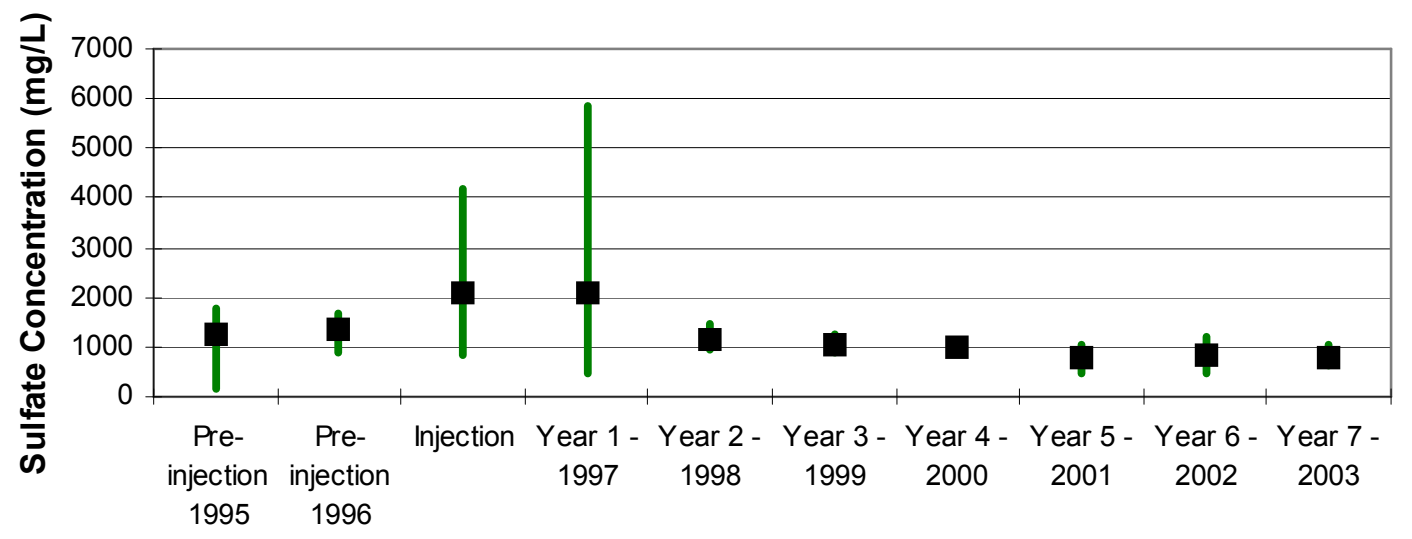

Sampling Interval

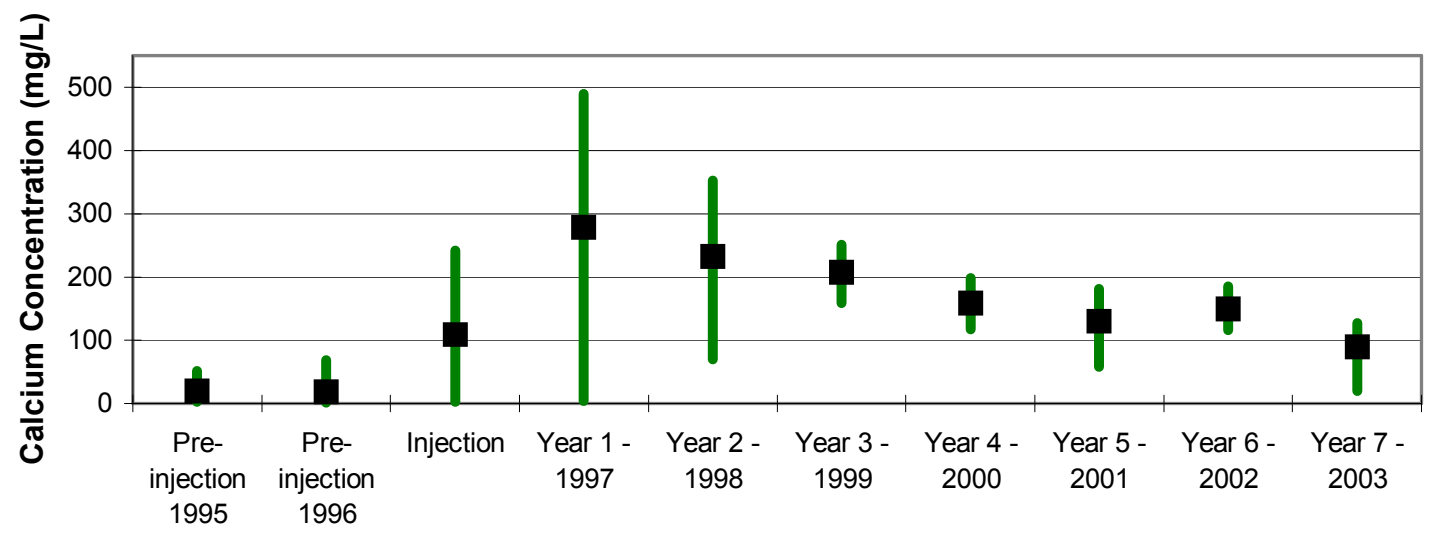

Sampling Interval

Figure 3.9 (Cont'd). Concentrations of various AMD parameters before and after placement of the grout 
In the above reactions, $\mathrm{Fe}^{3+}$ and oxygen are the major pyrite oxidants. In Eq. 1, the pyrite is oxidized by atmospheric oxygen and water to form sulfuric acid and soluble ferrous ions, which are then oxidized to ferric ions (Eq. 2). The reaction shown in Eq. 2 is $\mathrm{pH}$ dependant and occurs very slowly at a $\mathrm{pH}$ of about 3 . However, the presence of iron-oxidizing bacteria Thiobacillus ferrooxidans can accelerate the oxidation of $\mathrm{Fe}^{2+}$ by a factor of $10^{6}$ (Singer and Stumm 1970). The next reaction is a major reaction in the release of acid to the environment (Eq. 3). During this reaction, hydrolysis of ferric ion occurs at $\mathrm{pH}$ values of above 3.5 and the ferric hydroxide is formed. In the last reaction, pyrite is then oxidized by the ferric ions.

The increase in $\mathrm{pH}$ observed in Figure 3.9 may be due to neutralization of acidic mine water by the alkaline grout. Calcium hydroxide and calcium carbonate are formed due to hydration reactions in the grout and the reactions occurring between calcium oxide (free lime) and water and carbon-dioxide are as follows:

$$
\begin{aligned}
& \mathrm{CaO}+\mathrm{CO}_{2} \rightarrow \mathrm{CaCO}_{3} \\
& \mathrm{CaO}+\mathrm{H}_{2} \mathrm{O} \rightarrow \mathrm{Ca}(\mathrm{OH})_{2}
\end{aligned}
$$

These alkaline compounds neutralize the sulfuric acid in the mine water and increase the $\mathrm{pH}$. The neutralization reaction with calcium hydroxide can be written as follows:

$$
\mathrm{Ca}(\mathrm{OH})_{2}+\mathrm{H}_{2} \mathrm{SO}_{4} \rightarrow \mathrm{Ca}^{2+}+\mathrm{SO}_{4}{ }^{2-}+2 \mathrm{H}_{2} \mathrm{O}
$$


On the other hand, neutralization with calcium carbonate depends on the behavior of carbon dioxide during the reaction and on the $\mathrm{pH}$ achieved after neutralization (Rose and Cravotta 1998). If all $\mathrm{CO}_{2}$ formed is allowed to be released into the gas phase and the $\mathrm{pH}$ of AMD is to be only about 5, then the reaction may be written as (Cravotta et al. 1990):

$\mathrm{FeS}_{2}+2 \mathrm{CaCO}_{3}+3.75 \mathrm{O}_{2}+1.5 \mathrm{H}_{2} \mathrm{O} \rightarrow \mathrm{Fe}(\mathrm{OH})_{3}+2 \mathrm{SO}_{4}{ }^{2-}+2 \mathrm{Ca}^{2+}+2 \mathrm{CO}_{2}$

However if the AMD is to be neutralized to a $\mathrm{pH}$ of 6.3 or higher and no $\mathrm{CO}_{2}$ is released into the gas phase, the reaction may be written as (Cravotta et al. 1990):

$\mathrm{FeS}_{2}+4 \mathrm{CaCO}_{3}+3.75 \mathrm{O}_{2}+3.5 \mathrm{H}_{2} \mathrm{O} \rightarrow \mathrm{Fe}(\mathrm{OH})_{3}+2 \mathrm{SO}_{4}{ }^{2-}+4 \mathrm{Ca}^{2+}+4 \mathrm{HCO}_{3}{ }^{-}$

It is believed that a combination of both the above cases occurs in Frazee mine. The neutralization process that is dominant depends on how open or closed the mine is (Smith and Brady 1998).

The reactions shown in Eqs. 8 and 9 are relevant to calculate the amount of alkalinity (in terms of $\mathrm{CaCO}_{3}$ ) to be added to neutralize the acidity formed due to pyrite oxidation. For instance, AMD generated by 1 mole of pyrite requires 2 moles of $\mathrm{CaCO}_{3}$ to neutralize it, i.e., $200 \mathrm{~g}$ of $\mathrm{CaCO}_{3}$ for $64 \mathrm{~g}$ of pyrite, according to Eq. 8 . If the reaction shown in Eq. 9 occurs, then 4 moles of $\mathrm{CaCO}_{3}$ are required to neutralize AMD generated by 1 mole of pyrite, i.e., $400 \mathrm{~g}$ of $\mathrm{CaCO}_{3}$ for $64 \mathrm{~g}$ of pyrite (Rose and Cravotta 1998). However, the exact amount of pyrite in Frazee mine was 
not known in order to calculate the amount of alkalinity necessary to be injected into the mine to produce nearly neutral discharge. It is also difficult to quantify the amount of alkalinity presently injected into the mine, since fly ash-lime hydration reactions consume a part of the alkaline materials.

A small increase in $\mathrm{pH}$ and a considerable decrease in acidity shown in Figure 3.9 may be due the buffering capacity of the surrounding soil, which does not allow for significant changes in $\mathrm{pH}$. Furthermore, $\mathrm{pH}$ generally takes into account only the $\mathrm{H}^{+}$ions of strong acids and is not significantly influenced by weak acids, whereas total acidity considers both weak and strong acids (Stumm and Morgan 1996). Accordingly, the relatively small increase in $\mathrm{pH}$ may be due to the existence of strong acids in the AMD. Nevertheless, it is reasonable to say that the grout reduced the preinjection area of exposed pyritic surfaces that otherwise would have been available for acid formation.

An alternate method to increase $\mathrm{pH}$ would be to place pure $\mathrm{FBC}$ by-product or pure lime in the mine so that more alkalinity would be available for neutralization reactions. Even though lime can provide more neutralization potential than FBC byproduct (Schueck et al. 2001), it would be very expensive as illustrated in Table 3.3. Furthermore, pure FBC by-product or lime cannot be pumped into a deep mine, as in the study by Shcueck et al. (2001) where the site was a shallow surface mine. In order for the alkaline material to be available throughout the Frazee mine, it had to be proportioned with granular materials such as Class F fly ash and FGD by-product to attain adequate flowability so that it may be pumped into the mine. The grout once in place would not only provide alkalinity in the mine, but also entomb and encapsulate 
the acid producing pyrite rocks as far as possible, thus rendering it unavailable to oxidize to form AMD.

\section{AMD-Related Ions in the Lower Seep}

The phenomenon of fluctuating concentrations during injection (i.e., transient conditions) followed by a decrease in concentrations after injection, can be observed for the measured water quality parameters given in Figure 3.9. It appears that the mine is re-equilibrating during this injection. A similar phenomenon was reported when FGD material was injected into the Roberts-Dawson mine in central-eastern Ohio (Taerakul et al. 2004). The transient conditions observed in the acidity as well as aluminum and iron concentrations in the lower seep may be due to a combination of factors. One factor could be the lowering of mine pool during pumping for grout mixing. Lowering of the mine pool could have exposed previously submerged mine areas to oxidizing conditions to create acidic weathering products available for mobilization once the mine pool rose to pre-injection levels. Another factor could be the possible re-routing of mine waters through previously isolated mine areas or mixing with a stagnant mine pool and recharging itself with acidic discharge to create acidic weathering products. However, it is unlikely that the FBC-based grout was responsible for the elevated changes, since the flow rates were comparable in the preand post-injection phases (Figure 3.8). It can be seen from Figure 3.9 that the transient conditions were relatively short-lived and did not continue, in general, after the injection. 
The subsequent decrease in iron concentrations after injection of grout is due to three reasons. First, the grout forms a physical barrier between the pyrite $\left(\mathrm{FeS}_{2}\right)$ and the oxygen and water, thus preventing the oxidation of pyrite (Eq. 1). In the areas of the mine where oxidation of pyrite still occurs, the neutralization of acidic water by the alkalinity in grout will not maintain the acidic conditions necessary for reaction in Eq. 2 to take place. Moreover, insoluble ferric hydroxide is precipitated due to higher $\mathrm{pH}$ during neutralization (Eq. 3). Iron concentrations in the water are reduced through these mechanisms. As the acidity of the water is decreased, leaching of other metals such as $\mathrm{Al}^{3+}$ also decreases, thus reducing its concentrations in the water.

Two major ions, calcium and sulfate, did not exhibit the same patterns as other AMD-related ions. One year after injection, the concentrations of these two ions increased. This may be due to dissolution of calcium sulfate and sulfite minerals present in the grout surface that came into contact with the mine water. However, this does not seem to be a major concern as the grout cores retrieved showed good strength and little weathering. Furthermore, their concentrations decreased due to prolonged dissolution. The trace elements that were present in the collected water samples were cobalt, copper, manganese, nickel, and zinc. Additionally, arsenic, beryllium, cadmium, chromium, lead, mercury, selenium, silver, thallium, and vanadium were sporadically detected. The concentration plots of those elements also exhibited transient conditions during injection and a decrease in concentration approaching asymptotic levels lower than their respective pre-injection values (Rafalko and Petzrick 2000). 
Groundwater and Surface Water Quality

Table 3.5 summarizes the water quality monitoring data collected from groundwater and surface water wells. Groundwater and surface water monitoring data show no evidence of AMD or adverse impacts from grouting the mine. MW-5 and MW-6 are located topographically downgradient of the Frazee Mine and their well screen elevations are commensurate with the elevations of the mine tunnels. As seen in Table 3.5, these two wells have not been impacted by the AMD. A pH of around 6 was measured in these groundwater monitoring wells, and the values are much higher than the $\mathrm{pH}$ of the AMD collected from the mine opening MO2. Additionally, the total acidity and sulfate levels are significantly lower. The same is evident for the Frazee mine residential well and surface water sampling locations. The sulfate data from the deep groundwater monitoring well (MW-7), however, suggest that there might have been a vertical leakage of AMD through the mine floor. This well was installed after grout injection and there are no pre-injection data for comparison. The other parameters do not show immediate impact of the AMD on groundwater or surface water. 
Table 3.5. Water quality results for groundwater and surface water (All units are in $\mathrm{mg} / \mathrm{L}$; post-injection values in the monitoring wells correspond to average values over a period of eight years between 1996 and 2004)

\begin{tabular}{|c|c|c|c|c|c|c|c|c|c|}
\hline & \multirow[t]{2}{*}{$\begin{array}{l}\text { AMD during pre- } \\
\text { injection (from MO2) }\end{array}$} & \multicolumn{2}{|c|}{ Monitoring Well - 5} & \multicolumn{2}{|c|}{ Monitoring Well - 6} & \multirow{2}{*}{\begin{tabular}{c|}
$\begin{array}{c}\text { Deep Monitoring } \\
\text { Well (MW-7) }\end{array}$ \\
Post - injection \\
\end{tabular}} & \multirow{2}{*}{$\begin{array}{c}\begin{array}{c}\text { Residential } \\
\text { Well }\end{array} \\
\text { Post - injection } \\
\end{array}$} & \multicolumn{2}{|c|}{ Surface Water Samples } \\
\hline & & Pre - injection & Post - injection & Pre - injection & Post - injection & & & Pre - injection & Post - injection \\
\hline $\mathrm{pH}$ & $2.5-3.1$ & $6.02-6.14$ & 5.99 & $5.84-6.08$ & 5.91 & 6.24 & $5.7-6.8$ & 5.89 & 5.56 \\
\hline \begin{tabular}{|l|} 
Total \\
Acidity
\end{tabular} & $700-2,361$ & $0-42.6$ & 36.93 & $6.2-26.0$ & 20.98 & 61.98 & $0-48.8$ & 10.00 & 0.00 \\
\hline \multicolumn{10}{|l|}{ Major Ions } \\
\hline Calcium & $1-67$ & $2.9-4.94$ & 12.62 & $1.24-3.79$ & 5.34 & 71.67 & $5.2-47$ & 0.05 & 0.07 \\
\hline Iron & $30-329$ & $3.36-4.58$ & 8.24 & $5.2-18$ & 8.44 & 47.59 & $0.1-5.24$ & 2.14 & 3.03 \\
\hline Magnesium & $3-97$ & $6.0-10.0$ & 11.48 & $4.0-10.0$ & 10.38 & 38.69 & $2.3-8$ & 9.00 & 1.15 \\
\hline Potassium & $1-3$ & $1.64-2.47$ & 2.39 & $0.77-1.33$ & 2.26 & 3.52 & $1.06-3.9$ & 0.69 & 0.70 \\
\hline Sodium & $1-3$ & $1.6-1.84$ & 1.61 & $0.42-0.45$ & 2.37 & 1.87 & $0.34-25.4$ & 1.01 & 1.21 \\
\hline Chloride & $1-37$ & 1.1 & 2.82 & $1.3-1.9$ & 1.83 & 3.33 & $0.1-10$ & 6.30 & 26.20 \\
\hline Sulfate & $87-1,769$ & $33.2-15.8$ & 40.42 & $0.97-31.2$ & 13.71 & 246.18 & $2.2-279.2$ & 2.60 & 3.70 \\
\hline \multicolumn{10}{|c|}{ Dissolved Trace Elements } \\
\hline Aluminum & $10-110$ & $0.1-0.2$ & 0.21 & $0.1-0.55$ & 0.28 & 0.2856 & $0.01-0.3$ & $<0.1$ & $<0.1$ \\
\hline Antimony & $0.2 .-0.768$ & 0.413 & 0.07 & $<0.089$ & 0.02 & 0.0137 & $0.01-0.05$ & $<0.0031$ & $<0.01$ \\
\hline Arsenic & $0.003-0.02$ & $0.0021-0.046$ & 0.03 & $0.0021-0.037$ & 0.01 & 0.0150 & $0.01-0.04$ & $<0.0027$ & $<0.01$ \\
\hline Barium & $0.002-0.07$ & $0.075-0.110$ & 0.12 & $0.123-0.18$ & 0.17 & 0.0529 & $0.09-0.23$ & 0.0415 & 0.0369 \\
\hline Beryllium & $0.02-0.217$ & $0.0012-0.009$ & 0.00 & $0.00071-0.009$ & 0.00 & 0.0019 & $0.0005-0.002$ & $<0.0071$ & $<0.002$ \\
\hline Cadmium & $0.03-0.02$ & $<0.01$ & 0.02 & $0.01-0.03$ & 0.03 & 0.0300 & $0.03-0.05$ & $<0.03$ & $<0.03$ \\
\hline Chromium & $0.03-0.15$ & $0.01-0.03$ & 0.03 & $0.01-0.03$ & 0.03 & 0.0300 & $0.03-0.06$ & $<0.03$ & $<0.03$ \\
\hline Cobalt & $0.04-0.93$ & 0.0089 & 0.01 & $0.0062-6.2$ & 0.01 & 0.0079 & $0.002-0.007$ & $<0.0092$ & $<0.002$ \\
\hline Copper & $0.02-0.32$ & $<0.01$ & 0.03 & $0.01-0.03$ & 0.03 & 0.0300 & $<0.03$ & $<0.03$ & $<0.03$ \\
\hline Lead & $0.01-0.06$ & $<0.01$ & 0.08 & $0.01-0.03$ & 0.06 & 0.0420 & $<0.03$ & $<0.03$ & 0.06 \\
\hline Manganese & $0.48-16$ & $0.69-0.73$ & 1.16 & $0.61-0.63$ & 0.67 & 3.7078 & $0.4-3.75$ & $<0.03$ & $<0.03$ \\
\hline Mercury & $4.3 \times 10^{-5}$ & 0.000046 & 0.00 & $3.2-4.3 \times 10^{-5}$ & 0.00 & 0.0002 & $<0.0002$ & $4.3 \times 10^{-5}$ & $<0.0002$ \\
\hline Nickel & $0.08-2$ & $0.01-0.06$ & 0.11 & $0.02-0.09$ & 0.07 & 0.0940 & $0.02-0.04$ & $<0.03$ & 0.08 \\
\hline Selenium & $<0.5$ & $0.0021-0.026$ & 0.02 & $0.0026-0.028$ & 0.01 & 0.0136 & $0.01-0.05$ & $<0.0027$ & $<0.01$ \\
\hline Silver & $0.03-0.08$ & $0.01-0.08$ & 0.04 & $0.01-0.05$ & 0.04 & 0.0240 & $0.01-0.17$ & $<0.03$ & $<0.01$ \\
\hline Thallium & $0.004-3$ & $<0.0037$ & 0.02 & $0.0037-0.0045$ & 0.02 & 0.0218 & $0.02-0.05$ & $<0.0045$ & $<0.02$ \\
\hline Vanadium & $<0.329$ & $0.0052-0.046$ & 0.01 & $0.0007-0.049$ & 0.01 & 0.0050 & $0.002-0.017$ & 0.00082 & $<0.002$ \\
\hline Zinc & $0.26-4$ & 0.02 & 0.11 & $0.01-0.96$ & 0.18 & 0.1003 & $0.03-0.06$ & $<0.03$ & 0.04 \\
\hline
\end{tabular}




\section{SECTION 4}

\section{LABORATORY EVALUATION OF GEOMECHANICAL PROPERTIES}

\subsection{MATERIALS}

\subsubsection{Fly Ash / Bottom Ash mix}

A mixture of Class F fly ash and bottom ash was used as the base material for grouts in this study. The material was obtained from R. Paul Smith Power Plant in Williamsport, Maryland in 170 L drums. This fly ash - bottom ash mixture was placed outside the power plant in large heaps. Thus, the material had mixed with local shale and weeds and had to be sieved before its use in the grout mixture. The mixture was sieved from US No. $8(2.36 \mathrm{~mm})$ and No. $16(1.18 \mathrm{~mm})$ sieves to remove any local shale and weeds present in the material and then was used in grout mixtures. The physical and chemical properties of the fly ash - bottom ash (FA-BA) mixture used in the current study are shown in Table 4.1. Grain size distribution was performed by sieve analysis and hydrometer analysis following the procedures listed in ASTM D 422 (Figure 4.1). The material was initially wash sieved from the U. S. Sieve No. $200(0.075 \mathrm{~mm}$.) sieve. Atterberg limit tests conducted on the ash as per ASTM D 4318 (Standard Test Methods for Liquid Limit, Plastic Limit, and Plasticity Index of Soils) indicated that the material was non-plastic. 
Table 4.1. Physical and chemical properties of materials used.

\begin{tabular}{|c|c|c|c|c|}
\hline \multicolumn{5}{|c|}{ Physical Properties } \\
\hline & FA-BA & FBC & LKD & Pyrite \\
\hline $\mathrm{D}_{10}(\mathrm{~mm})$ & 0.003 & 0.002 & 0.009 & 7 \\
\hline $\mathbf{D}_{30}(\mathrm{~mm})$ & 0.011 & 0.003 & 0.011 & 10.15 \\
\hline$D_{85}(\mathrm{~mm})$ & 0.15 & 0.004 & 0.02 & 11.1 \\
\hline $\mathbf{C}_{\mathbf{u}}$ & 9.33 & 1.5 & 1.44 & 1.5 \\
\hline Ce & 1.44 & 1.5 & 1.03 & 1.4 \\
\hline Fines content $(\%)$ & 75.6 & 88.7 & 89.9 & - \\
\hline Moisture content $(\%)$ & 21.83 & 0 & 0 & - \\
\hline \multicolumn{5}{|c|}{ Chemical Constituents } \\
\hline$(\%)$ & FA-BA & FBC & LKD & Pyrite \\
\hline $\mathrm{SiO}_{2}$ & 49.03 & 32.78 & 3.99 & - \\
\hline $\mathbf{A l}_{2} \mathbf{O}_{3}$ & 24.5 & 15.05 & 2.41 & - \\
\hline $\mathrm{CaO}$ & 0.94 & 14.66 & 60.68 & - \\
\hline $\mathrm{Fe}_{2} \mathrm{O}_{3}$ & 9.07 & 5.49 & 0.69 & - \\
\hline $\mathrm{Cr}_{2} \mathrm{O}_{3}$ & 0.03 & 0.01 & $<0.01$ & - \\
\hline $\mathrm{K}_{2} \mathrm{O}$ & 2.06 & 1.64 & 0.8 & - \\
\hline MgO & 0.62 & 2.26 & 2.04 & - \\
\hline MnO & 0.02 & 0.02 & $<0.01$ & - \\
\hline $\mathrm{Na}_{2} \mathrm{O}$ & 0.3 & 0.2 & 0.09 & - \\
\hline $\mathbf{P}_{2} \mathbf{O}_{5}$ & 0.33 & 0.6 & 0.02 & - \\
\hline $\mathrm{TiO}_{2}$ & 1.33 & 0.74 & 0.1 & - \\
\hline $\mathrm{BaO}$ & 0.07 & 0.1 & 0.01 & - \\
\hline SrO & 0.06 & 0.12 & 0.02 & - \\
\hline LOI & 11.8 & 21.1 & 27.8 & - \\
\hline Total Fe & - & - & - & 1.89 \\
\hline Total S & - & - & - & 98.11 \\
\hline
\end{tabular}

Notes: FA: Fly Ash; BA: Bottom ash; FBC: Fluidized bed combustion ash; LKD: Lime kiln dust; LOI: loss on ignition (= total carbon) 


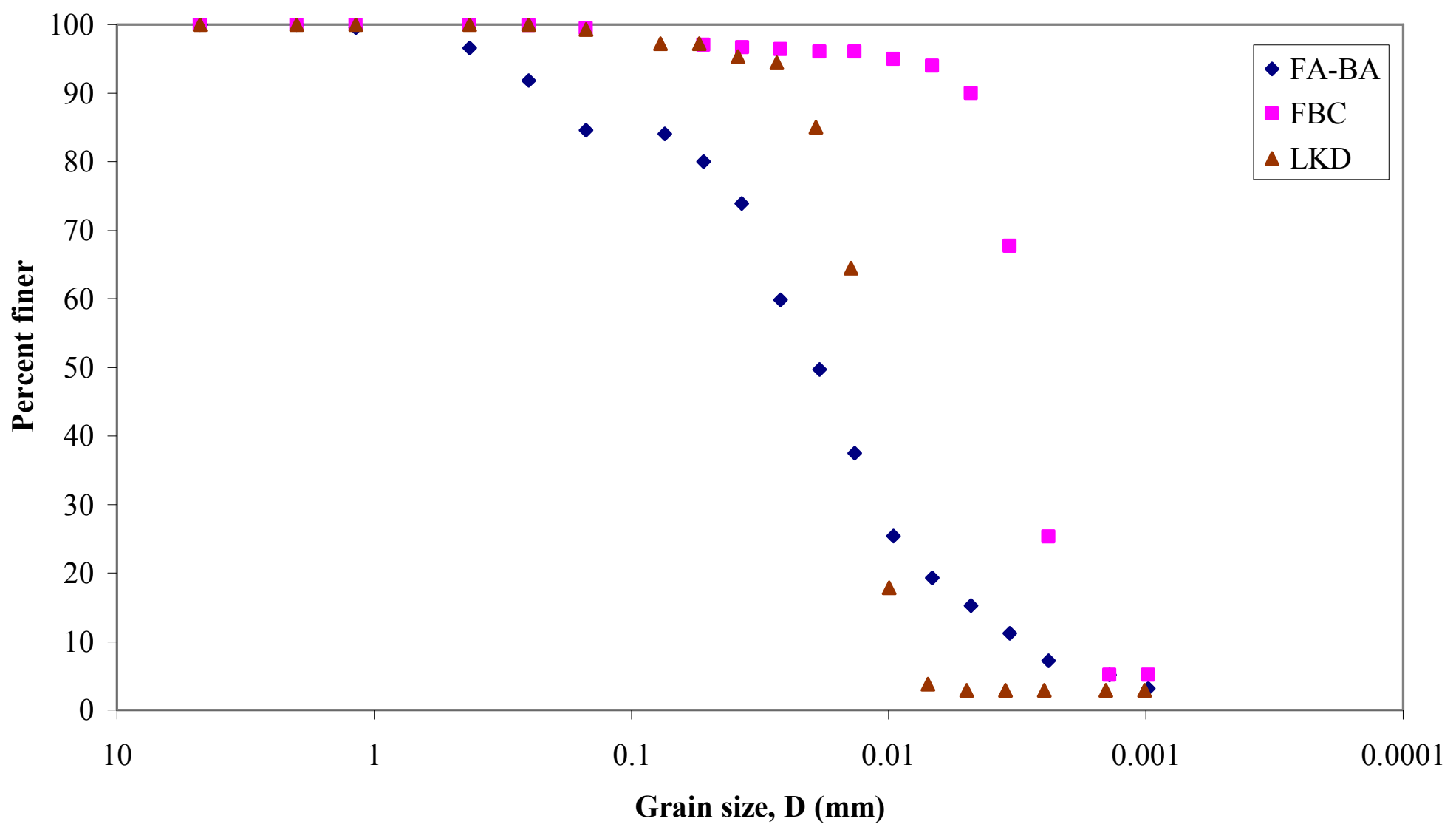

Figure 4.1. Grain Size Distribution for FA-BA, FBC, and LKD 


\subsubsection{Fluidized Bed Combustion By-Product}

The fluidized bed combustion (FBC) by-product used in the current study was obtained from Warrior Run Power Plant in Cumberland, Maryland. This ash has high calcium content (Table 4.1) and thus served as the lime activator for pozzolanic reaction in the grout. The ash was collected using the bag house method. The grain size distribution curve for the FBC is shown in Figure 4.1. Wash sieving could not be conducted on this material due to its self-cementing tendency upon contact with water. Atterberg limit tests conducted per ASTM D 4318 indicated that the FBC ash is non-plastic. The FBC ash has high fines content with about $88 \%$ passing through the U.S. No. 200 sieve.

\subsubsection{Lime Kiln Dust}

The lime kiln dust (LKD) used in this study was obtained from Carmeuse Natural Chemicals Company located in Pittsburgh, Pennsylvania. LKD is known to have high free lime content and is another lime activator used in grout mixtures. The physical and chemical properties of LKD are given in Table 4.1 and the grain size distribution curve is shown in Figure 4.1. Wash sieving was not performed on this material due to its hardening on contact with water. The LKD was also very fine with almost $90 \%$ passing through the No. 200 sieve. This material was also non-plastic.

\subsubsection{Pyrite}

Pyrite is a very common mineral that exists in a wide variety of geological formations and is commonly found in coal mines. The pyrite used in this study was 
collected from Kempton Mine Complex located in Kempton, Maryland. Pyrite is usually pale-yellow in color and is thus called "Fool's Gold". In the coal industry, pyrite is known as the major source of sulfur in coal. The grain size distribution, and chemical composition of the pyrite used in the current study are given in Figure 4.2 and Table 4.1 respectively. Figure 4.3 is a photograph of a sample of the pyrite stored at the University of Maryland Geotechnical Laboratories.

Chemical characterization of the FA-BA mix, FBC by-product, and LKD utilized in this study were conducted by using lithium meta or tetra borate fusion and X-Ray Fluorescence (XRF) techniques by ALS Chemex Laboratory in Reno, Nevada.

\subsection{GEOTECHNICAL LABORATORY TEST PLAN}

In the laboratory, grout mixtures were prepared with different proportions of the base material (FA-BA mix), lime activator (FBC by-product or LKD), and water. Therefore, the grout mixtures are classified as FBC-based and LKD-based mixtures. The mixture ratios for grout were selected to encompass a range of base and activator ranges to observe their effect on various geotechnical properties. The grout mixture ratios are listed in Table 4.2. Grout mixture ratios with high percentage $(>70 \%)$ of activator were not considered during testing, since mixing and handling of grout was very difficult and the grout hardened very quickly.

A total of 45 different grout mixtures, 22 mixtures with FBC by-product as the activator and 23 with LKD as the activator, were prepared (Tables 4.3 and 4.4). The water contents of the grout mixtures were varied within each mixture ratio to obtain the "optimal" water content which provided good 


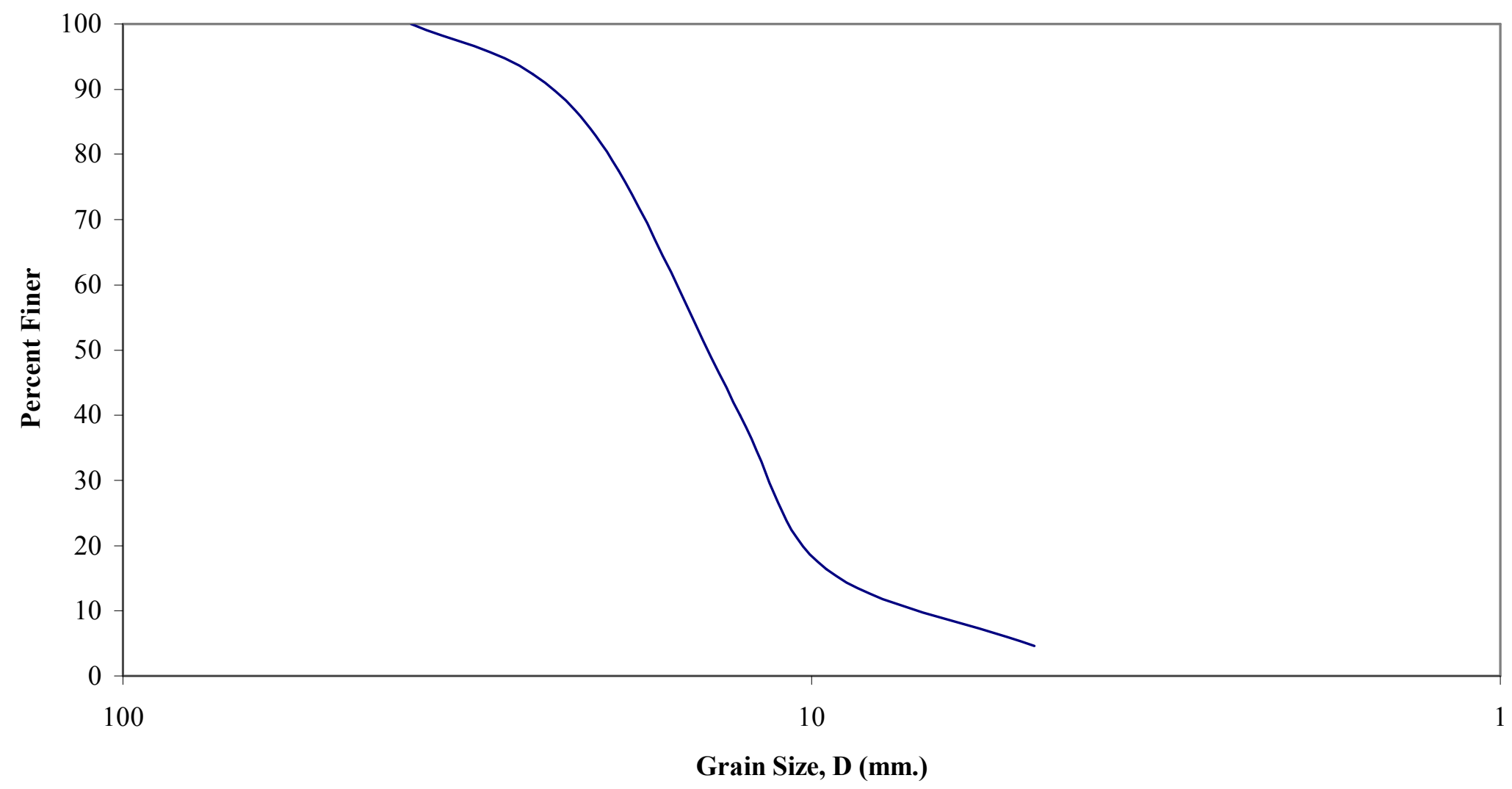

Figure 4.2. Grain Size Distribution for Pyrite. 


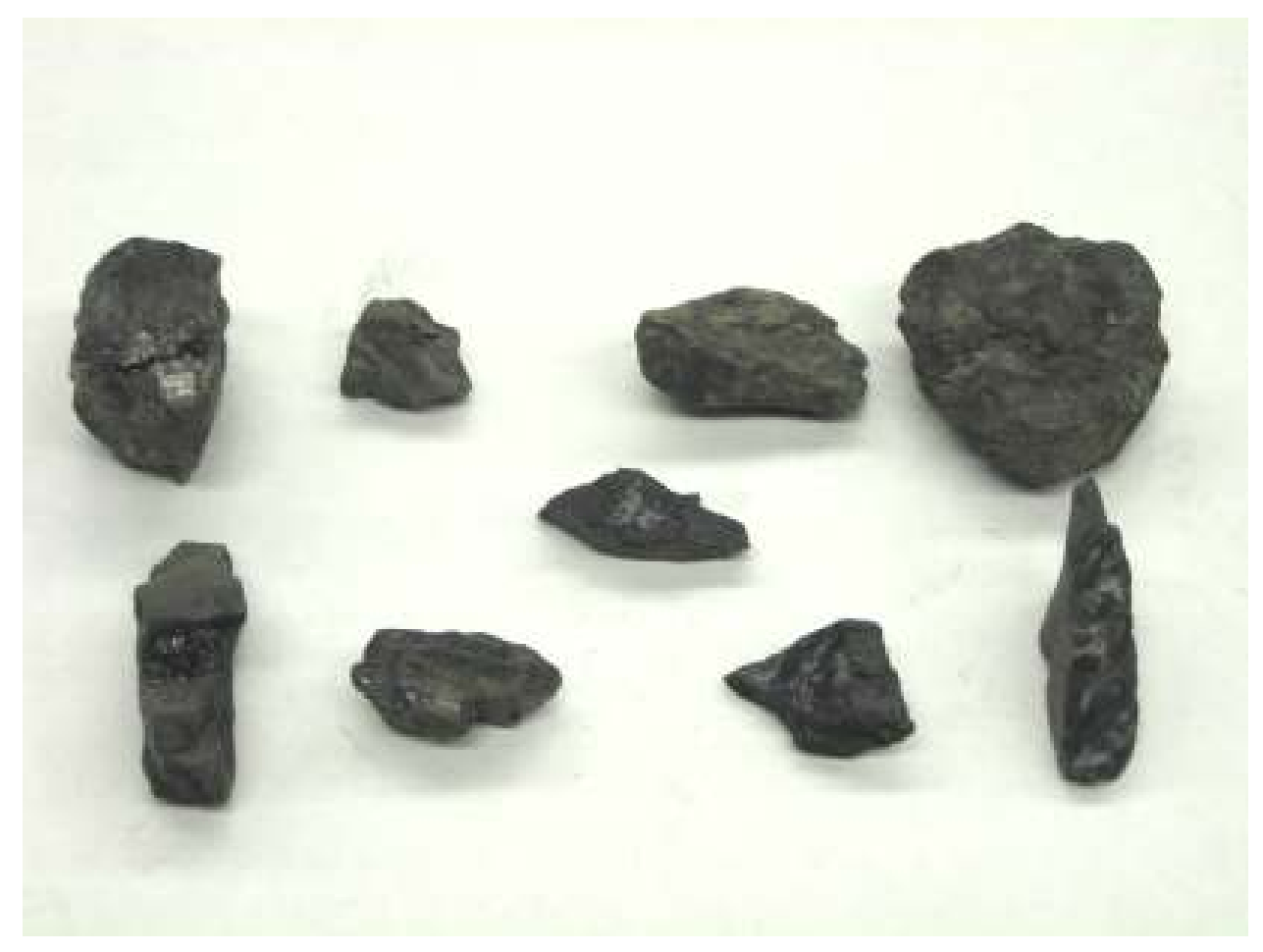

Figure 4.3. Pyrite used in this Study 
Table 4.2. Legend and composition of grout mixture ratios

\begin{tabular}{|c|c|c|}
\hline \multicolumn{3}{|c|}{ FBC-based Mixtures } \\
\hline Mix ID & FA-BA $(\%)$ & FBC $(\%)$ \\
\hline F1 & 30 & 70 \\
\hline F2 & 40 & 60 \\
\hline F3 & 50 & 50 \\
\hline F4 & 60 & 40 \\
\hline F5 & 70 & 30 \\
\hline F6 & 80 & 20 \\
\hline F7 & 90 & 10 \\
\hline \multicolumn{3}{|c|}{ LKD-based Mixtures } \\
\hline Mix ID & FA-BA (\%) & LKD (\%) \\
\hline L1 & 30 & 70 \\
\hline $\mathbf{L} 2$ & 40 & 60 \\
\hline L3 & 50 & 50 \\
\hline L4 & 60 & 40 \\
\hline L5 & 70 & 30 \\
\hline L6 & 80 & 20 \\
\hline L7 & 90 & 10 \\
\hline
\end{tabular}

Note: All percentages are by weight 
Table 4.3. Initial testing of FBC-based grout mixtures

\begin{tabular}{|c|c|c|c|c|}
\hline Specimen ID & FA-BA $(\%)$ & FBC $(\%)$ & Water Content (\%) & Spread (mm) \\
\hline F1 (a) & 30 & 70 & 35 & $* \mathrm{NA}$ \\
\hline F1 (b) & 30 & 70 & 50 & $* \mathrm{NA}$ \\
\hline $\mathrm{F} 1(\mathrm{c})$ & 30 & 70 & 80 & 105 \\
\hline F1 (d) & 30 & 70 & 88 & 130 \\
\hline F1 (e) & 30 & 70 & 92 & 190 \\
\hline F1 (f) & 30 & 70 & 93 & 205 \\
\hline F2 (a) & 40 & 60 & 80 & 120 \\
\hline $\mathrm{F} 2(\mathrm{~b})$ & 40 & 60 & 83 & 150 \\
\hline $\mathrm{F} 2(\mathrm{c})$ & 40 & 60 & 85 & 185 \\
\hline F2 (d) & 40 & 60 & 88 & 210 \\
\hline F3 (a) & 50 & 50 & 75 & 165 \\
\hline F3 (b) & 50 & 50 & 78 & 165 \\
\hline F3 (c) & 50 & 50 & 80 & 210 \\
\hline F4 (a) & 60 & 40 & 70 & 195 \\
\hline F4 (b) & 60 & 40 & 71 & 210 \\
\hline F5 (a) & 70 & 30 & 60 & 145 \\
\hline F5 (b) & 70 & 30 & 63 & 200 \\
\hline F5 (c) & 70 & 30 & 65 & 225 \\
\hline F6 (a) & 80 & 20 & 55 & 175 \\
\hline F6 (b) & 80 & 20 & 58 & 210 \\
\hline F7 (a) & 90 & 10 & 44 & 278 \\
\hline F7 (b) & 90 & 10 & 40 & 204 \\
\hline
\end{tabular}

Note: All percentages are by weight.

*NA: Not Applicable - Water content not sufficient for homogeneous grout mixing. 
Table 4.4. Initial testing of LKD-based grout mixtures for water contents

\begin{tabular}{|c|c|c|c|c|}
\hline Specimen ID & FA-BA (\%) & LKD (\%) & Water Content (\%) & Spread (mm) \\
\hline L1 (a) & 30 & 70 & 45 & 155 \\
\hline L1 (b) & 30 & 70 & 53 & 290 \\
\hline $\mathrm{L} 1$ (c) & 30 & 70 & 52 & 275 \\
\hline L1 (d) & 30 & 70 & 51 & 234 \\
\hline L1 (e) & 30 & 70 & 50 & 200 \\
\hline L2 (a) & 40 & 60 & 50 & 170 \\
\hline L2 (b) & 40 & 60 & 52 & 204 \\
\hline L3 (a) & 50 & 50 & 55 & 270 \\
\hline L3 (b) & 50 & 50 & 40 & 95 \\
\hline L3 (c) & 50 & 50 & 45 & 120 \\
\hline L3 (d) & 50 & 50 & 48 & 178 \\
\hline L3 (e) & 50 & 50 & 50 & 210 \\
\hline L4 (a) & 60 & 40 & 40 & *Failed \\
\hline L4 (b) & 60 & 40 & 45 & 154 \\
\hline L4 (c) & 60 & 40 & 48 & 205 \\
\hline L5 (a) & 70 & 30 & 40 & 162 \\
\hline L5 (a) & 70 & 30 & 45 & 225 \\
\hline L5 (c) & 70 & 30 & 44 & 202 \\
\hline L6 (a) & 80 & 20 & 35 & *Failed \\
\hline L6 (b) & 80 & 20 & 40 & 153 \\
\hline L6 (c) & 80 & 20 & 42 & 203 \\
\hline L7 (a) & 90 & 10 & 33 & 185 \\
\hline L7 (b) & 90 & 10 & 35 & 210 \\
\hline
\end{tabular}

Note: All percentages are by weight

*Failed: The specimen did not have any spread due to shear failure. 
grout flowability. Good flowability can be defined as a horizontal spread value of at least $200 \mathrm{~mm}$ and a slump of between 200 and $250 \mathrm{~mm}$. Considering the difficulties associated with slump tests, spread (ASTM D 6103) tests were conducted on all 45 grout mixtures to arrive at "optimal" water contents. Tap water was used in all the grout mixtures. Most mixing was done by hand as recommended in ASTM C 192/C 192M. For slump measurements, a large concrete mixer was used to mix the large quantities of grout required.

Based on spread values ( $\geq 200 \mathrm{~mm}$ ), 14 grout mixtures were selected from the initial 45 mixtures. These 14 grout mixtures were then tested for slump (ASTM C 143/C 143M) at "optimal" water contents. Bleed (ASTM C 940) of the freshly prepared grout was measured for the 14 mixture ratios. Unconfined compressive strength tests were conducted after 7, 14, and 28 day curing times. For some mixes that had low 14-day compressive strengths, strength was determined after 56-day curing instead of 28-day. Rigid wall constant head hydraulic conductivity tests (ASTM D 5856) were performed on selected grout mix - pyrite columns.

\subsection{SPREAD}

Horizontal spread of the grout mixtures was determined following the procedures in ASTM D 6103 (Standard Test Method for Flow Consistency of Controlled Low Strength Material - CLSM). According to D 6103, CLSM is defined as "a mixture of soil or aggregates, cementitious material, fly ash, water and sometimes chemical admixtures, that hardness into a material with a higher strength 
than soil, but less than $8400 \mathrm{kPa}(1200 \mathrm{psi})$ ". CLSM is also known as flowable fill and is self-compacting, with typical strengths of 350 to $700 \mathrm{kPa}$ (50 to $100 \mathrm{psi}$ ).

In this method, a predetermined volume of grout is placed in a flow cylinder on a flat, non-porous surface that is free of vibrations and other disturbances. Within 5 seconds of placing the grout in the flow cylinder, the cylinder is raised up in the vertical direction quickly by at least $15 \mathrm{~cm}$. Two largest spread diameters that are perpendicular to each other are measured immediately, and the spread value is reported as an average of the two.

Flow cylinders, $76 \mathrm{~mm}$ (3 inch) in diameter and $150 \mathrm{~mm}(6 \mathrm{inch})$ in length, were prepared from PVC to accommodate specimens for spread testing. The ASTM D 6103 recommends a spread value of between 200 and $300 \mathrm{~mm}$ for a CLSM that is used in ready to fill spaces without requiring any vibration. Spread was measured for grout mixtures at varying water contents to estimate the threshold water content required for good flowability, i.e., a spread of at least $200 \mathrm{~mm}$. The spread and water content values are summarized in Tables 4.3 and 4.4.

Figure 4.4 provides a summary of spread values for different FBC / FA-BA ratios. It can be seen from the figure that the spread increases with increasing water content of the mixture for a given FBC / FA-BA ratio. This is mainly due to the fact that the grout is more flowable with presence of more water in the environment. It can also be seen that the water content required to attain the minimum required spread for good flowability decreases with decreasing FBC / FA-BA ratio i.e., decrease in FBC by-product content or increase in FA-BA mix content. This may be due to the fact 


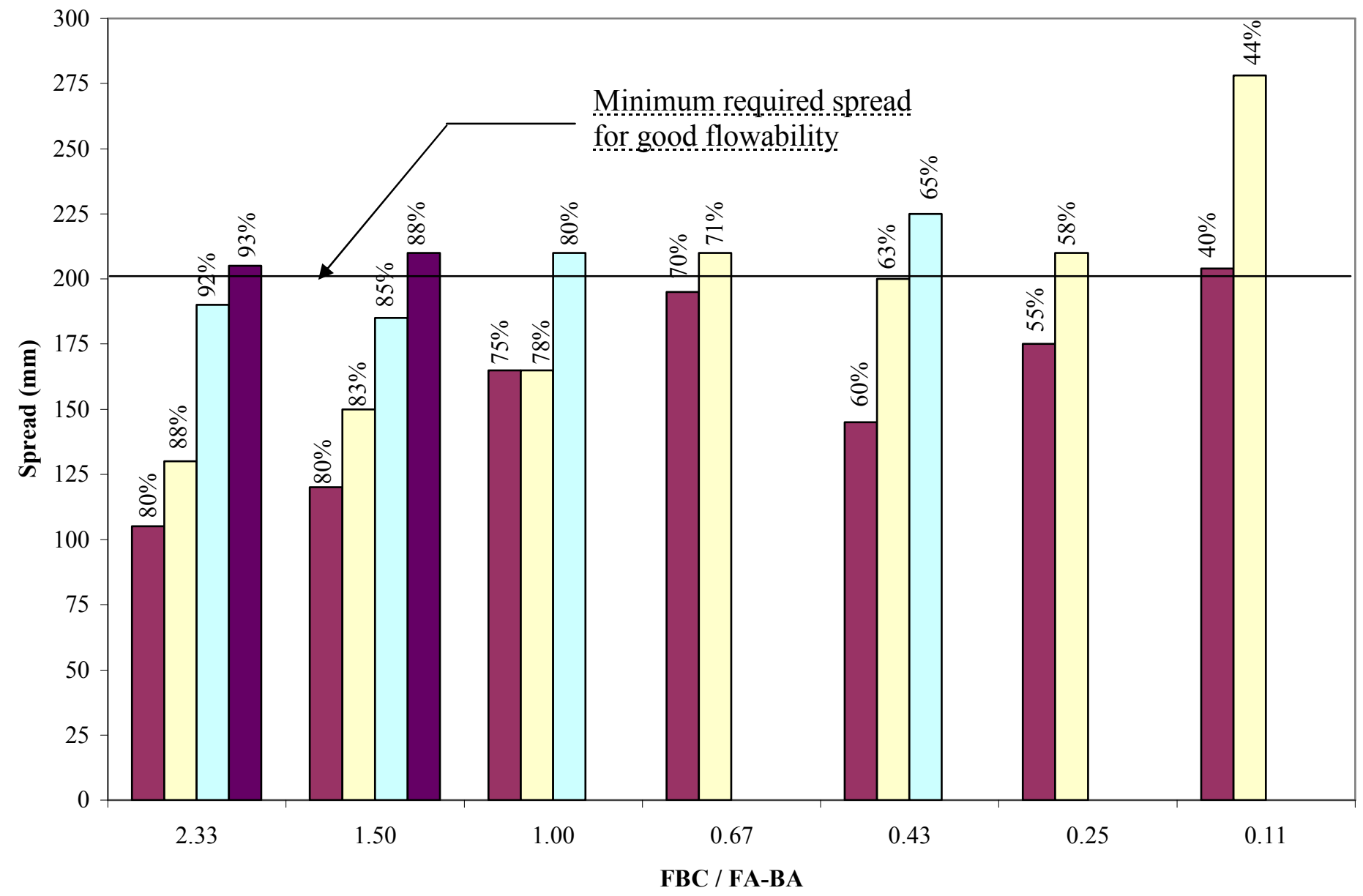

Figure 4.4. FBC / FA-BA versus Spread for different water contents 
that the pozzolanic hydration reaction decreases as the FBC by-product content decreases in the grout mixture ratio. Consequently, lesser amount of water is required for hydration, and the remaining water contributes to the flowability of the grout. It can also be observed from Figure 4.4 that the materials used in the testing program are highly sensitive to water content variations. A difference of 1 to $5 \%$ in water content causes a difference of 15 to $80 \mathrm{~mm}$ in slump values.

Similar behavior was also observed for the LKD-based grout mixtures, as shown in Figure 4.5. The spread increases with increasing water content at a given FBC / FA-BA ratio. Additionally, the amount of water required to achieve a spread of $200 \mathrm{~mm}$ was lower for mixtures with relatively low LKD contents. In general, the water contents range from $40 \%$ to $93 \%$ for FBC-based mixtures, whereas the range is between $50 \%$ and $35 \%$ for LKD-based mixtures. Table 4.5 summarizes water contents at which at least $200 \mathrm{~mm}$ spread is achieved for various FBC-based and LKD-based grout mixture ratios.

The threshold water contents for a minimum spread of $200 \mathrm{~mm}$ are plotted against the free lime content $(\mathrm{FBC}$ or $\mathrm{LKD}) / \mathrm{FA}-\mathrm{BA}$ ratio in Figure 4.6(a). It is observed that the water content increases with increasing free lime content / FA-BA ratio. This is due to the fact that more water is used up for hydration reactions in the grout with increasing free lime content. Figure 4.6(b) is a plot of water content against FA-BA contents for all the grout mixtures listed in Tables 4.3 and 4.4. Water contents decrease with increasing amounts of FA-BA. This is because the FA-BA mix is a granular material, and contributes to flowability of the grout. Thus, higher FA-BA contents require lower amounts of water to achieve good flowability. 


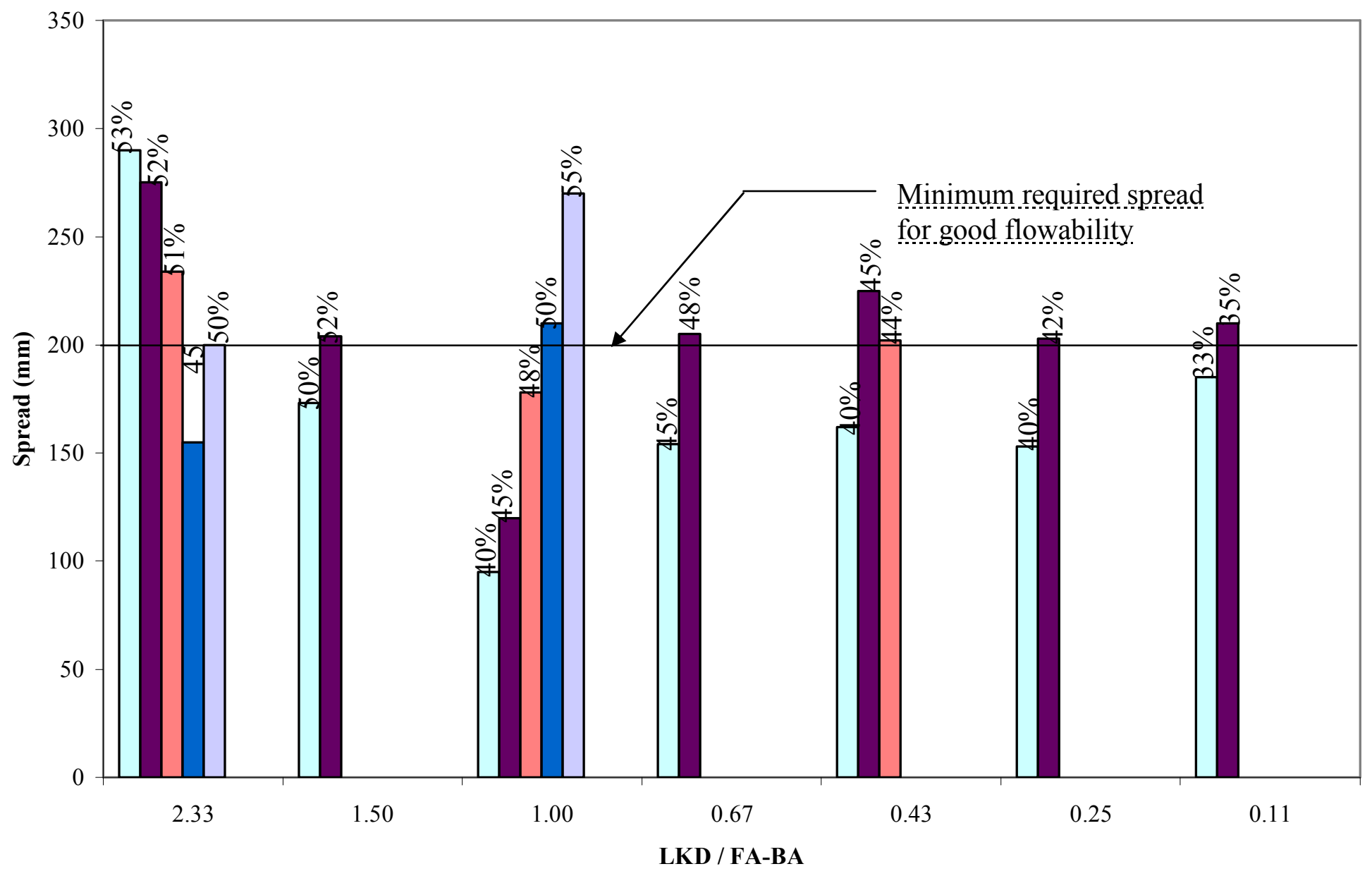

Figure 4.5. LKD / FA-BA mix versus Spread for different water contents 
Table 4.5. Results of spread, slump, and bleed for "optimal" grout mixtures

\begin{tabular}{|c|c|c|c|c|c|c|}
\hline \multicolumn{7}{|c|}{ FBC-based Mixtures } \\
\hline Mix ID & $\begin{array}{c}\text { FA-BA } \\
(\%)\end{array}$ & $\begin{array}{r}\text { FBC } \\
(\%)\end{array}$ & $\begin{array}{c}\text { Water } \\
\text { Content } \\
(\%) \\
\end{array}$ & $\begin{array}{c}\text { Spread } \\
(\mathrm{mm})\end{array}$ & $\begin{array}{c}\text { Slump } \\
(\mathrm{mm})\end{array}$ & $\begin{array}{c}\text { Bleed } \\
(\%)\end{array}$ \\
\hline F1 & 30 & 70 & 93 & 205 & 266 & 1.74 \\
\hline F2 & 40 & 60 & 88 & 210 & 262 & 1.93 \\
\hline F3 & 50 & 50 & 80 & 210 & 269 & 4.88 \\
\hline F4 & 60 & 40 & 71 & 210 & 271 & 3.49 \\
\hline F5 & 70 & 30 & 63 & 200 & 276 & 2.59 \\
\hline F6 & 80 & 20 & 58 & 210 & 280 & 5.81 \\
\hline F7 & 90 & 10 & 40 & 204 & 270 & 2.38 \\
\hline \multicolumn{7}{|c|}{ LKD-based Mixtures } \\
\hline Mix ID & $\begin{array}{c}\text { FA-BA } \\
(\%)\end{array}$ & $\begin{array}{c}\text { LKD } \\
(\%)\end{array}$ & $\begin{array}{c}\text { Water } \\
\text { Content } \\
(\%) \\
\end{array}$ & $\begin{array}{c}\text { Spread } \\
(\mathrm{mm})\end{array}$ & $\begin{array}{c}\text { Slump } \\
(\mathrm{mm})\end{array}$ & $\begin{array}{c}\text { Bleed } \\
(\%)\end{array}$ \\
\hline $\mathbf{L 1}$ & 30 & 70 & 50 & 200 & 243 & 0 \\
\hline $\mathbf{L 2}$ & 40 & 60 & 52 & 204 & 158 & 0 \\
\hline L3 & 50 & 50 & 50 & 210 & 164 & 1.49 \\
\hline L4 & 60 & 40 & 48 & 205 & 231 & 1.61 \\
\hline L5 & 70 & 30 & 44 & 202 & 267 & 1.56 \\
\hline L6 & 80 & 20 & 42 & 203 & 271 & 1.66 \\
\hline L7 & 90 & 10 & 35 & 210 & 261 & 1.75 \\
\hline
\end{tabular}



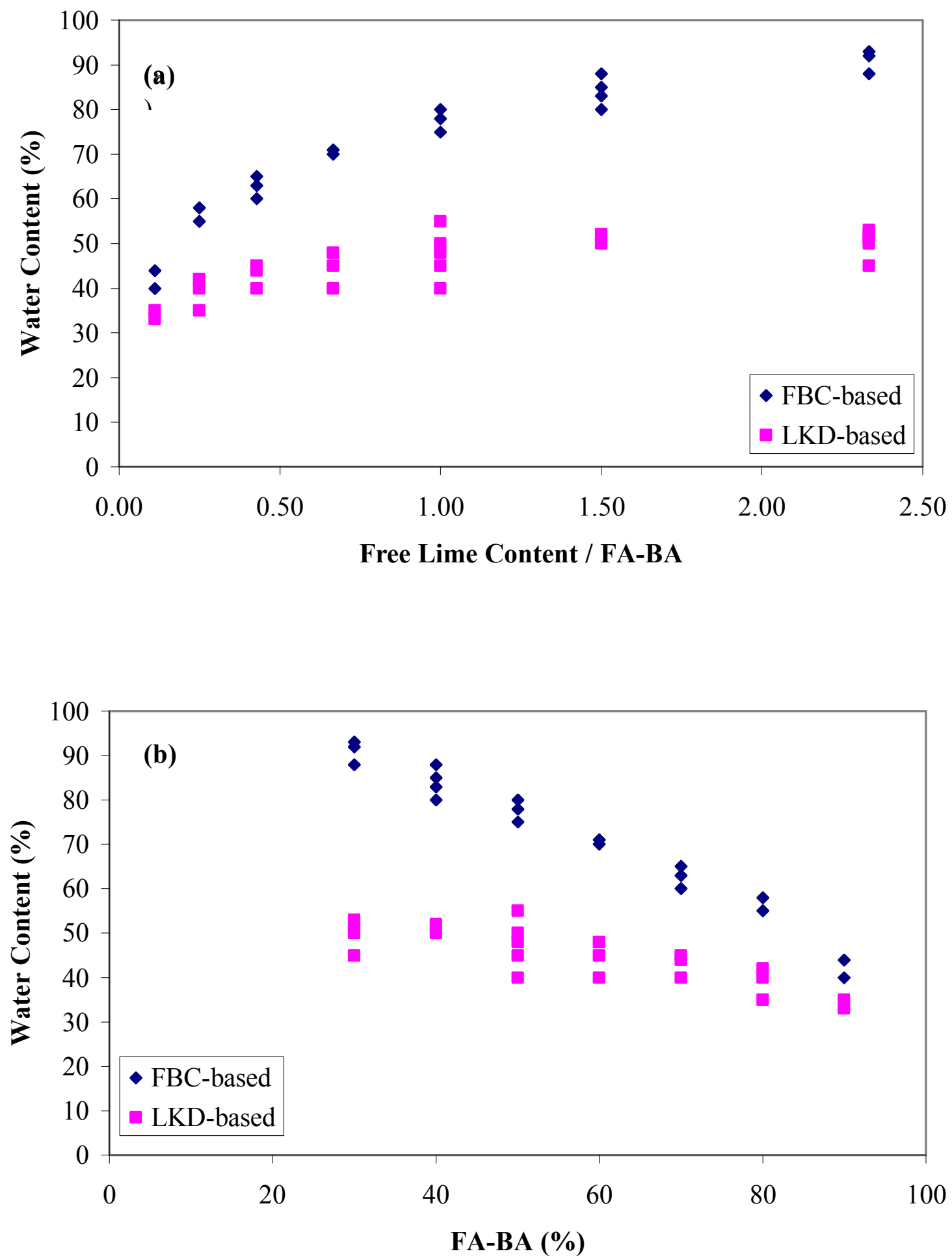

Figure 4.6. Water content versus (a) Free lime content / FA-BA, and (b) FA-BA \% 
Figure 4.7 presents the relationships between free lime content / FA-BA ratio and the spread value normalized by water content $(\mathrm{Sp} / \mathrm{w})$. The spread values cannot be directly compared as each grout mixture ratio involves different water contents. Thus, normalizing spread by water content provided a ratio that is independent of water content of the grout mixture. Figure $4.7(\mathrm{a})$ shows that the $\mathrm{Sp} / \mathrm{w}$ ratio decreases with increasing free lime content / FA-BA ratio. The rate of decrease is higher at relatively lower free lime content / FA-BA ratios, and the curve flattens out at higher ratios. This decrease can be attributed to pozzolanic hydration reactions taking place in the grout. At higher FBC by-product or LKD contents (higher free lime content / FA-BA mix ratios), there is more hydration taking place in the grout. The flattening of the curve may be due to the fact that the corresponding FA-BA contents are low at high FBC or LKD contents. There is not enough base material to react with the large amounts of available lime which slows down pozzolanic hydration reactions and makes the water that is in excess of hydration reactions available to contribute to the flowability of the grout. Hydration reactions require water, thus these reactions use up the water content of the grout mixture leaving lesser amount of water for flow of grout.

Figure 4.7 (b) shows an increasing trend with increase in FA-BA contents. Increasing FA-BA contents spread increases due to increase in bulky base material which aids in making the grout more flowable. The free lime content of the mixture also decreases correspondingly to the increase in FA-BA contents decreasing the pozzolanic hydration reactions which contribute to the stiffness or strength of the grout. 

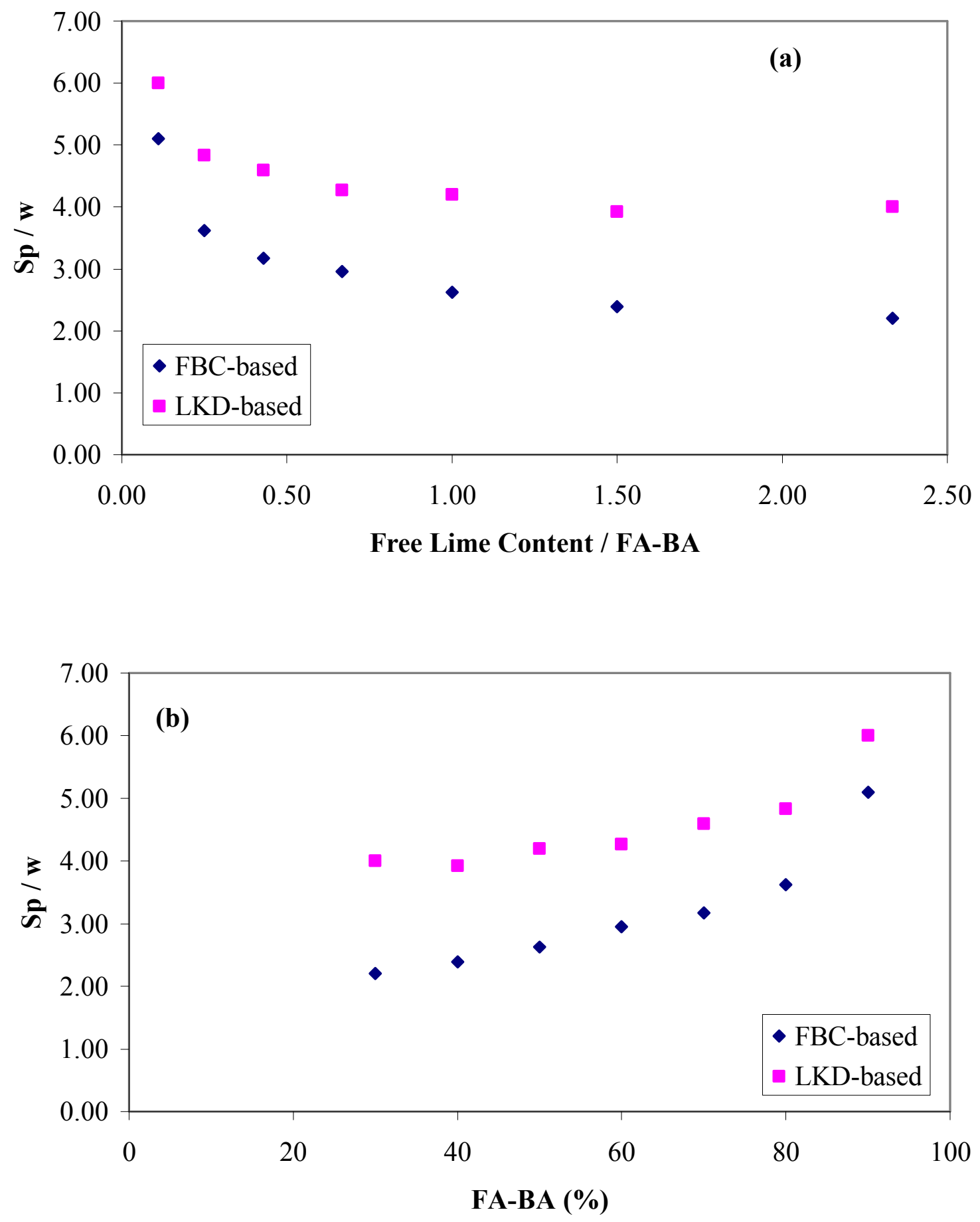

Figure 4.7. Spread / Water Content versus (a) Free lime content / FA-BA, and (b) FA-BA \% 


\subsection{SLUMP}

The slump of grout mixtures was measured in accordance with the procedures outlined in ASTM C 143/C 143M (Standard Test Method for Slump of HydraulicCement Concrete). The specimens for slump tests were prepared in a large concrete mixer. A sample of freshly prepared grout was placed in a mold that was built in the shape of a frustum of a cone. The sample was filled in the mold in three layers, and each layer was rodded. The mold was then raised and the vertical displacement of the grout from its original position (top of the truncated cone) was measured and reported as the slump of that grout mixture. As reported in ACI 229R, a material has high flowability if it has at least $200 \mathrm{~mm}$ spread and slump greater than $200 \mathrm{~mm}(8$ inches). Slump tests were conducted on the fourteen FBC-based and LKD-based grouts. From the grout mixtures in Table 4.3 and Table 4.4, mixtures with spread of approximately $200 \mathrm{~mm}$ were selected for measuring the slump. Slump values for the selected "optimal" grout mixtures are shown in Table 4.5. The slump for FBC-based mixtures is above $250 \mathrm{~mm}$. For LKD-based mixtures, on the other hand, the slump stayed in a range of 158 to $271 \mathrm{~mm}$ indicating that the high $\mathrm{CaO}$ content of LKD may have an effect on the flowability.

In order to study the effect of LKD or FBC on slump, the slump values are normalized by the mixture water content $(\mathrm{Sl} / \mathrm{w})$ and plotted against free lime content / FA-BA in Figure 4.8. Similar to the trend observed for spread in Figure 4.7, slump also decreases with increasing free lime content / FA-BA. As discussed above, this loss of flowability may be because of hardening of grout due to higher pozzolanic reactions caused by the free lime. At lower free lime content / 

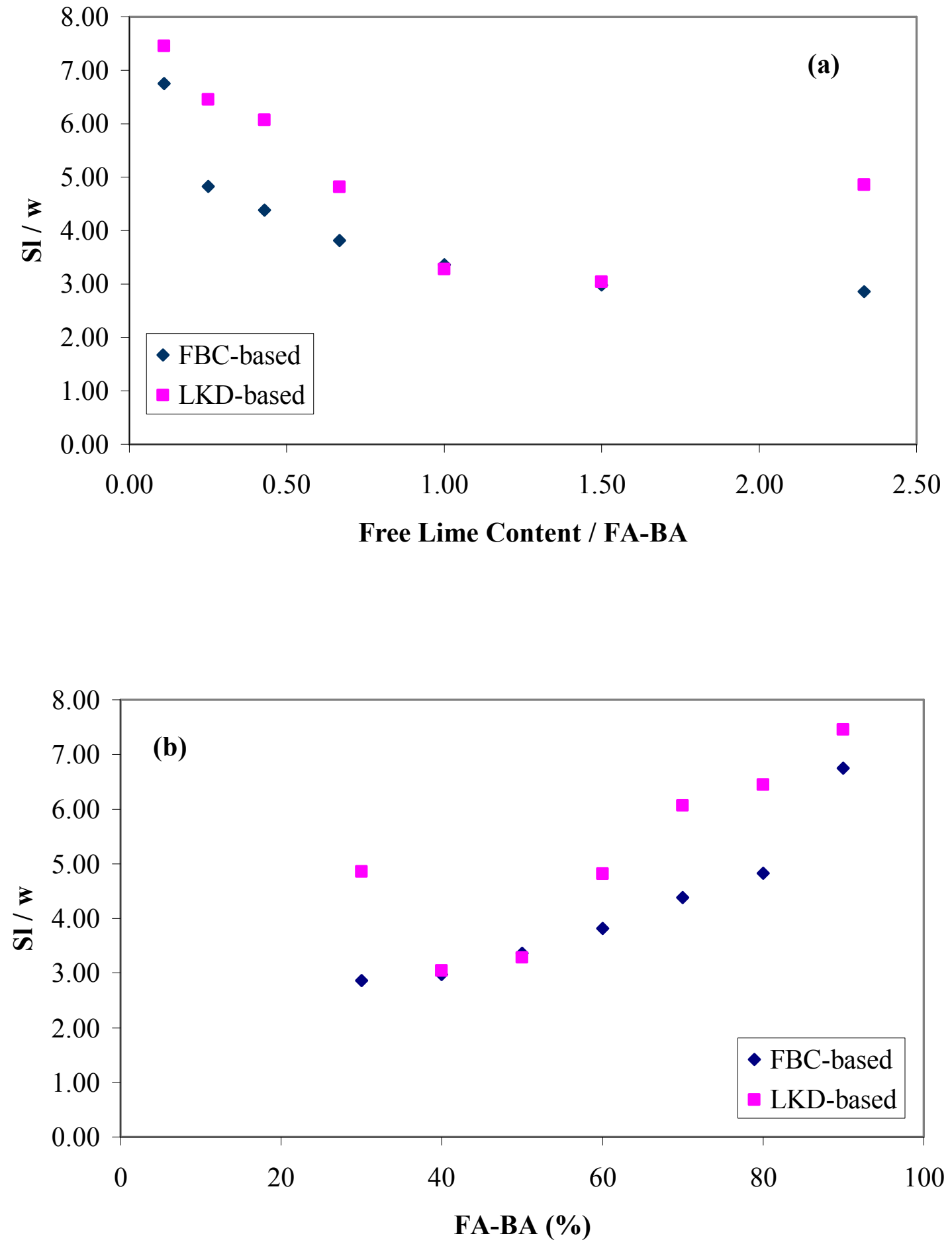

Figure 4.8. Slump / Water Content versus (a) Free lime content / FA-BA, and (b) FA-BA $\%$ 
FA-BA mix ratios the slump and spread are higher because these mixtures have lower free lime contents and more bulky base material in the grout mixture which aids in the flowability of the grout.

\subsection{BLEED}

Bleed tests were conducted on the seven FBC-based, and seven LKD-based "optimal" grout mixtures. Bleed is defined as the excess water that is not required for hydration reactions. The bleed tests were conducted following the standard procedures of ASTM C 940 (Standard Test Method for Expansion and Bleeding of Freshly Mixed Grouts for Preplaced-Aggregate Concrete in the Laboratory). A known volume of freshly prepared grout was placed in a $1000 \mathrm{~mL}$ graduated cylinder, and the changes in total volume and any accumulation of bleed water on the surface of the grout were observed. The values of bleed for "optimal" grout mixtures are reported in Table 4.5. Similar to spread and slump, the bleed values are normalized with the water content of the mixture and plotted against free lime content / FA-BA and FA-BA content in Figure 4.9.

A general trend of decrease in bleed with increasing free lime content / FABA ratio is observed in Figure 4.9(a). As the lime content of a grout mixture increases, more hydration reaction takes place using up larger amounts of water in the mix. Thus, the bleed decreases with increasing free lime content/ base ratio. On the other hand, higher quantity of FA-BA base material may increase the bleed water due to its granular structure (Figure 4.9b) and, as a result, less hydration takes place. Similar trends were observed for spread and slump. 

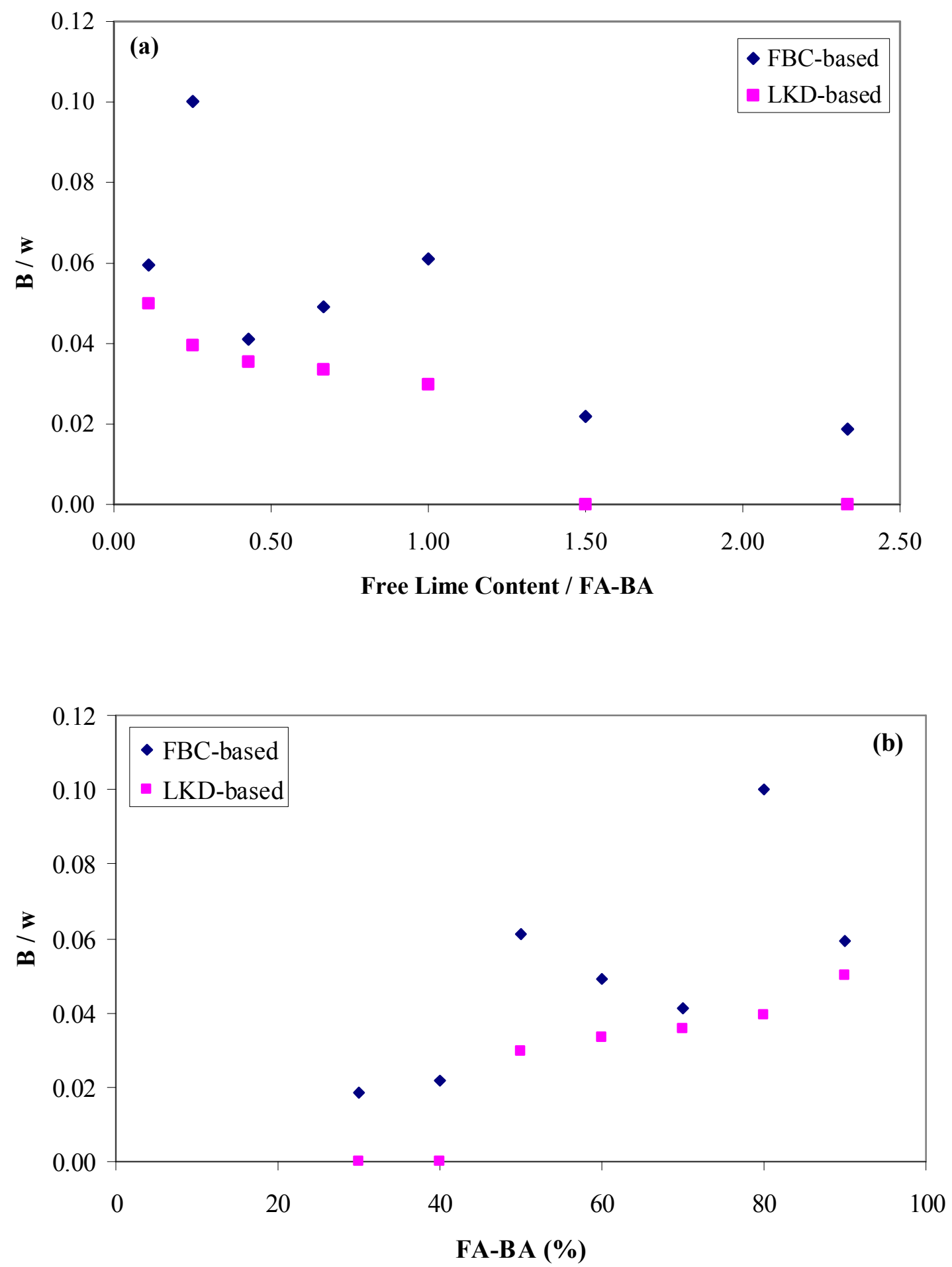

Figure 4.9. Bleed / Water Content versus (a) Free lime content / FA-BA, and (b) FA-BA \% 
The data in Table 4.5 suggests that all of the LKD-based grout mixtures had low bleed values $(<2 \%)$. LKD-based mixtures L1 and L2 showed no visible bleed water, therefore their bleed values were reported as zero. The FBC-based mixtures indicated higher bleed values when compared to the LKD-based mixtures. This may be attributed to the lower lime content $(\mathrm{CaO})$ of $\mathrm{FBC}$ by-product $(14.66 \%)$ compared to the lime content of LKD $(60.68 \%)$. Higher lime requires more water for hydration reactions to take place, resulting in lower bleed water.

\subsection{UNCONFINED COMPRESSIVE STRENGTH}

The 14 "optimal" grout mixtures were placed in PVC moulds of $102 \mathrm{~mm}$ (4 inches) in diameter and $203 \mathrm{~mm}$ (8 inches) in height. All specimens were cured at 100

$\%$ relative humidity and constant temperature of $21 \pm 2^{\mathrm{O}} \mathrm{C}$, and the molds were covered with plastic wrap with holes punctured to allow access of moisture to the specimen. All specimens were demolded after seven days, with few exceptions. Specimens F6 and L6 were demolded after 14 days since they did not cure in 7 days. Additionally, specimens F7 and L7 did not harden sufficiently even after 14 days due to very low lime content, and both were demolded after 21 days.

Unconfined compression tests were conducted on the mixtures cured for 7, 14, and 28 days. On mixtures F3, F4, and F5, strengths tests were performed after curing for 56 days instead of 28 days, since the 28-day strength was anticipated to be low. All tests were performed on a Fourney Universal Testing Machine with maximum loading capacity of $130 \mathrm{kN}$ following the procedures outlined in ASTM C 39/C $39 \mathrm{M}$ (Standard Test Method for Compressive Strength of Cylindrical Concrete Specimens) 
Table 4.6. Results of unconfined compressive strength for "optimal" grout mixtures

\begin{tabular}{|c|c|c|c|c|c|c|c|}
\hline \multicolumn{8}{|c|}{ FBC-based Mixtures } \\
\hline \multirow{2}{*}{ Mix ID } & \multirow{2}{*}{$\begin{array}{c}\text { FA-BA } \\
(\%)\end{array}$} & \multirow{2}{*}{$\begin{array}{c}\text { FBC } \\
(\%)\end{array}$} & \multirow{2}{*}{$\begin{array}{c}\text { Water } \\
\text { Content } \\
(\%)\end{array}$} & \multicolumn{4}{|c|}{ Unconfined Compressive Strength (kPa) } \\
\hline & & & & 7-day & 14-day & 28-day & 56-day \\
\hline F1 & 30 & 70 & 93 & 686 & 796 & 851 & - \\
\hline $\mathbf{F} 2$ & 40 & 60 & 88 & 576 & 658 & 742 & - \\
\hline F3 & 50 & 50 & 80 & 466 & 521 & - & 800 \\
\hline F4 & 60 & 40 & 71 & 357 & 604 & - & 700 \\
\hline F5 & 70 & 30 & 63 & 219 & 329 & - & 384 \\
\hline F6 & 80 & 20 & 58 & NA & 120 & 137 & - \\
\hline F7 & 90 & 10 & 40 & NA & NA & 82 & - \\
\hline \multicolumn{8}{|c|}{ LKD-based Mixtures } \\
\hline \multirow{2}{*}{ Mix ID } & \multirow{2}{*}{$\begin{array}{c}\text { FA-BA } \\
(\%)\end{array}$} & \multirow{2}{*}{$\begin{array}{c}\text { LKD } \\
(\%)\end{array}$} & \multirow{2}{*}{$\begin{array}{c}\text { Water } \\
\text { Content } \\
(\%) \\
\end{array}$} & \multicolumn{4}{|c|}{ Unconfined Compressive Strength (kPa) } \\
\hline & & & & 7-day & 14-day & 28-day & 56-day \\
\hline $\mathbf{L 1}$ & 30 & 70 & 50 & 650 & 1920 & 2277 & - \\
\hline $\mathbf{L} 2$ & 40 & 60 & 52 & 439 & 1728 & 1948 & - \\
\hline $\mathbf{L 3}$ & 50 & 50 & 50 & 384 & 521 & 2058 & - \\
\hline L4 & 60 & 40 & 48 & 219 & 439 & 3594 & - \\
\hline L5 & 70 & 30 & 44 & 165 & 411 & 1591 & - \\
\hline L6 & 80 & 20 & 42 & NA & 206 & 220 & - \\
\hline L7 & 90 & 10 & 35 & NA & NA & 82 & - \\
\hline
\end{tabular}


Table 4.6 shows the strength values for the "optimal" grout mixtures for 7day, 14-day, 28-day, and 56-day curing times. Figure 4.10 shows the 7-day curing strengths plotted against FBC/FA-BA ratios and FA-BA contents. As seen in Figure 4.10(b), strength decreases with increasing base material content. Conversely, strength increases with increasing free lime content / FA-BA ratios (Figure 4.10a) due to hydration reactions forming calcium silicate hydrates and calcium alumina hydrates, which cause hardening of the specimen. However the rate of increase in strength is relatively lower for higher lime contents. This may be due to a decrease in pozzolanic reactions due to lesser base material available for the large amount of lime content.

Figure 4.11 is a plot of strength against curing time. Relatively higher FA-BA content mixtures (F3, L3, F4, L4) have low 7-day strengths, but they gain strength after 14 days of curing. Fly ashes have slow reactive nature but upon sufficient curing gain substantial strength. This phenomenon was also observed by Mirza et al. (2002). It is observed that the rate of strength gain is relatively lower after 14 days for FBCbased specimens, compared to their 7-day strengths. This may be due to the relatively lower amount of lime as compared to LKD. For LKD-based specimens with higher lime content, the 7-day strengths are relatively low and appreciable strength is gained after 14 days. This is also evident in Figure 4.10 that all LKD-based specimens demonstrate lower 7-day strength compared to their FBC-based counterparts. 

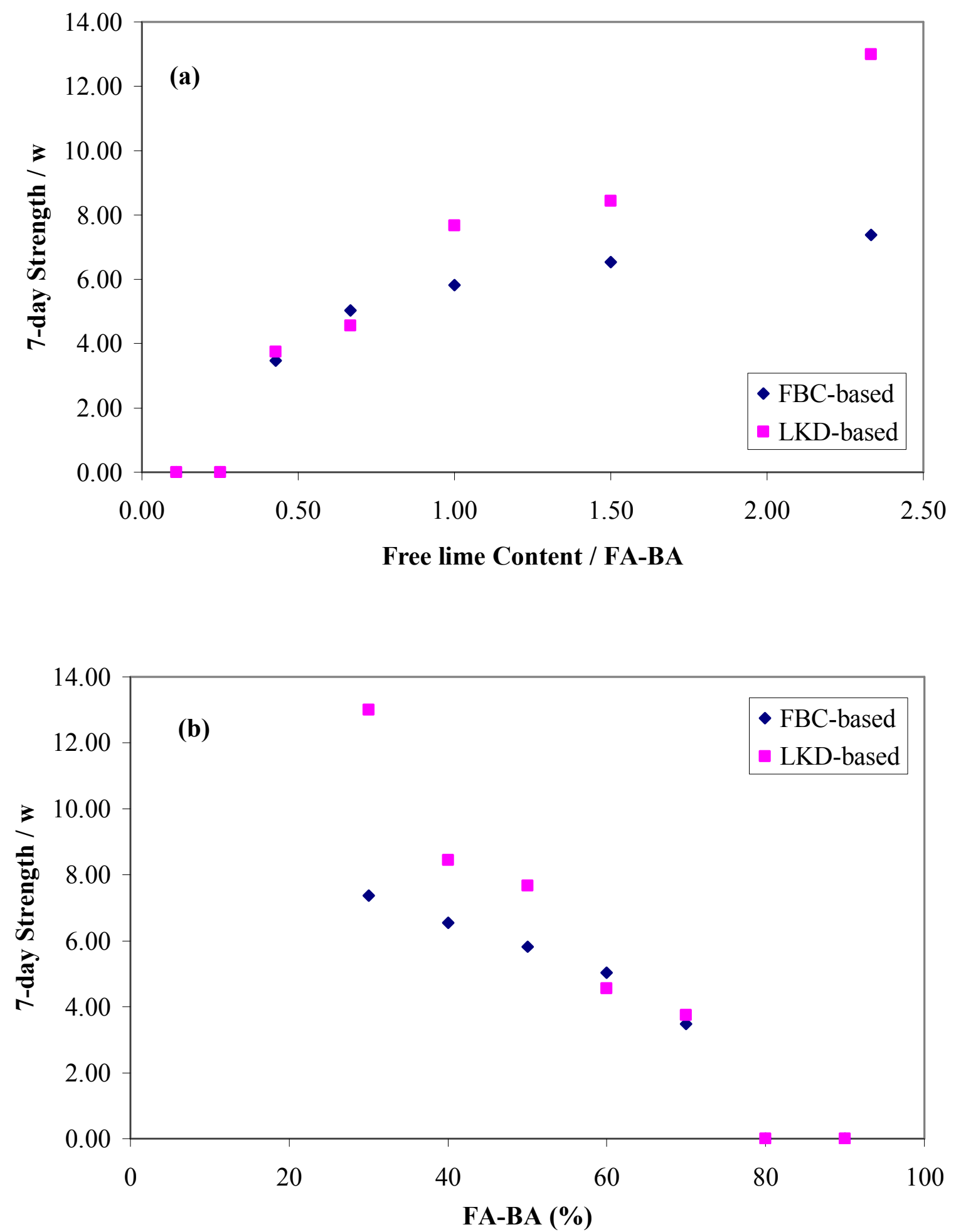

Figure 4.10. Strength (at 7-day curing) versus (a) Free lime content /FA-BA, and (b) FA-BA \% 

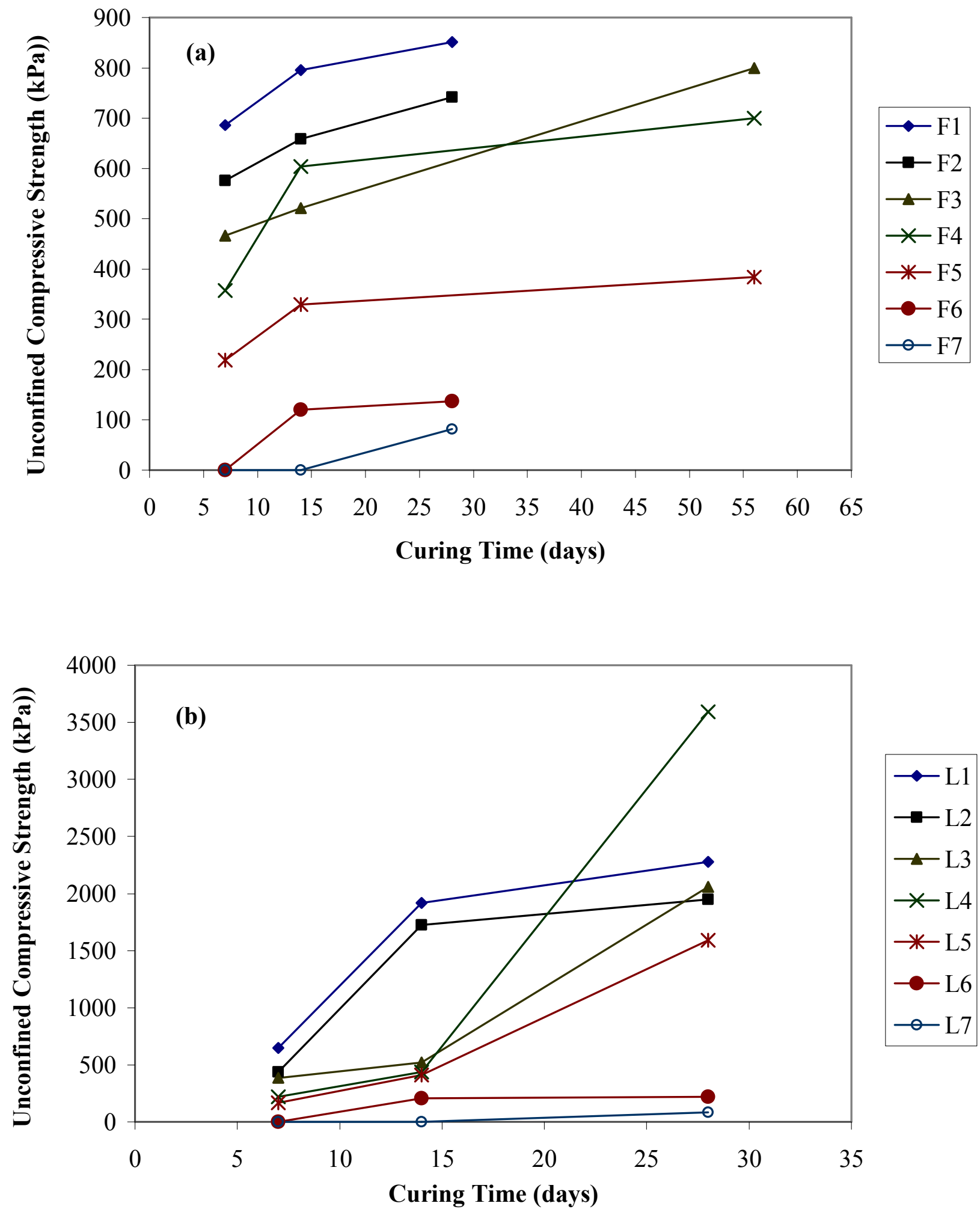

Figure 4.11. Strength versus Curing Time for (a) FBC-based, and (b) LKD-based mixtures 


\section{SECTION 5}

\section{LABORATORY EVALUATION OF HYDRAULIC CONDUCTIVITY AND LEACHING BEHAVIOR}

\section{$5.1 \quad$ INTRODUCTION}

It has been inferred from previous research reported by Taerakul et al. (2004) as well as through the observations made in the Winding Ridge Demonstration Project (Section 3) that total filling of mine with grout is usually not possible due to unknown voids that exist, and/or limited penetration of the grout into deep mine voids and pyritic rock on the mine pavement. This was evident from the flow rates which were not altered greatly at both mine sites even after the grouting operation. However, significant but slow improvement in the quality of water discharged from the mines was observed. Therefore it can be concluded that it may be more practical to aim at proper "encapsulation" of the pyritic rock in the mine pavements and shafts than to expect entire filling of mine voids, which may have been the case at both sites. Pyrite may exist in the field on the mine pavements and on the walls of the mine shaft as shown in Figure 5.1. Rainwater and/or groundwater (depending on the elevation of mine pavement with respect to the groundwater table) along with oxygen may interact with the pyrite and result in the formation of AMD. As seen from the Figure 5.1, injected grout may not penetrate into deeper voids of the pyrite, resulting in a barrier between the pyrite and the environment, rather than filling up of entire mine voids. 


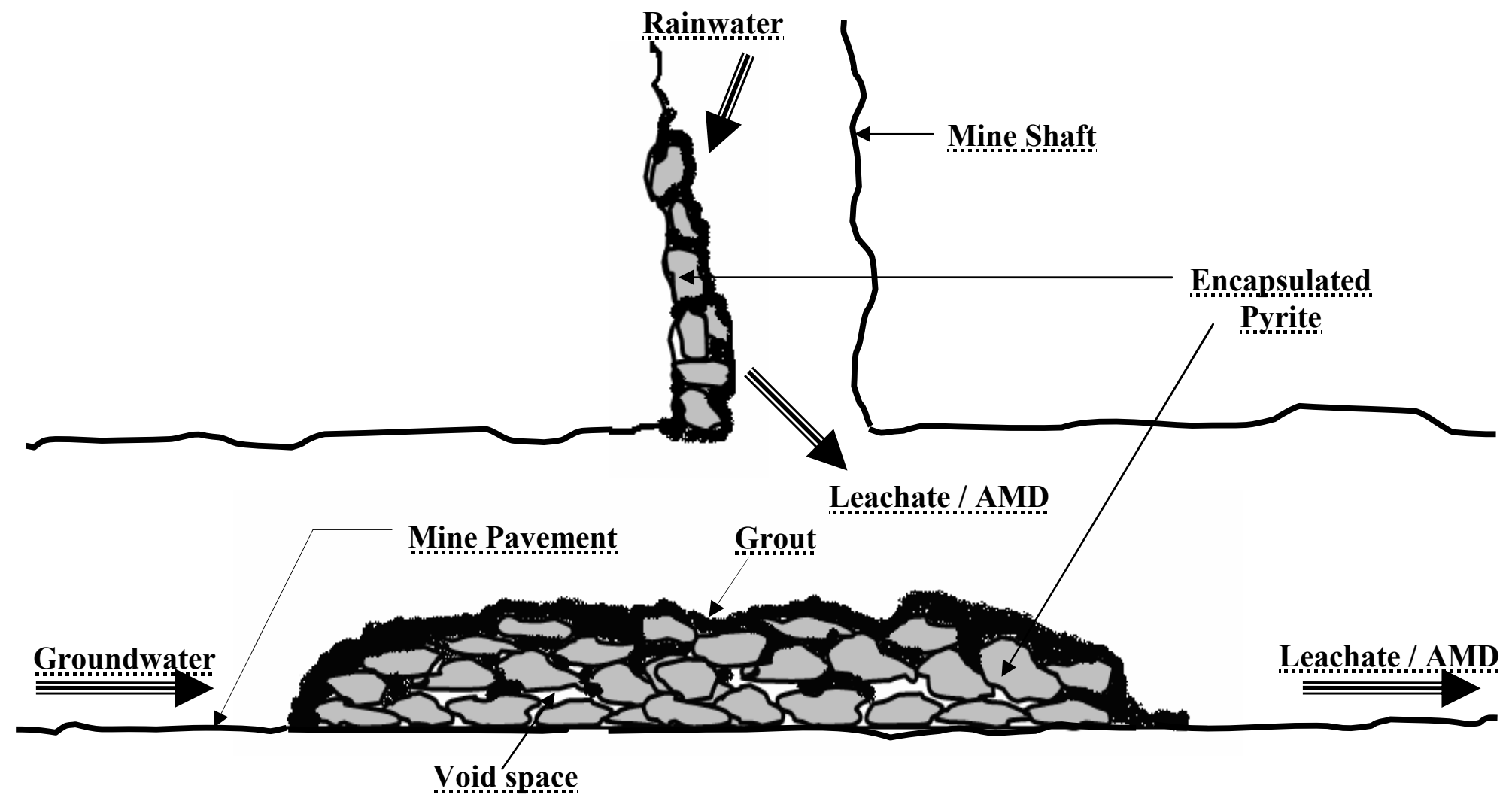

Figure 5.1. Grout-encapsulated pyrite in the mine pavement and shaft 
To simulate the pyrite/grout mixtures present in mine pavements and on the walls of the mine shafts, and evaluate their hydraulic performance and leaching behavior, long-term laboratory flow tests were conducted. Eight selected grouts, F2 through F6 and L3 through L5, were mixed with pyrite following the procedures described in ASTM C192/C192 M, and placed in $100 \mathrm{~mm}$ (4 inches) in diameter and $200 \mathrm{~mm}$ (8 inches) in height clear PVC columns. All eight grout, mixtures with the exception of L3, had spread and slump above $200 \mathrm{~mm}$ indicating good flowability. Furthermore, mixture F6 was selected to observe the behavior of low free lime content grout in remediating AMD, even though it had low 28-day strength.

Preliminary analyses were made to calculate the amount of grout to fill nearly all the voids inside the pyrite rock which had a porosity of 0.32 . These pyrite/grout columns were set up to simulate an ideal field condition, where all the pyrite in the mine pavement and mine shaft is entirely encapsulated by the injection of the grout. The debris and large size particles in the pyrite rock were pulverized until they passed through a 38.1-mm sieve. Additionally, small size particles in the rock were eliminated by sieving through a 2.36-mm sieve (U.S. Sieve size \#8). A photograph of the grout-encapsulated pyrite column is shown in Figure 5.2.

\subsection{HYDRAULIC CONDUCTIVITY}

The hydraulic conductivity of each pyrite/grout mixture was determined using the constant - head method in accordance with ASTM D 5856. The specimens were cured for 7 days at $100 \%$ relative humidity and at $21 \pm 2^{\mathrm{O}} \mathrm{C}$ for equilibrium inside the rigid - wall cells before initiating the tests. The only exception was F6, which was 

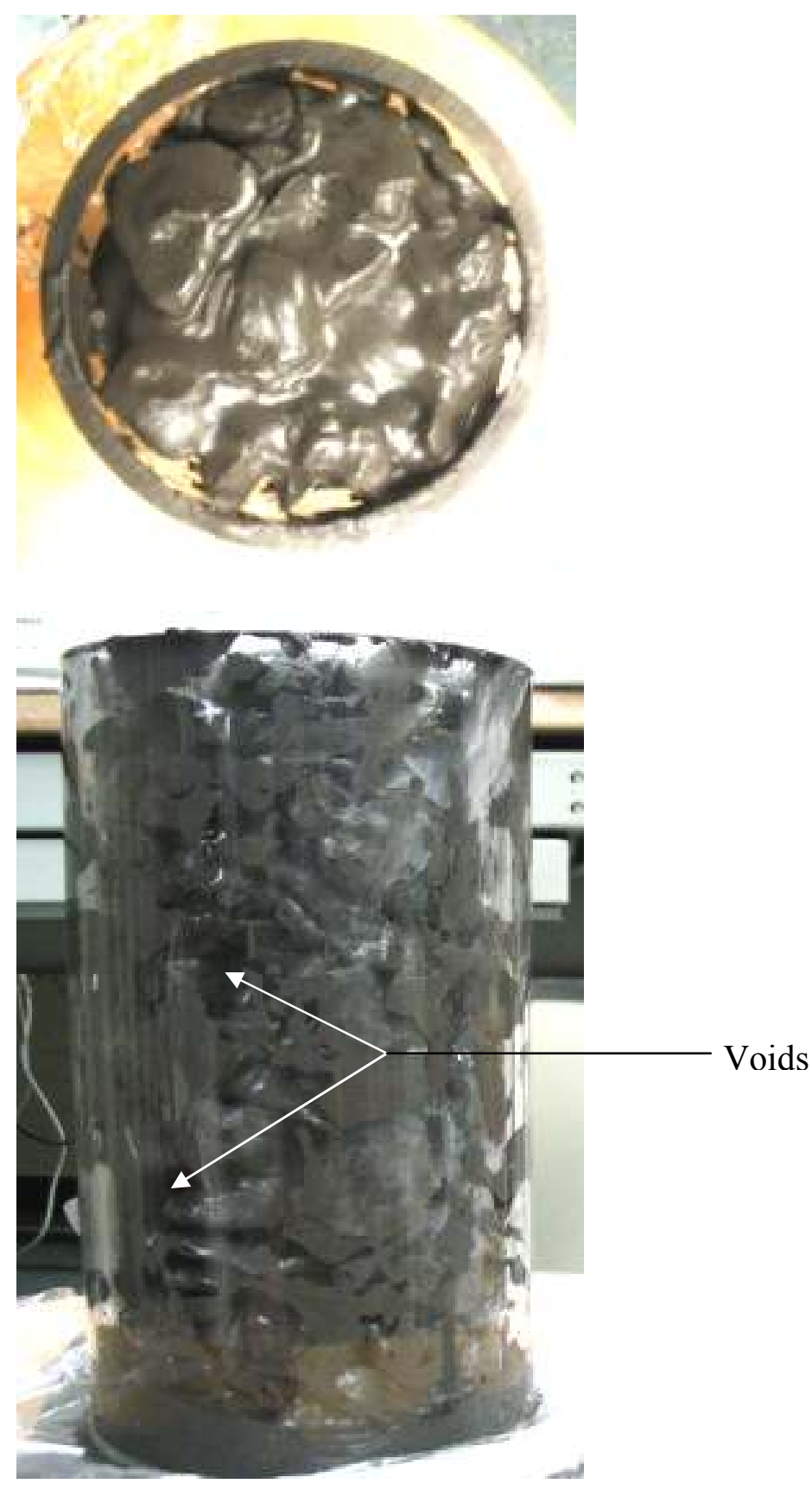

Figure 5.2. Pyrite/Grout column top and front view 
cured for 14 days since the grout did not set within 7 days. The influent was College Park water, which had a $\mathrm{pH}$ of 7.79 , comparable with the properties of water in the natural environment (Tuncan et al. 2000, Lee et al. 2004). The hydraulic gradient was selected as 2.5 based on the effective stress conditions present in mine pavements. A photograph of the constant head column set-up is shown Figure 5.3. Each test was terminated after ensuring the stabilization of flow, following the criteria given in ASTM D 5856. The termination criteria were satisfied when the four consecutive values of the steady-state curve varied within the $25 \%$ of their mean value and when the $\mathrm{Q}_{\text {out }} / \mathrm{Q}_{\text {in }}$ was between 0.75 and 1.25.

Figures 5.4 and 5.5 present the temporal variations in hydraulic conductivity for FBC-based and LKD-based mixtures, respectively. The hydraulic conductivities range from $5.3 \times 10^{-5} \mathrm{~cm} / \mathrm{s}$ to $2.3 \times 10^{-2} \mathrm{~cm} / \mathrm{s}$ as seen in Table 5.1. The measured hydraulic conductivities are relatively higher than expected even though grout volume was nearly equal to the volume of voids present in the pyrite. This was due to coating of the pyrite rock with the grout rather than filling of all the void spaces. Performance of grout-encapsulated pyrite rather than pyrite with its void spaces entirely filled with grout is of interest, since it is often difficult in the field to accurately estimate the volume of voids. Similar observations were made in the Winding Ridge Field Remediation Project (see Section 3), where the injection process required about 4,300 $\mathrm{m}^{3}$ of grout although initially the volume of voids in the mine was estimated to be $3,000 \mathrm{~m}^{3}$. 


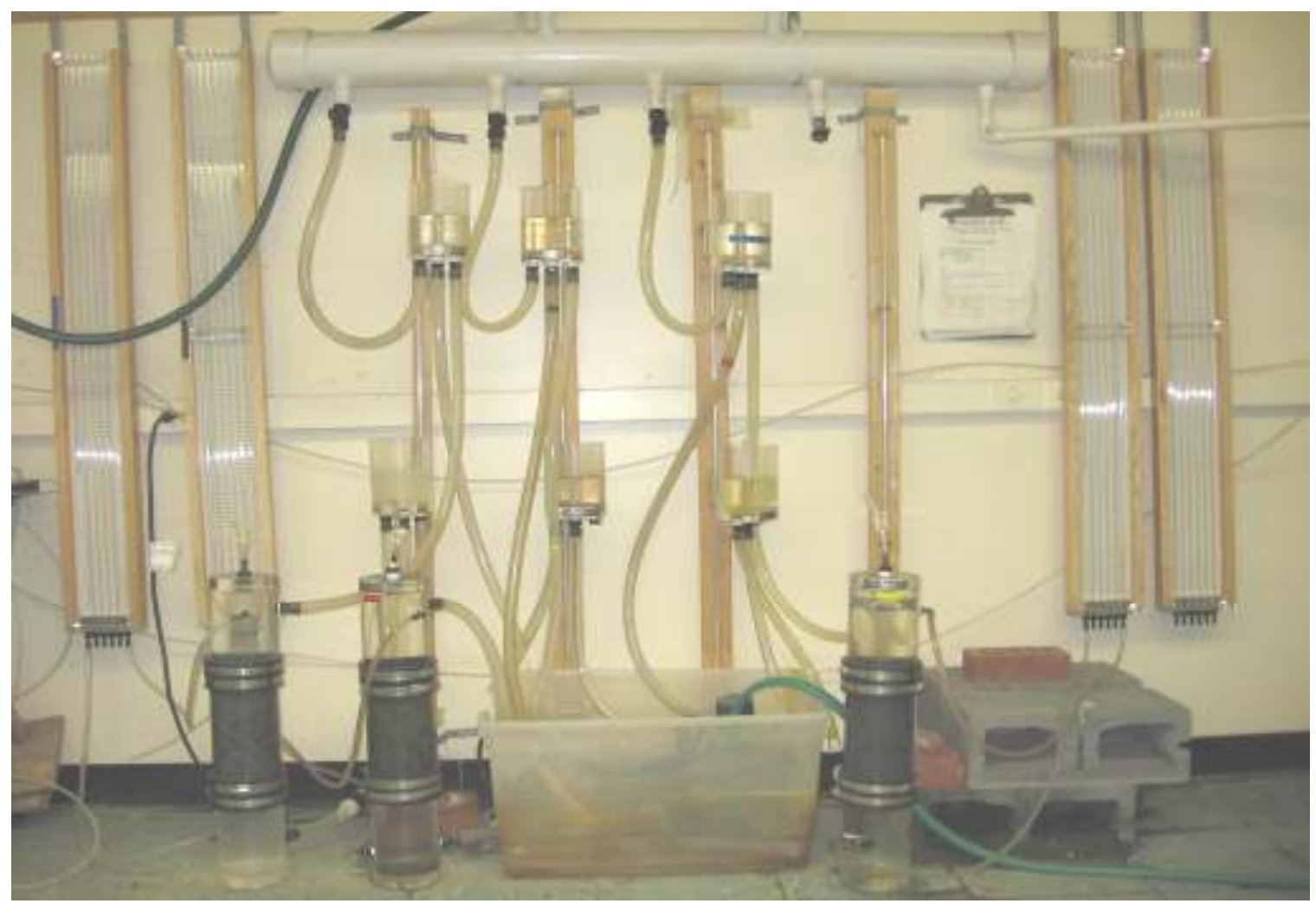

Figure 5.3. Constant-head hydraulic conductivity set-up for pyrite-grout columns 
Column ID: F2

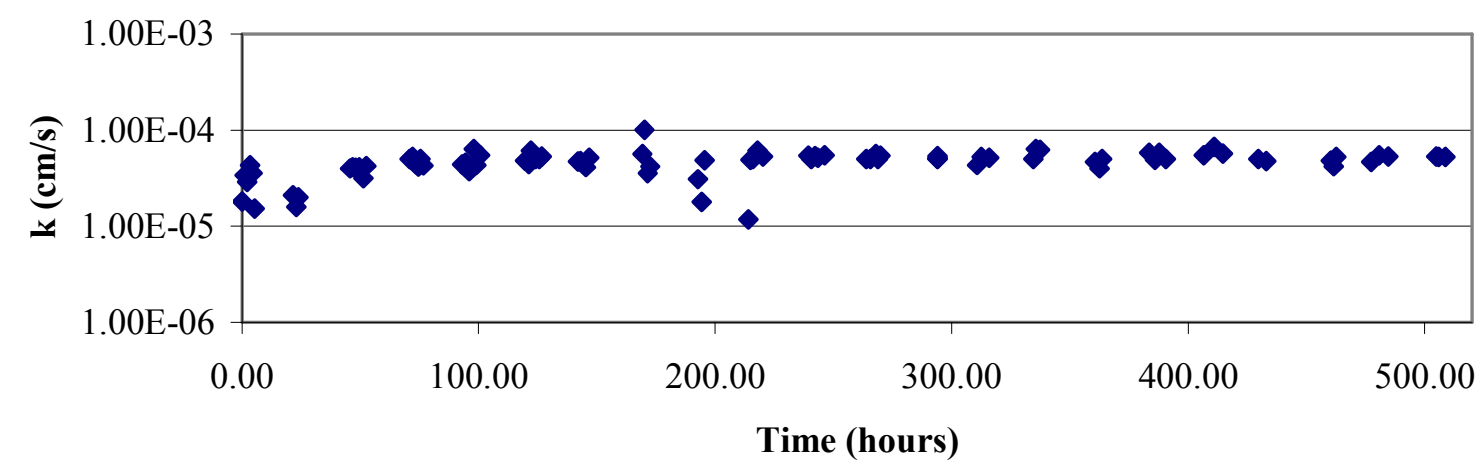

Column ID: F3

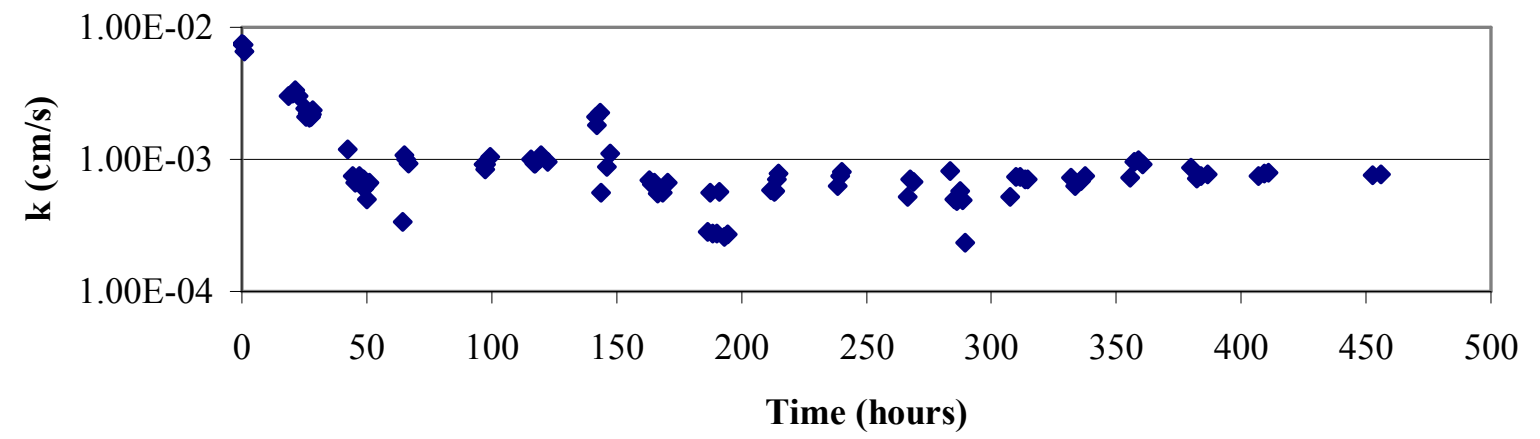

Column ID: F4

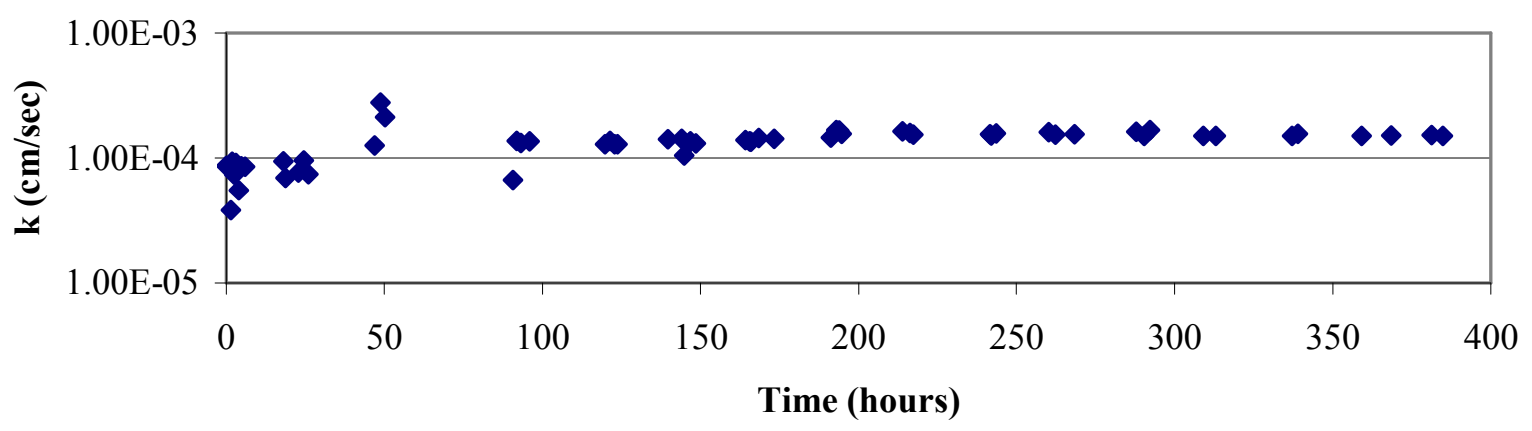

Figure 5.4. Hydraulic conductivity (k) versus time for FBC-based mixtures 

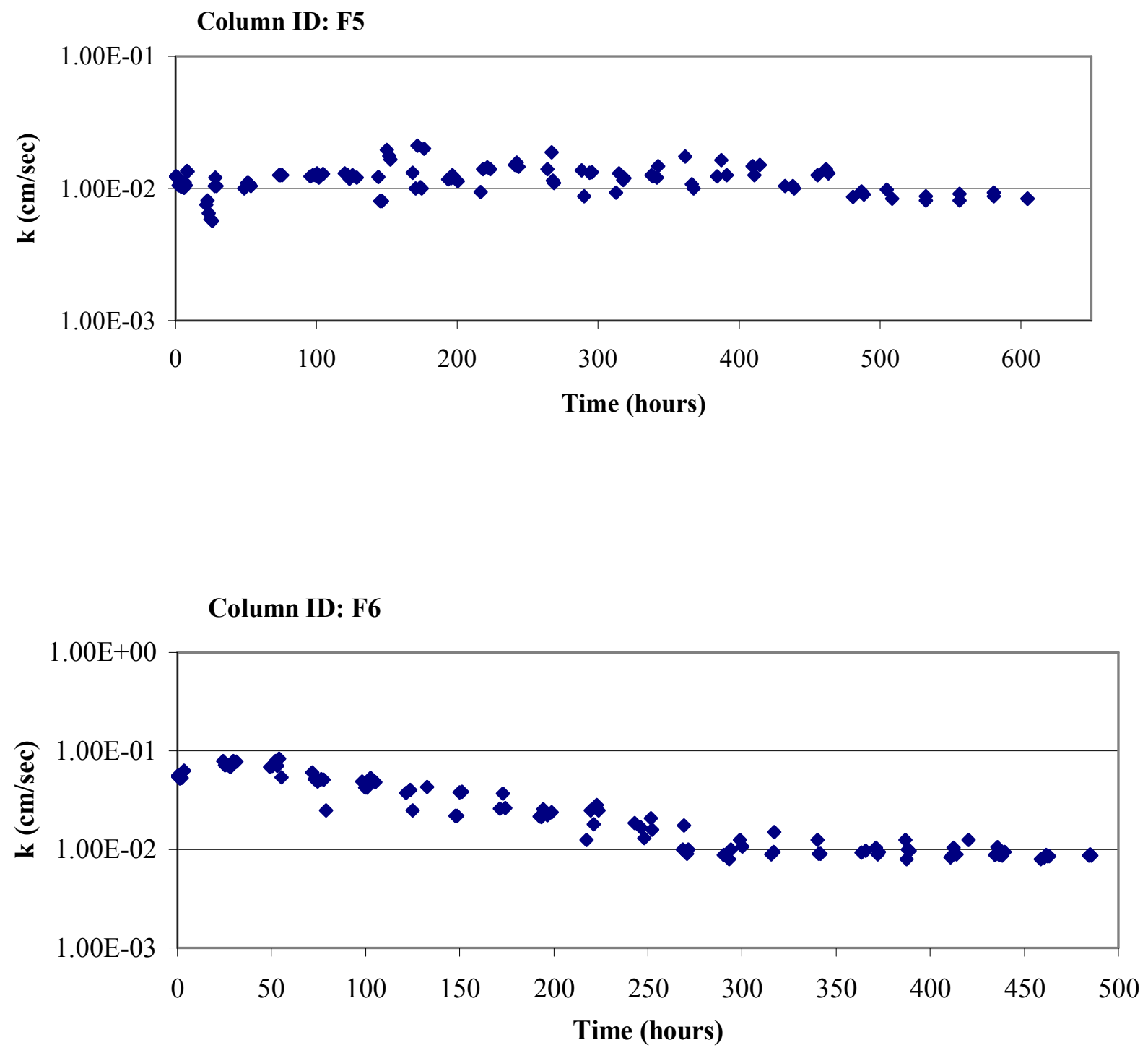

Figure 5.4 (Cont'd). Hydraulic conductivity (k) versus time for FBC-based mixtures 
Column ID: L3

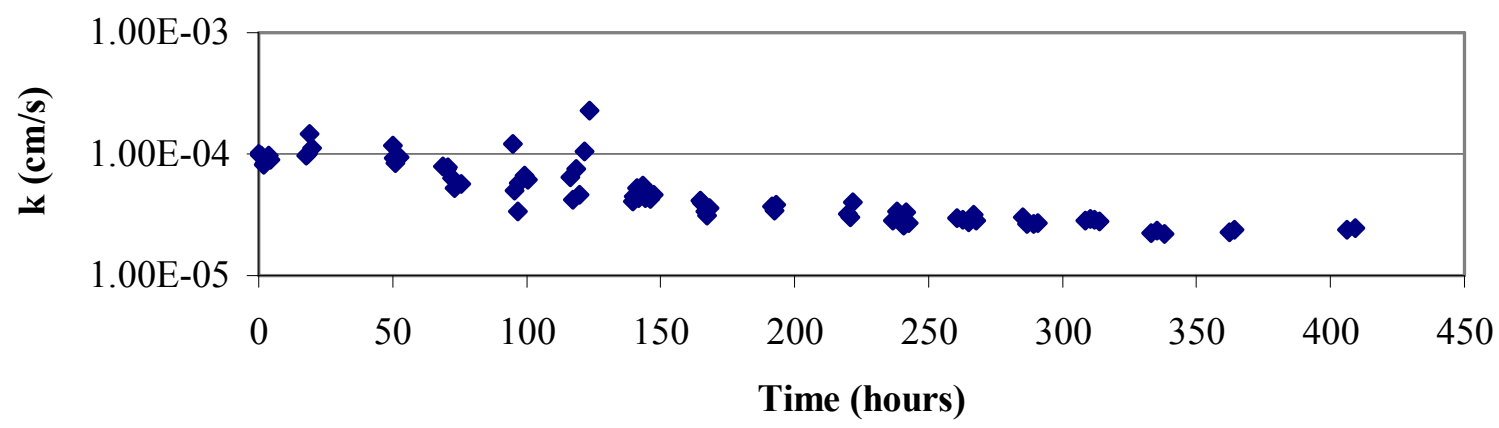

Column ID: L4

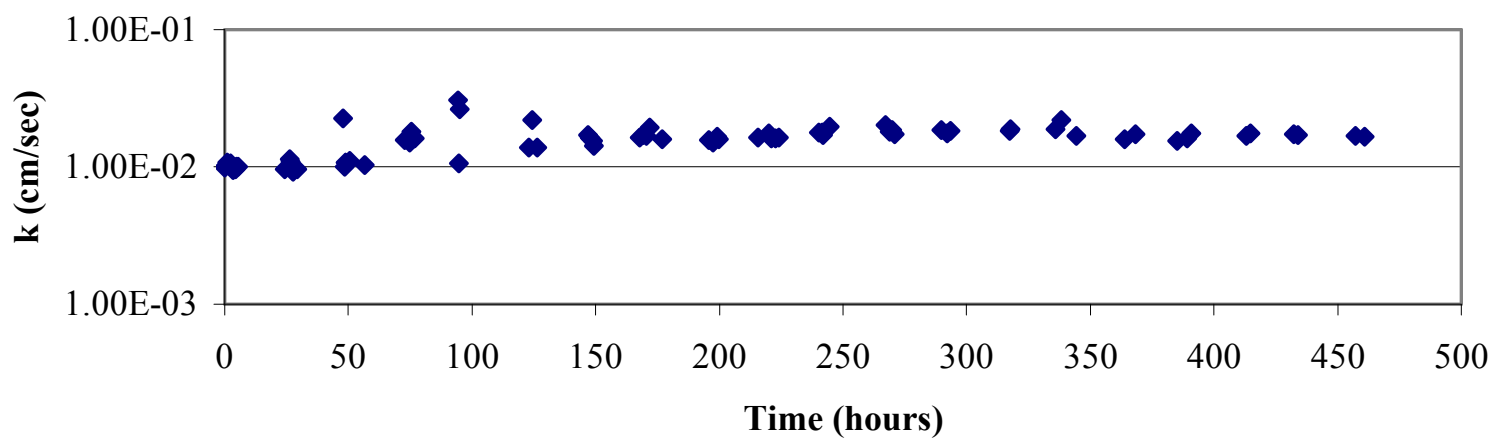

Column ID: L5

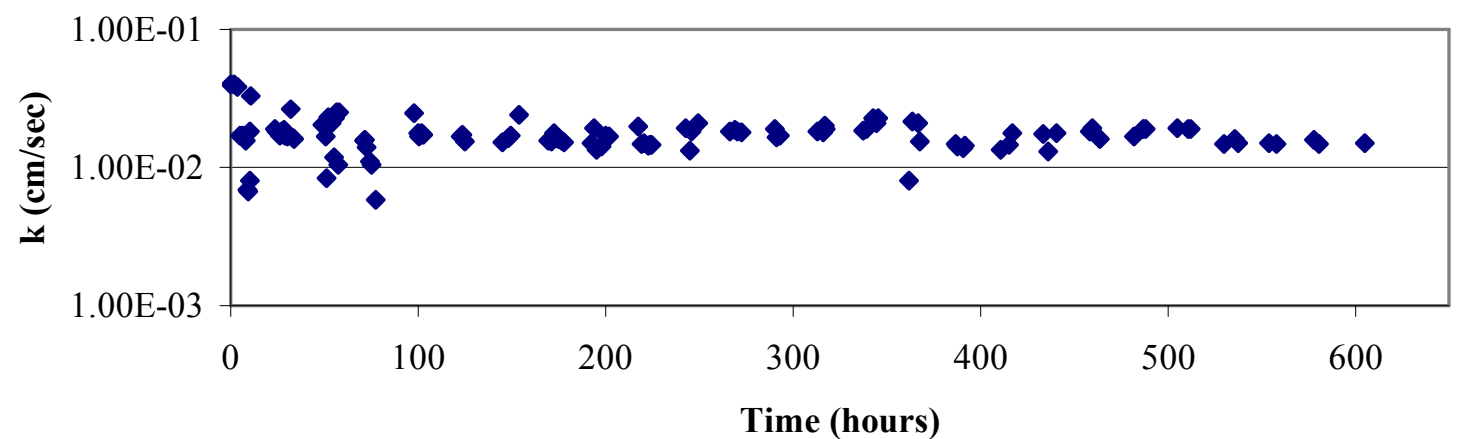

Figure 5.5. Hydraulic conductivity versus time for LKD-based mixtures 
Table 5.1. Hydraulic conductivity of pyrite-grout columns

\begin{tabular}{|c|c||}
\hline \multicolumn{2}{|c||}{ FBC-based } \\
\hline Column ID & $\begin{array}{c}\text { Hydraulic Conductivity } \\
\text { (cm/s) }\end{array}$ \\
\hline \hline F2 & $5.34 \times 10^{-5}$ \\
\hline F3 & $7.77 \times 10^{-4}$ \\
\hline F4 & $1.51 \times 10^{-4}$ \\
\hline F5 & $8.67 \times 10^{-3}$ \\
\hline F6 & $8.70 \times 10^{-3}$ \\
\hline \hline Column ID & $\begin{array}{c}\text { Hydraulic Conductivity } \\
(\mathbf{c m} / \mathbf{s})\end{array}$ \\
\hline \hline L3 & $2.36 \times 10^{-5}$ \\
\hline L4 & $1.69 \times 10^{-2}$ \\
\hline L5 & $1.51 \times 10^{-2}$ \\
\hline
\end{tabular}


The hydraulic conductivity is plotted against free lime content / FA-BA ratio, and FA-BA content in Figure 5.6. It is evident from Figure 5.6 that the hydraulic conductivities decrease with increasing lime / FA-BA ratio. This may be attributed to relatively higher strength of grouts with higher lime content resulting in relatively less permeable grout in the column. Low hydraulic conductivities may also be due to an increase in fines content associated with lime present in the pyrite-grout column.

Hydraulic conductivities increase with increasing FA-BA contents as observed in Figure 5.6(b), due to an increase in coarser base material content. Similar trends in permeability were observed by Gabr et al. (1996) when fly ash was mixed with FBC, and quicklime. In their study, hydraulic conductivities were reported to decrease by 0.5 to 3 orders of magnitude with an increase in FBC content from $5 \%$ to $15 \%$.

\subsection{LEACHING PERFORMANCE}

The effluent (leachate) from the column was collected on a regular basis, and the samples were stored for chemical analysis. Standard methods for examination of water, listed jointly by American Public Health Association, American Water Works Association, and Water Environment Federation, were used to store and analyze the leachates for various AMD-related parameters such as $\mathrm{pH}$, and concentrations of iron, aluminum, calcium and sulfate. The three metals $(\mathrm{Fe}, \mathrm{Al}, \mathrm{Ca})$ were analyzed by using an atomic absorption spectrometer, whereas sulfate was analyzed by using an ion chromatograph. 

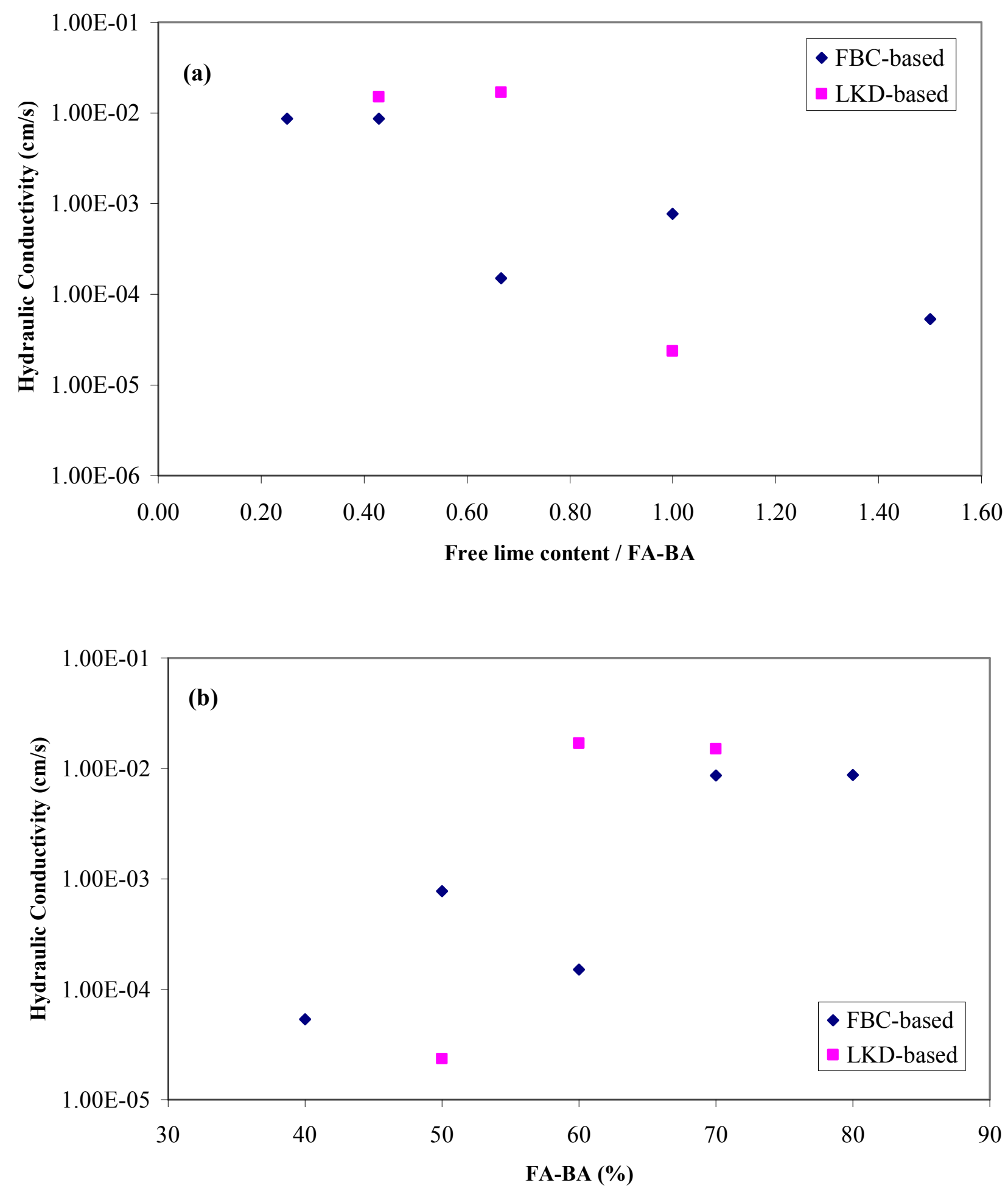

Figure 5.6. Hydraulic Conductivity versus (a) Free lime content / FA-BA

(b) FA-BA \% 
The leachate was collected in 50-mL centrifuge tubes with caps and stored in the refrigerator at a temperature of $4^{\circ} \mathrm{C}$. Samples used for determination of metal concentrations were digested using concentrated nitric acid $\left(\mathrm{HNO}_{3}\right)$ to a $\mathrm{pH}<2$. Metal digestion with nitric acid is usually performed to reduce interference by organic matter and to convert the metals to a free metal form that can be determined by atomic absorption spectrometry. After digestion, the samples were filtered using a Supor ${ }^{\circledR} 0.2 \mu \mathrm{m}$ membrane filter. Samples used for determination of sulfate concentrations did not require digestion and were only filtered before analysis. For quality assurance / quality control purposes, a blank was analyzed for five samples to verify baseline stability for metal analyses by atomic absorption spectrometry and for sulfate measurements using ion chromatograph. A standard solution was analyzed for every ten samples to confirm the testing is accurate.

\subsection{1 pH}

The $\mathrm{pH}$ of water samples was measured using an electrode $\mathrm{pH}$ meter (Mettler Toledo MA235 pH/Ion Analyzer). The $\mathrm{pH}$ was measured for all water samples collected for each of the eight columns tested. Two replicate $\mathrm{pH}$ readings were taken for each sample and the average value was reported as the $\mathrm{pH}$ of the sample.

Figure 5.7 presents temporal variations in $\mathrm{pH}$. The leachate from all eight columns is alkaline. The $\mathrm{pH}$ of leachate ranges from 7.6 to 8.5 for the FBC-based columns and from 8.8 and 12.3 for LKD-based columns. The higher lime content of LKD as compared to $\mathrm{FBC}$ results in higher $\mathrm{pH}$ values indicating dissolution of grout. The $\mathrm{pH}$ values are in general above the range of $\mathrm{pH}$ recommended in the U. S. EPA 

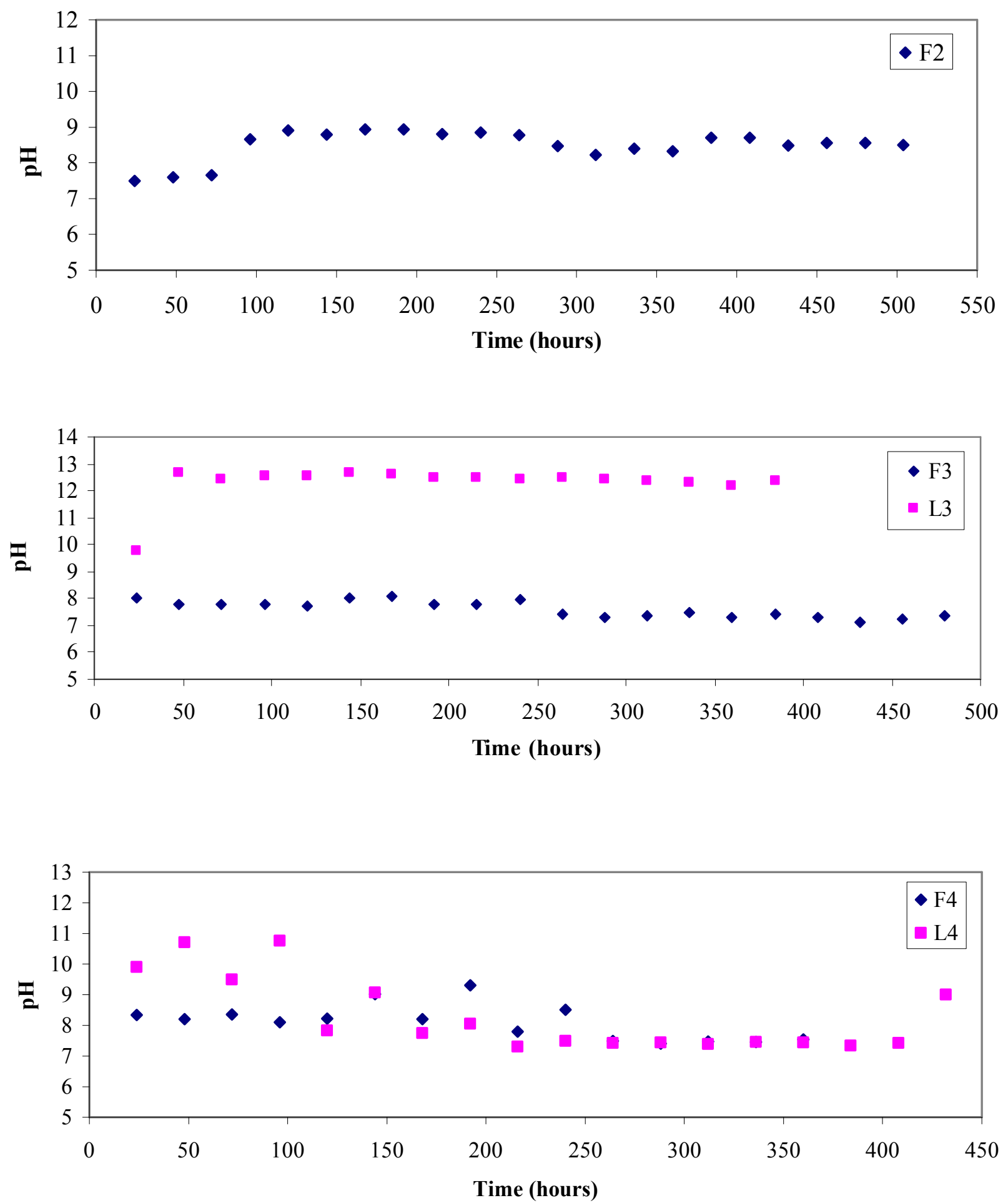

Figure 5.7. $\mathrm{pH}$ versus time for FBC-based and LKD-based pyrite-grout columns 

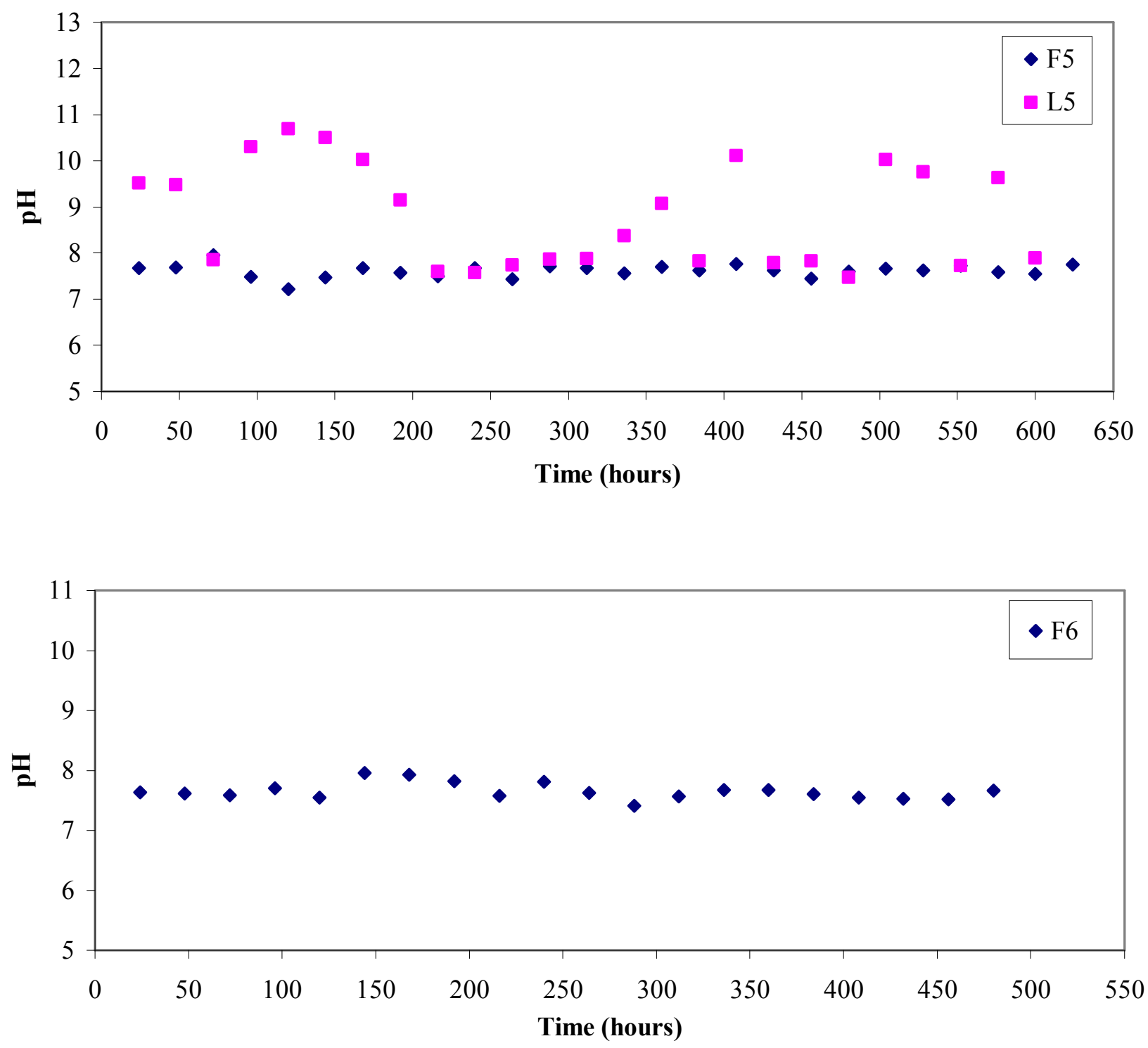

Figure 5.7 (Cont'd). $\mathrm{pH}$ versus time for FBC-based and LKD-based pyrite-grout columns 
Water Quality Criteria (USEPA 2004). However, it should be noted that the limits are set for aesthetic reasons, such as odor, taste, and color. U.S. EPA recommends secondary standards to water systems but does not require systems to comply. The $\mathrm{pH}$ of AMD from Kempton mine complex in western Maryland was measured to be 2.9, comparable with the pH of AMD reported in previous studies (Schueck et al. 2001).

The average of $\mathrm{pH}$ measured at different times was calculated for each mixture and plotted versus free lime content in Figure 5.8. Increase in lime content in the column caused an increase in $\mathrm{pH}$ of leachate due to dissolution of the lime in the grout and possible neutralization of any acidity produced in the column. Alkalinity is produced due to reactions of free lime $(\mathrm{CaO})$ that is present in FBC and LKD with carbon dioxide $\left(\mathrm{CO}_{2}\right)$ and water in the environment. Calcium carbonate and calcium hydroxide are formed as a result, and increase the $\mathrm{pH}$ of the environment.

$$
\begin{gathered}
\mathrm{CaO}+\mathrm{CO}_{2} \rightarrow \mathrm{CaCO}_{3} \\
\mathrm{CaO}+\mathrm{H}_{2} \mathrm{O} \rightarrow \mathrm{Ca}(\mathrm{OH})_{2}
\end{gathered}
$$

These two compounds not only contribute to increase in $\mathrm{pH}$ directly, but also neutralize any acidity formed due to pyrite oxidation reactions and maintain the $\mathrm{pH}$. Neutralization reactions between the alkaline compounds and sulfuric acid are as follows:

$$
\mathrm{Ca}(\mathrm{OH})_{2}+\mathrm{H}_{2} \mathrm{SO}_{4} \rightarrow \mathrm{Ca}^{2+}+\mathrm{SO}_{4}{ }^{2-}+2 \mathrm{H}_{2} \mathrm{O}
$$




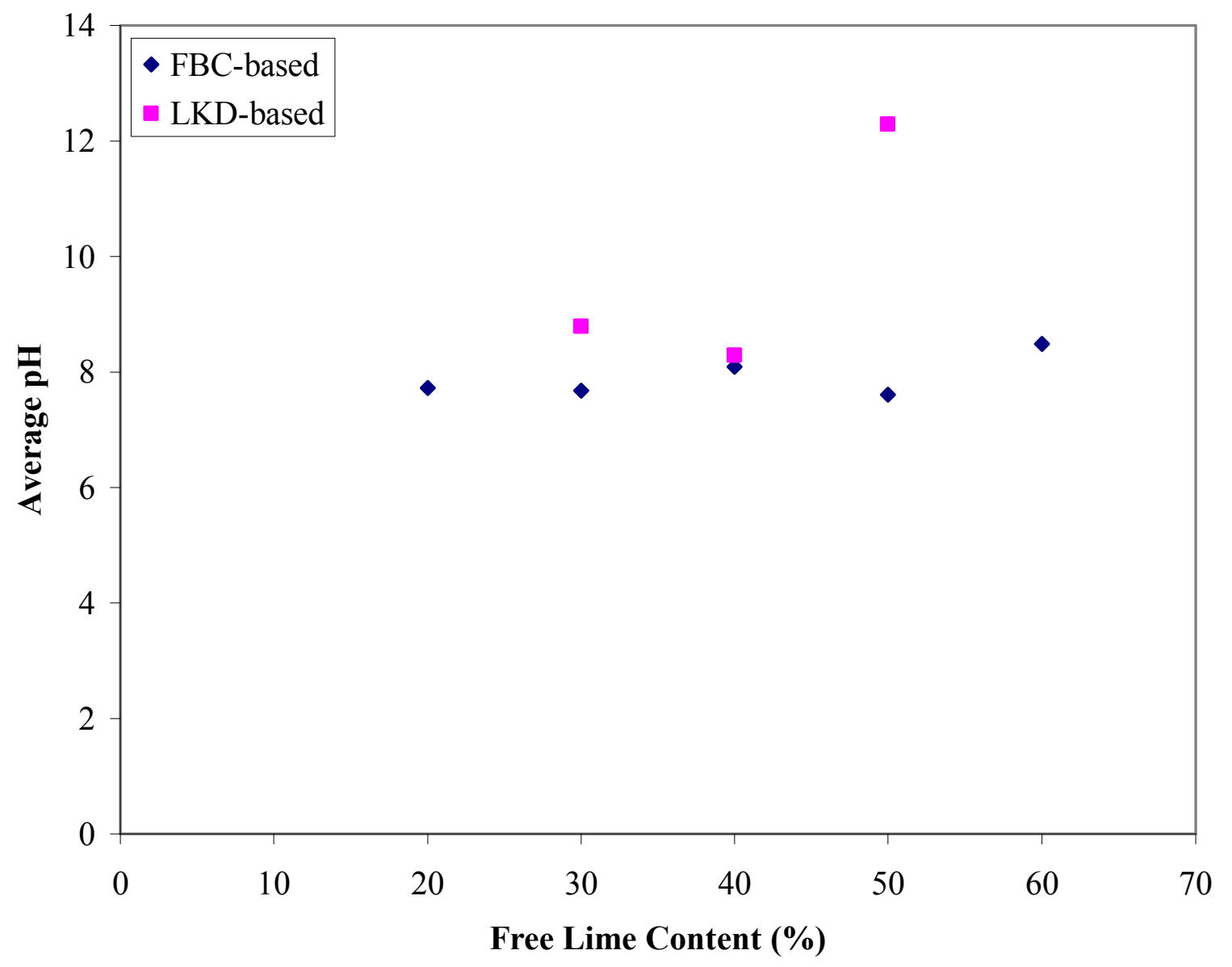

Figure 5.8. Average $\mathrm{pH}$ versus Free lime Content 


$$
\mathrm{CaCO}_{3}+\mathrm{H}_{2} \mathrm{SO}_{4} \rightarrow \mathrm{Ca}^{2+}+\mathrm{SO}_{4}^{2-}+\mathrm{CO}_{2}(\mathrm{~g})+\mathrm{H}_{2} \mathrm{O}
$$

The high $\mathrm{pH}$ due to the dissolution and neutralization reactions causes the dissolved metals in AMD to precipitate as hydroxides, thus remediating AMD. From the above neutralization reactions, it is possible to calculate the amount of carbonate / hydroxide alkalinity that needs to be applied in the field for given acidity. However, it is difficult to quantify the amount of alkaline materials that need to be injected into the mine since fly ash-lime hydration reactions consume some part of the alkalinity.

\subsubsection{Iron}

As observed from pyrite oxidation chemistry (Section 2), AMD consists of high levels of iron mainly in the soluble ferrous $\left(\mathrm{Fe}^{2+}\right)$ ion form. Iron is a major AMD-related parameter. The U.S. EPA Water Quality Criteria limit for iron in natural aquatic waters is $1 \mathrm{mg} / \mathrm{L}$ (U.S. EPA 2004). Concentration of iron in leachate was measured by direct air-acetylene flame method of atomic absorption spectrometry using a Perkin Elmer AA 5100 spectrometer. Four standard concentrations were prepared and used for calibration of the instrument to obtain a minimum correlation coefficient of 0.99 (i.e., $\mathrm{R}^{2}=0.99$ ). The instrument reports the concentration of iron in a sample as the average of two measurements conducted with a standard deviation of less than 1 .

Figure 5.9 presents temporal variations of $\mathrm{Fe}^{2+}$ concentrations in the leachate collected from the eight columns. The concentrations seem to follow a decreasing trend with time for FBC-based columns. The grout formed a barrier between pyrite and water preventing oxidation of pyrite, thus decreasing the formation of ferrous - 

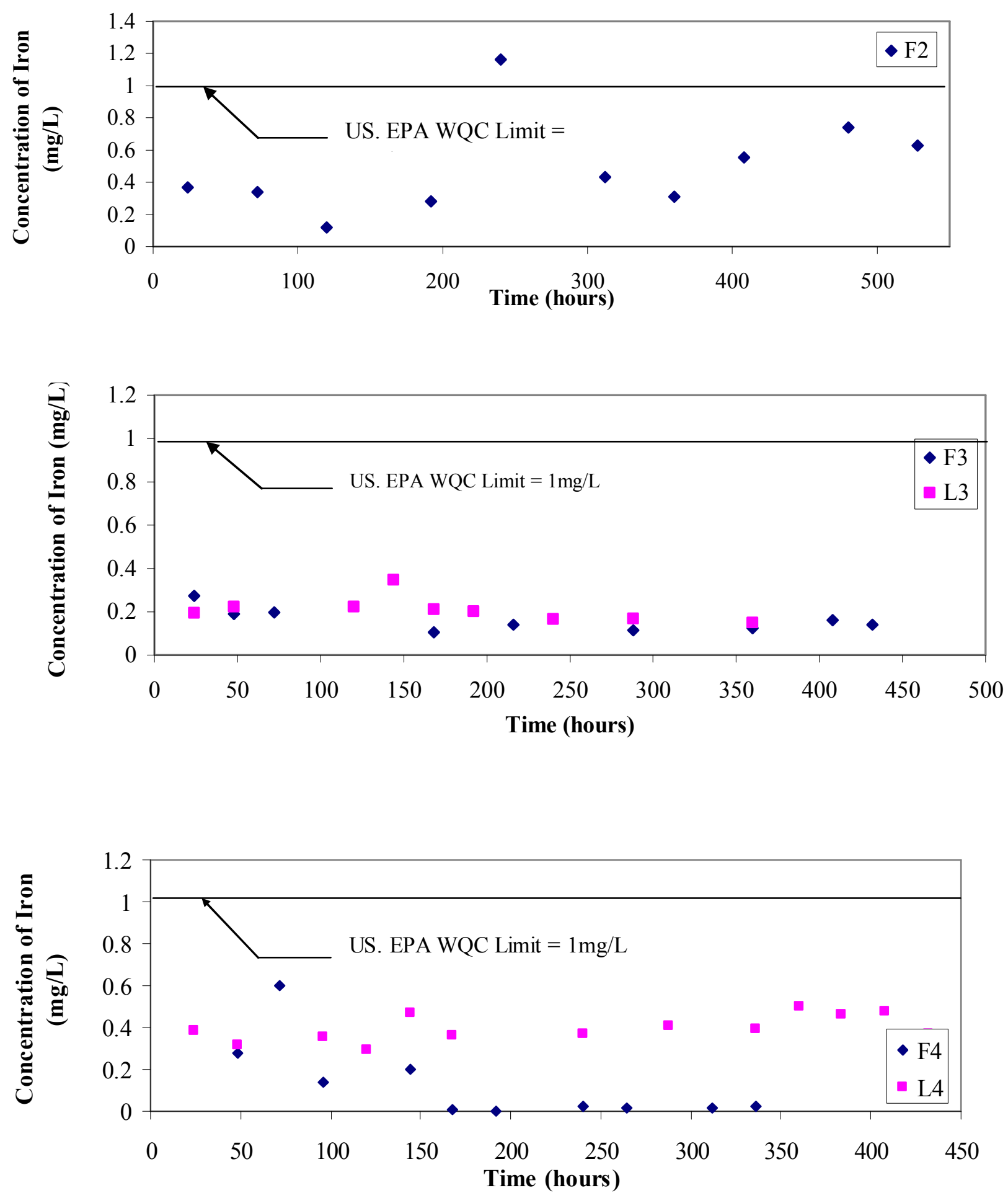

Figure 5.9. Concentration of Iron versus time for different pyrite/grout mixtures 

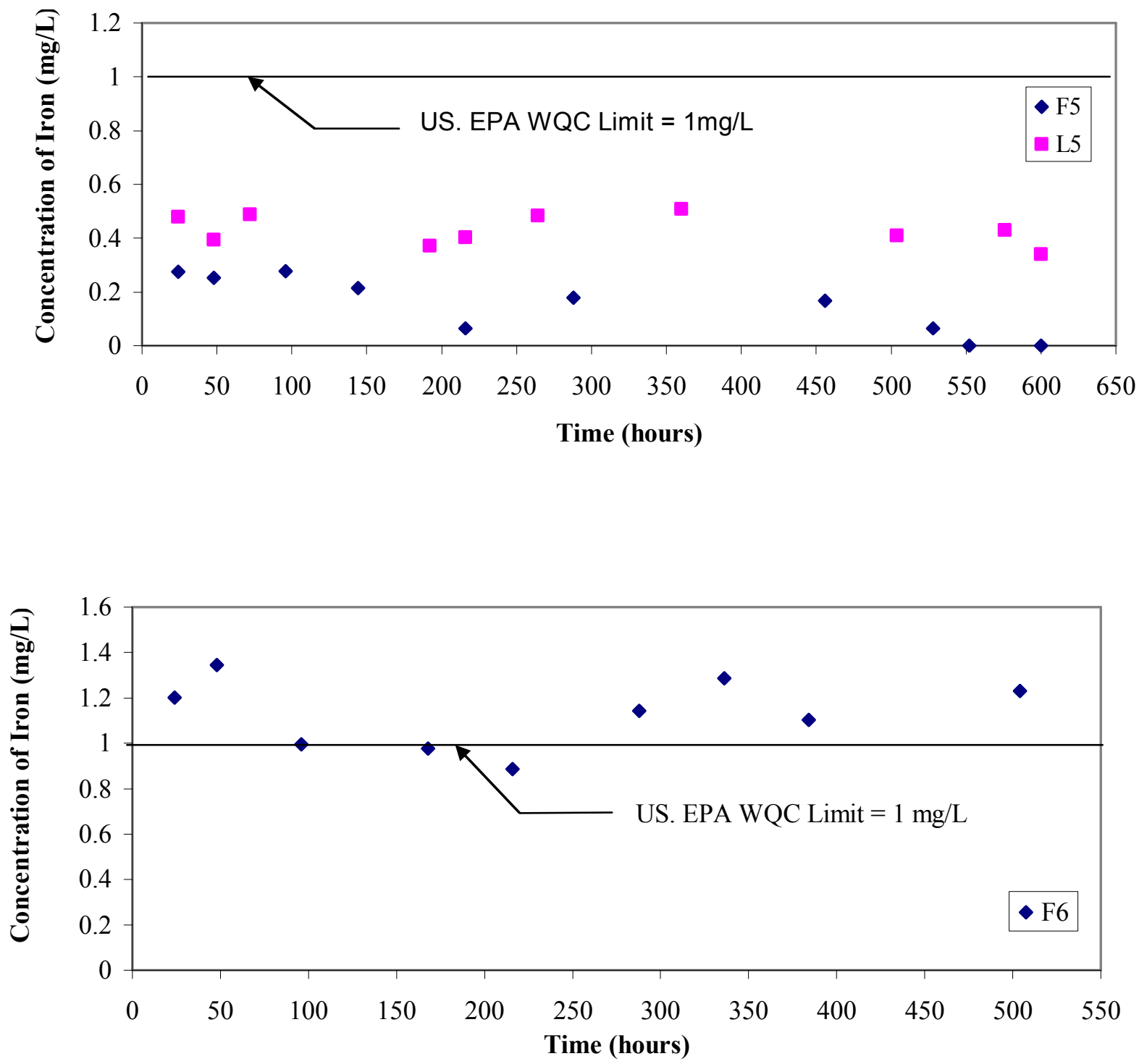

Figure 5.9 (Cont'd). Concentration of Iron versus time for different pyrite/grout mixtures 
rich acidic water. The high $\mathrm{pH}$ due to dissolution of grout caused any ferrous iron to precipitate as an insoluble ferric hydroxide $\left(\mathrm{Fe}(\mathrm{OH})_{3}\right)$.

In general, iron concentrations stay in a constant but relatively higher range for LKD-based columns as compared to FBC-based columns. This may be due to the fact that $\mathrm{LKD}$, which has higher free lime content $(\mathrm{CaO})$ than $\mathrm{FBC}$, hardens faster and as a result dissolves at lower rates than FBC. As evidenced from the high $\mathrm{pH}$ values in Figure 5.8, there is some dissolution of the LKD-grout, but this dissolution may not be at a rate that is required for significant decrease in iron concentrations.

The effect of hardening of high-lime content grouts on iron concentrations can also be observed from Figure 5.10. The average concentration of iron in the leachate follows an inverted bell-shaped trend with increasing free lime content / FA-BA ratio for FBC-based columns. High iron concentration observed at low FBC/ FA-BA ratio $(0.25)$ may be due to the lower amount of free lime in the grout mixture that provides less alkalinity to precipitate iron. For a $\mathrm{FBC} / \mathrm{FA}-\mathrm{BA}$ ratio of above 1.0, iron concentrations increase, because at high $\mathrm{FBC}$ contents $(>50 \%)$ the dissolution rate is low since the grout hardens rapidly and makes the alkalinity unavailable for precipitating iron. This observation was also supported by the behavior exhibited by LKD. The high hardening capacity of LKD increased the iron concentrations as shown in Figure 5.10(b).

All columns indicated much lower iron concentrations than that of AMD (22.32 $\mathrm{mg} / \mathrm{L})$ collected from the Kempton Mine Complex located in Western Maryland. Furthermore, most of these concentrations were lower than the U.S. EPA Water Quality Criteria (WQC) limit of $1 \mathrm{mg} / \mathrm{L}$ (USEPA 2004). These findings indica- 

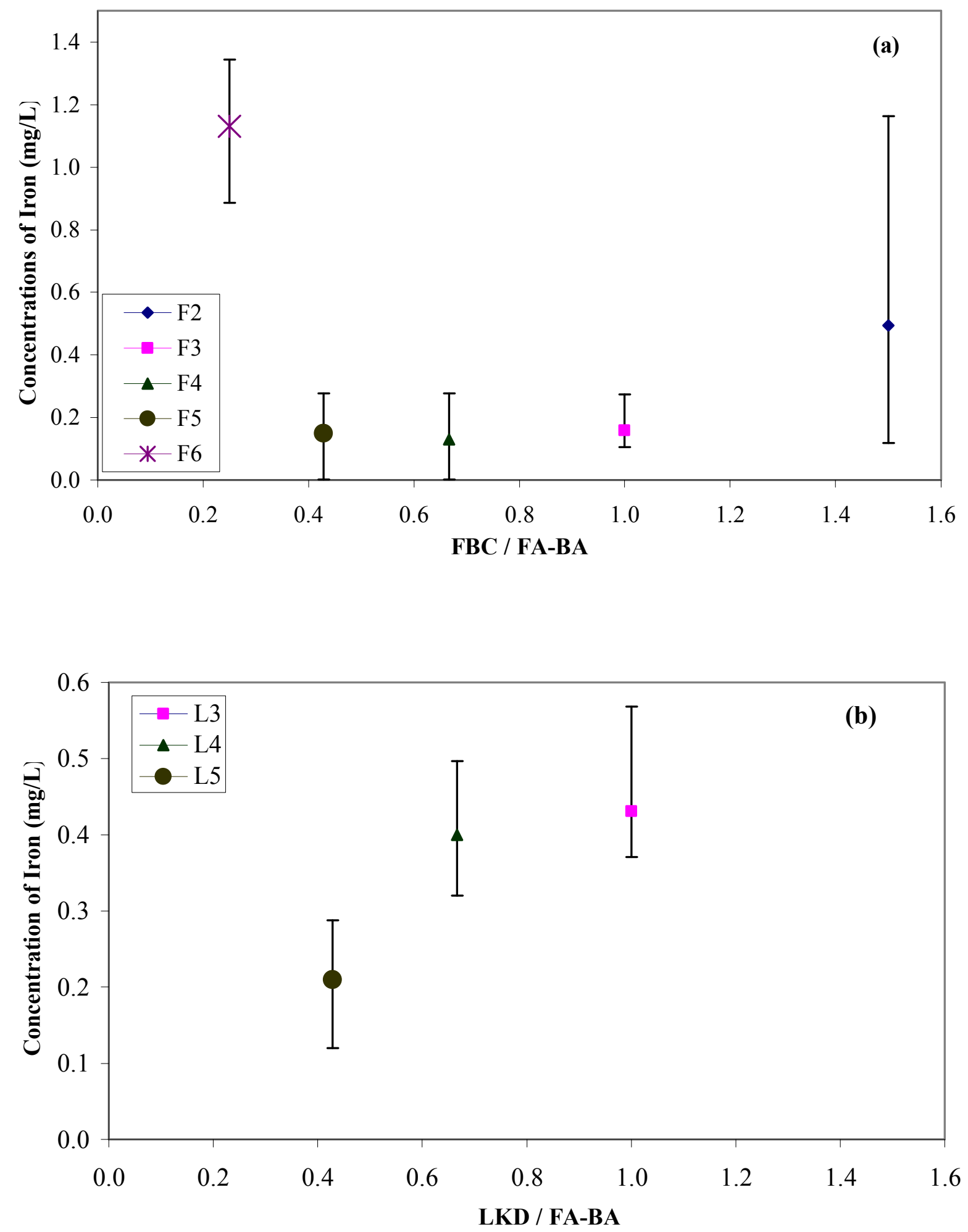

Figure 5.10. Concentration of Iron versus (a) FBC / FA-BA, and (b) LKD / FA-BA 
-te that the lime activators (FBC and LKD) are likely to encapsulate pyrite and thereby reduce the acidity and iron content in groundwater or surface waters.

It can be observed from Figure 5.9 that the iron concentrations drop to zero particularly for relatively low FBC-content specimens (e.g., F4 and F5) mainly due to the high dissolution rate of these mixtures. On the other hand this phenomenon is cannot be observed for high FBC-content grouts (F2-60\%, F3-50\%) and LKD-based grouts as these mixtures have low dissolution rates as discussed above.

\subsubsection{Aluminum}

Aluminum is another important inorganic compound produced as a result of AMD. At low $\mathrm{pH}$ values, leaching of aluminum from the soil and grout may take place (Schueck et al. 2001). Aluminum in the leachate samples was measured using an electrothermal atomic absorption spectrometry by Green Mountain Laboratories based in Vermont. The U.S. EPA Water Quality Criteria (U.S. EPA 2004) limit for aluminum in natural aquatic waters is $0.75 \mathrm{mg} / \mathrm{L}$.

Time-dependent changes in aluminum concentrations of leachate collected from each column are presented in Figure 5.11. The concentrations stay within a narrow range for most of the columns. Some columns with relatively higher lime activator contents (F2, F3, and F4) exhibit an initial increase in their aluminum concentrations, most probably due to presence of considerable amounts of aluminum in the FBC (15.05\%).

All columns except F2 and F4 have final aluminum concentrations lower than the U.S.EPA limit of $0.75 \mathrm{mg} / \mathrm{L}$. However, the values seem to decrease after a period of time indicating that the concentrations are like to further decrease in the long-term. 

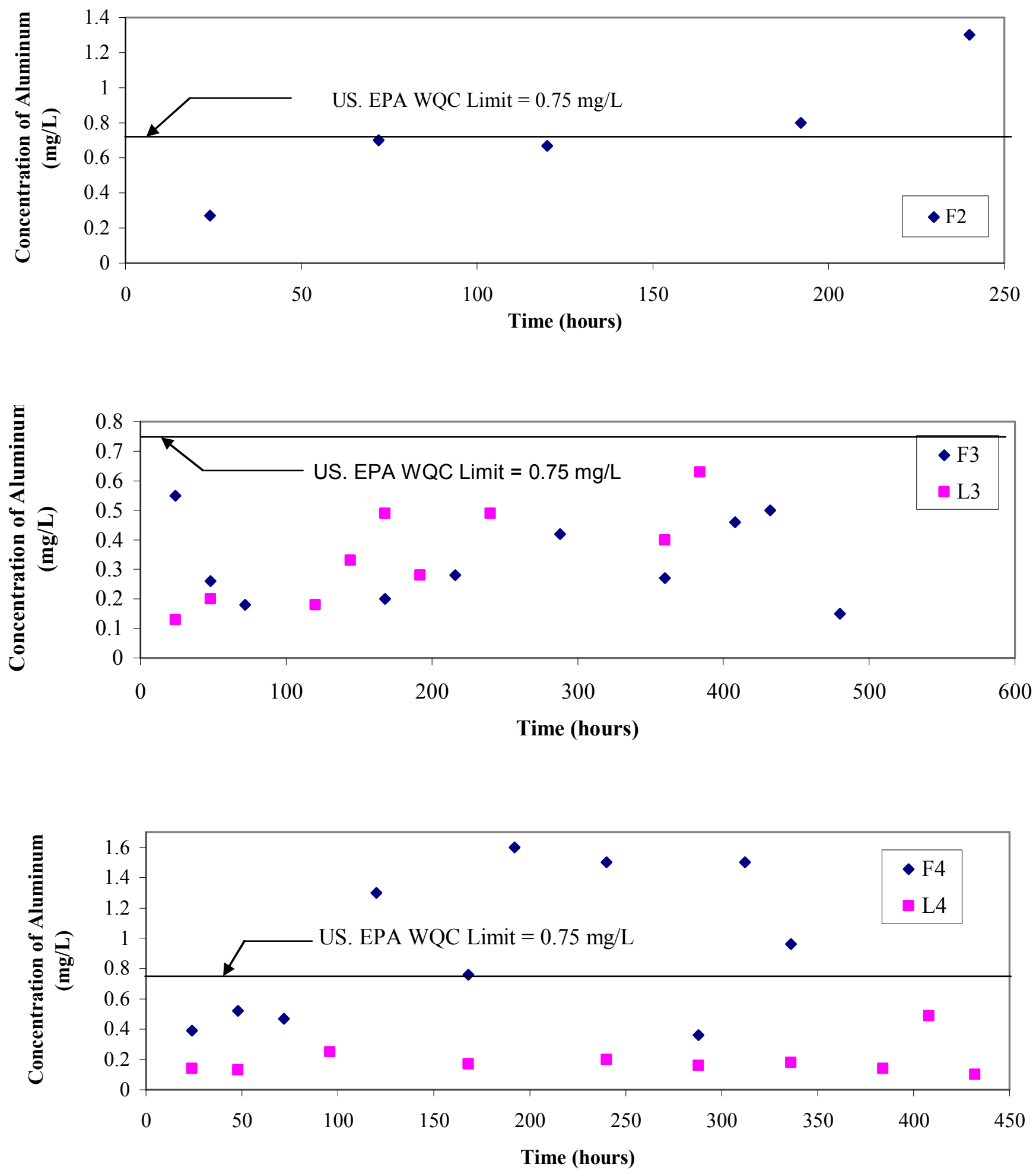

Figure 5.11. Concentration of Aluminum versus time for different pyrite/grout mixtures 

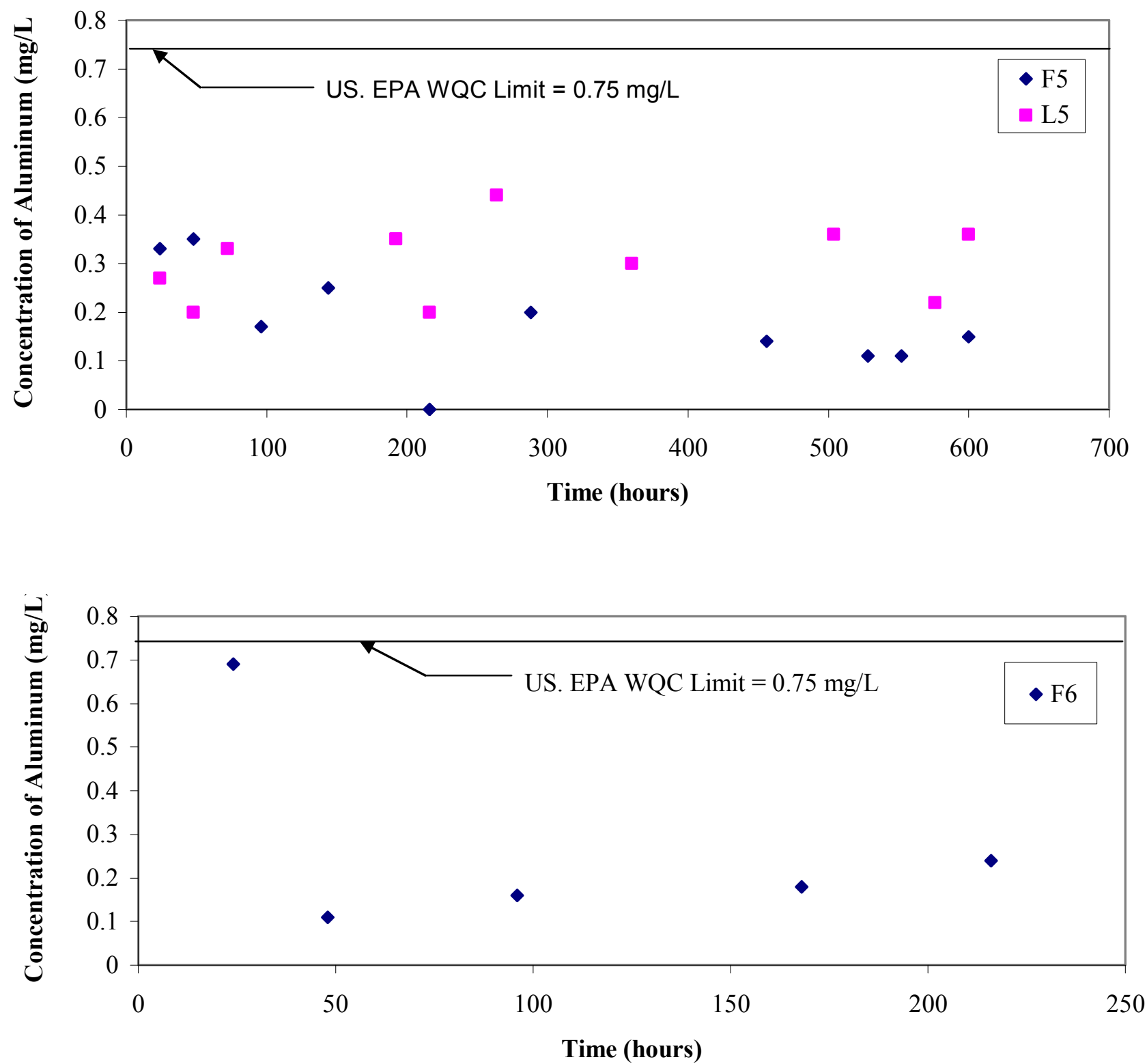

Figure 5.11 (Cont'd). Concentration of Aluminum versus time for different pyrite/grout mixtures 
Aluminum concentrations do no show any clear trends with increasing free lime / FABA ratios (Figure 5.12).

\subsubsection{Sulfate}

Analysis of sulfate concentration in the leachate is essential since high sulfate amounts in the leachate indicate production of alkalinity due to reactions of free lime $(\mathrm{CaO})$ in the grout with carbon dioxide and water (Eqs. 5.1 and 5.2). The sulfate concentrations in the leachate were determined by using a Dionex Ion Chromatograph (DX-100). The samples were loaded in the ion chromatograph using AS40 autosampler. The flow rate of the carbonate-bicarbonate buffer (eluent) was maintained at $1 \mathrm{~mL} / \mathrm{min}$. Calibration curves were constructed with at least three standards prepared in the range of expected concentrations.

Figure 5.13 indicates that the sulfate concentrations stay in a wide range $(0.1$ $\mathrm{mg} / \mathrm{L}$ to $125 \mathrm{mg} / \mathrm{L}$ ). Significant sulfate concentrations observed in the leachate may be due to dissolution of grout and neutralization reactions (Eqs. 5.3 and 5.4). In general, sulfate concentrations either decreased with time or showed an initial increase followed by a gradual decrease.

For the column with the highest $\mathrm{FBC}$ content (F2 - 60\% FBC), the initial concentration of sulfate in the leachate was high $(51.5 \mathrm{mg} / \mathrm{L})$, and the concentration rapidly decreased to a value of $7 \mathrm{mg} / \mathrm{L}$ in 528 hours. A similar decrease was observed for column L3 (from 54.32 to $6.24 \mathrm{mg} / \mathrm{L}$ ) which was the column with the highest LKD content. The initially observed high concentrations in these two columns may be due to dissolution of the high lime content grout. However, due to rapid harden- 

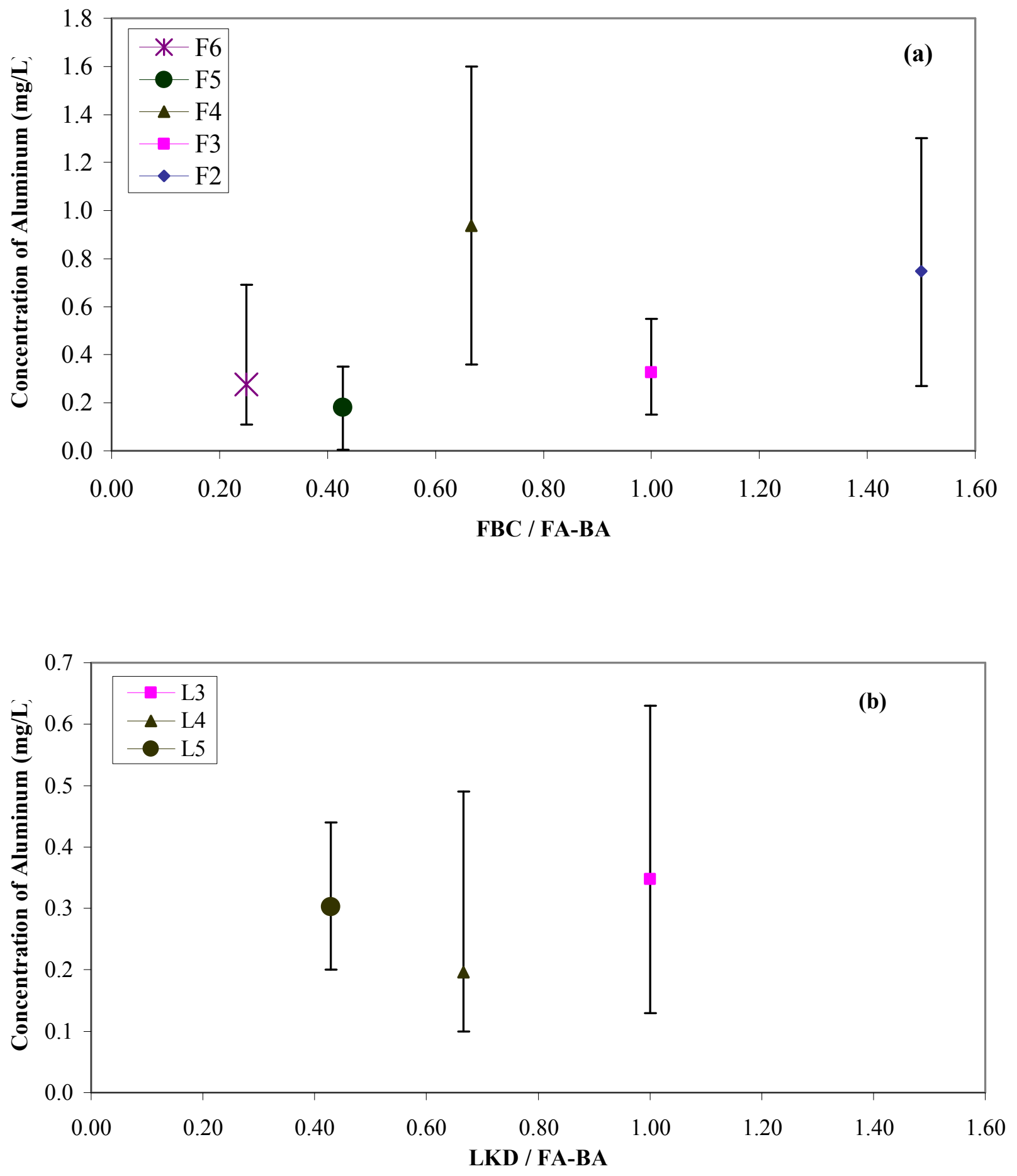

Figure 5.12. Concentration of Aluminum versus (a) FBC / FA-BA, and (b) LKD / FA-BA 

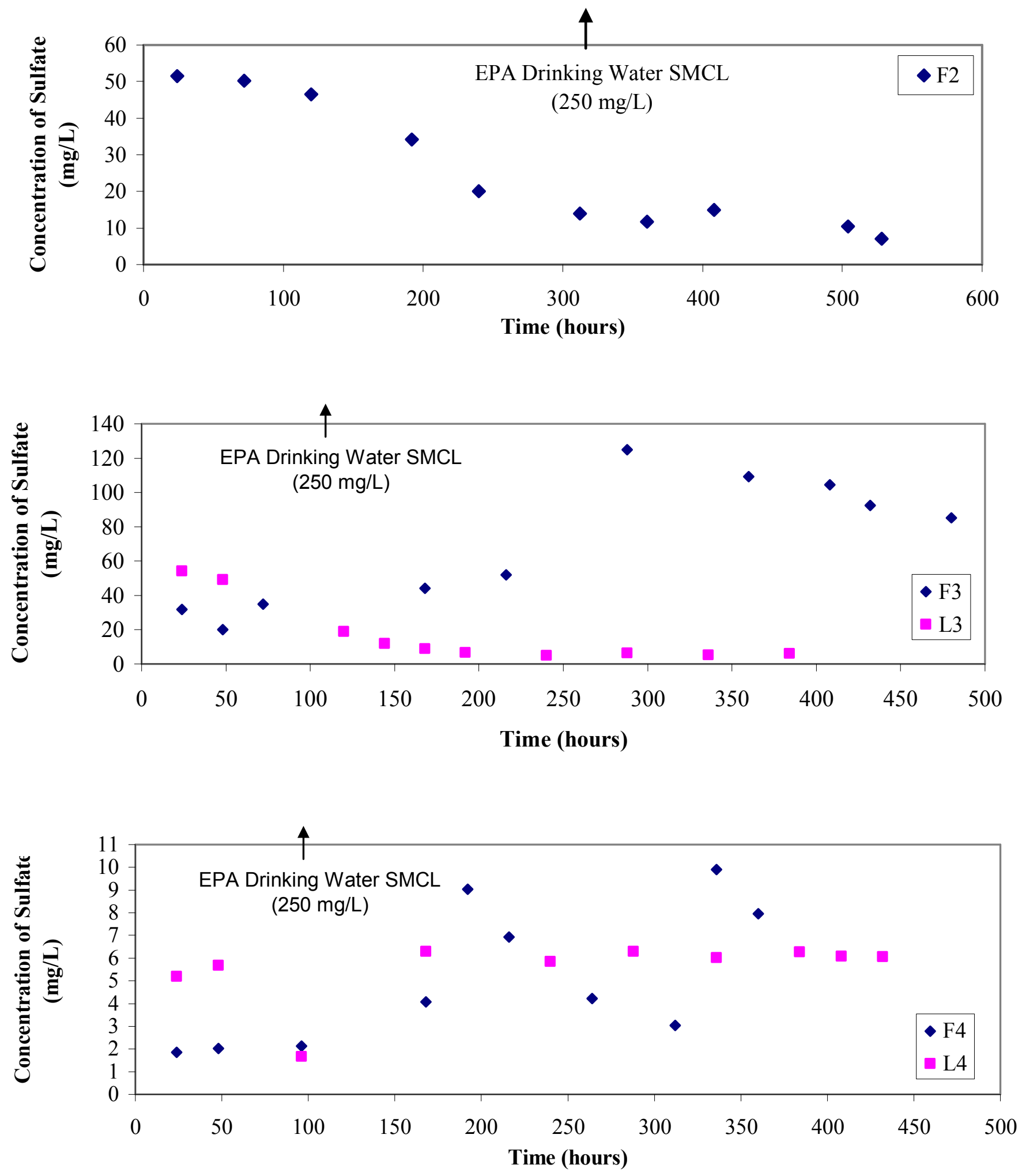

Figure 5.13. Concentration of Sulfate versus time for different pyrite/grout mixtures 

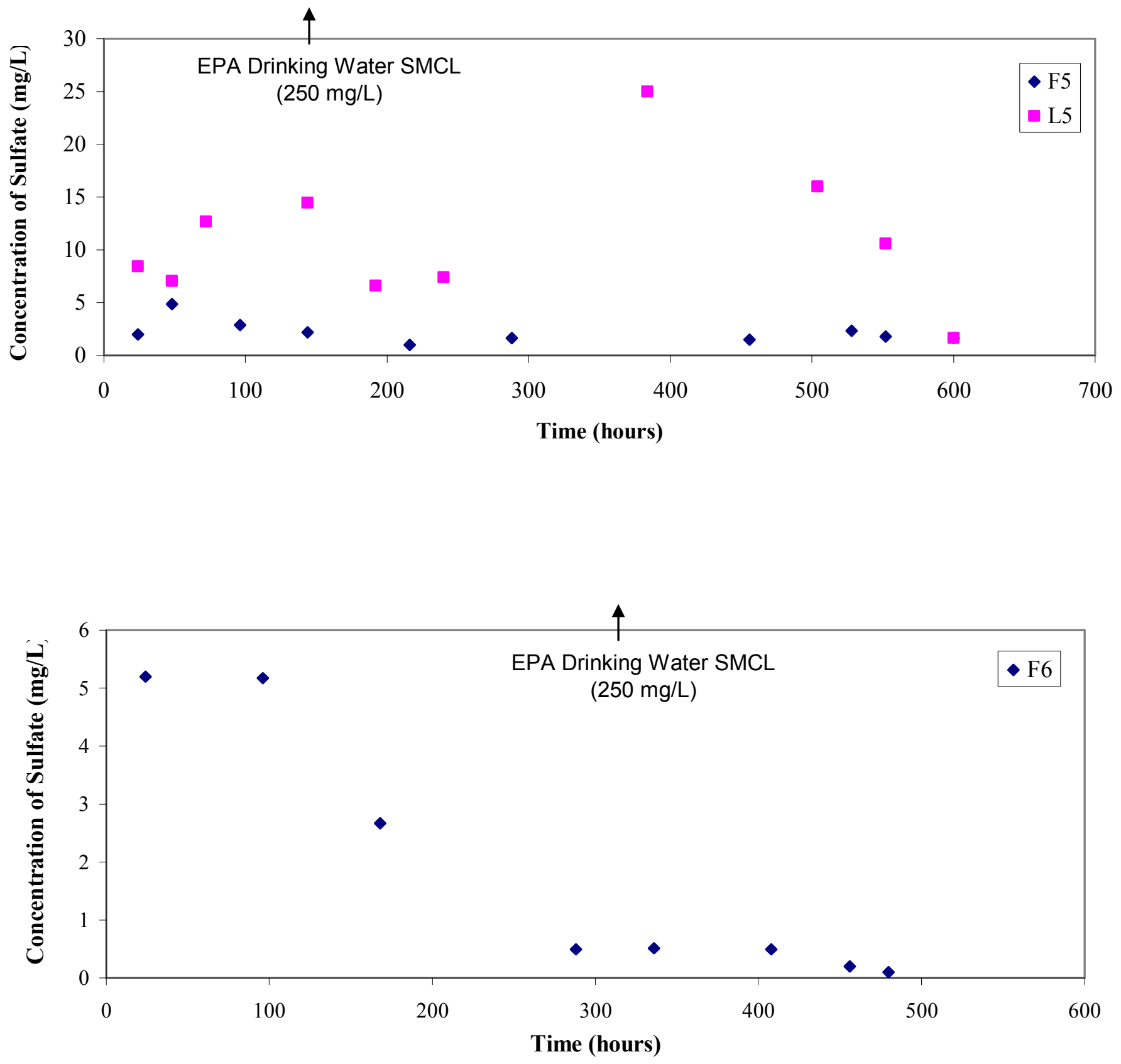

Figure 5.13 (Cont'd). Concentration of Sulfate versus time for different pyrite/grout mixtures 
- ing, the grouts may have dissolved at a much lower rate after some time, as indicated by a rapid decrease in their sulfate concentrations.

For column F3, on the other hand, the sulfate concentration is initially lower than that for F2. It is speculated that the delayed hardening of this grout allowed for continuing dissolution. This can be observed from the graph where the sulfate concentrations gradually increase indicating that dissolution is still taking place. Sulfate reaches a peak of $125 \mathrm{mg} / \mathrm{L}$ and then gradually decreases as the grout gains strength and dissolution decreases. A similar trend, a peak in sulfate concentration and a subsequent decrease, was also observed by Laperche and Traina (1999) when AMD from Roberts-Dawson mine in Ohio was remediated with flue gas desulfurization grout (FGDG). L5 (30\% LKD) exhibits a similar trend but at a lower concentration range (1.63 to $25 \mathrm{mg} / \mathrm{L}$ ) due to presence of relatively lower free lime content.

Column F4, which has relatively lower FBC content (40\%) showed an increasing trend indicating that the grout dissolution is taking place due to very slow hardening. Moreover, the low FBC content of F4 results in lower sulfate concentrations as compared to F2 and F3. Columns F5 and F6 (FBC contents 30\% and $20 \%$ respectively), showed rapid decrease in sulfate concentrations. The decrease may be due to depletion of the little amount of free lime present in the grout.

The data in Figure 5.13 indicate that the higher lime content of an activator results in higher sulfate concentrations due to neutralization reactions. For instance grout mixture F2 has the highest amount of FBC (i.e., 60\% FBC) and resulted in an initial sulfate concentration if $50 \mathrm{mg} / \mathrm{L}$. Grout mixture F6 which has the lowest lime 
activator content (i.e., 20\% FBC) generated an initial sulfate concentration of $5 \mathrm{mg} / \mathrm{L}$. similar observations were made for LKD-based grouts as well.

It can be seen from Figure 5.14(a) that sulfate concentrations increase with increasing $\mathrm{FBC} / \mathrm{FA}-\mathrm{BA}$ ratios, till an optimum $\mathrm{FBC} / \mathrm{FA}-\mathrm{BA}$ ratio is reached. Beyond a ratio of 1.0 , sulfate concentrations start to decrease. This may be due to excessive hardening of the grout due to higher free lime contents, which slows down the dissolution rate of the grout. No clear trends were observed with sulfate concentrations for LKD / FA-BA ratios.

\subsubsection{Calcium}

Calcium concentrations observed in the leachate indicate that dissolution of grout (Eqs 5.1 and 5.2) and neutralization of acidity (Eqs. 5.3 and 5.4) is taking place. Therefore, analysis of calcium concentrations in the leachate is important to estimate the efficiency of the grout in producing alkalinity and to determine its potential to remediate AMD. Concentration of calcium in leachate was measured by direct airacetylene flame method of atomic absorption spectrometry using a Perkin Elmer AA 5100 spectrometer. Four standard concentrations were prepared and used for calibration of the instrument to obtain a minimum correlation coefficient of 0.99 (i.e.,

$\left.\mathrm{R}^{2}=0.99\right)$. For leachate samples with high concentrations of calcium $(>50 \mathrm{mg} / \mathrm{L})$, the samples were diluted with de-ionized water, so that concentrations measured were in the range of standards used. The instrument reports the concentration in a sample as the average of two measurements conducted with a standard deviation of less than 1 . 

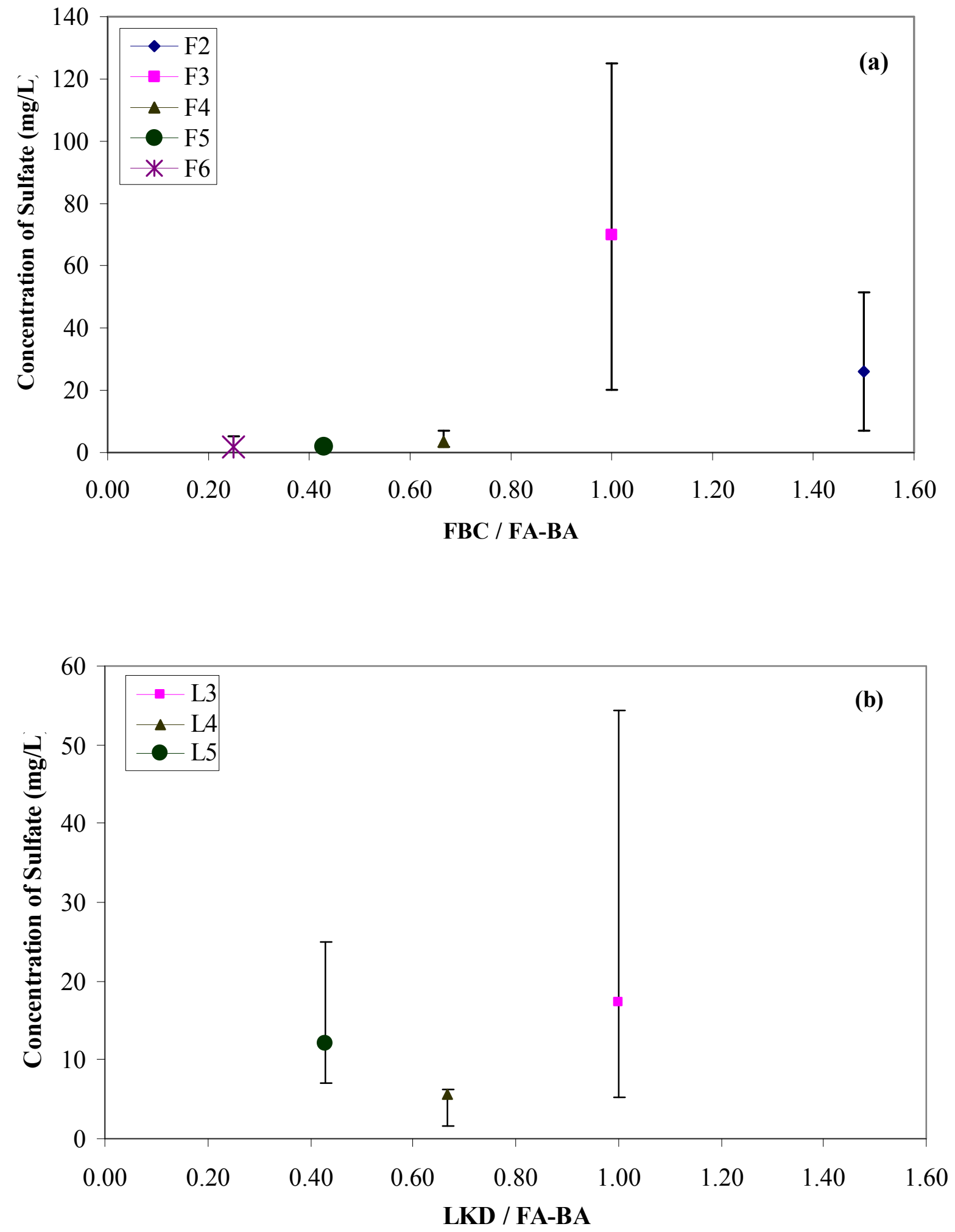

Figure 5.14. Concentration of Sulfate versus (a) FBC / FA-BA (b) LKD / FA-BA 
Figure 5.15 presents the changes in concentrations of calcium for different pyrite-grout columns with time. In general, calcium concentrations showed a decreasing trend with time. The decrease in calcium concentrations may be attributed to hardening of the grout causing the grout to dissolve at a slower rate. In general, the decrease was more rapid for higher lime content grout mixtures due to rapid hardening of the grouts.

Initial calcium concentrations for each grout mixture more often than not corresponded to its free lime content. For example, for the grout mixture with highest FBC content $(\mathrm{F} 2=60 \%)$ the initial calcium concentration was approximately 72 $\mathrm{mg} / \mathrm{L}$, and for the mixture with lowest $\mathrm{FBC}$ content $(\mathrm{F} 6=20 \%)$ the initial concentration was approximately $40 \mathrm{mg} / \mathrm{L}$ which immediately dropped to around 23 $\mathrm{mg} / \mathrm{L}$. This indicates that the calcium concentrations in the leachate are in fact due to dissolution of grout and neutralization reactions.

From Figure 5.16 it can be observed that concentrations of calcium observed in the leachate were in general higher for columns with higher free lime content / FABA ratios for both FBC and LKD-based columns. This could be attributed to the decrease in rates of dissolution of grout due to increasing hardening of grout.

In Figure 5.17 concentrations of calcium in the leachate are plotted against concentrations of sulfate for FBC and LKD-based columns. It can be seen that with increase in sulfate concentrations, concentrations of calcium also show an increasing trend which is proof that neutralization reactions are taking place and sufficient lime is present to neutralize acidity. This trend is also observed for LKD - based columns, 

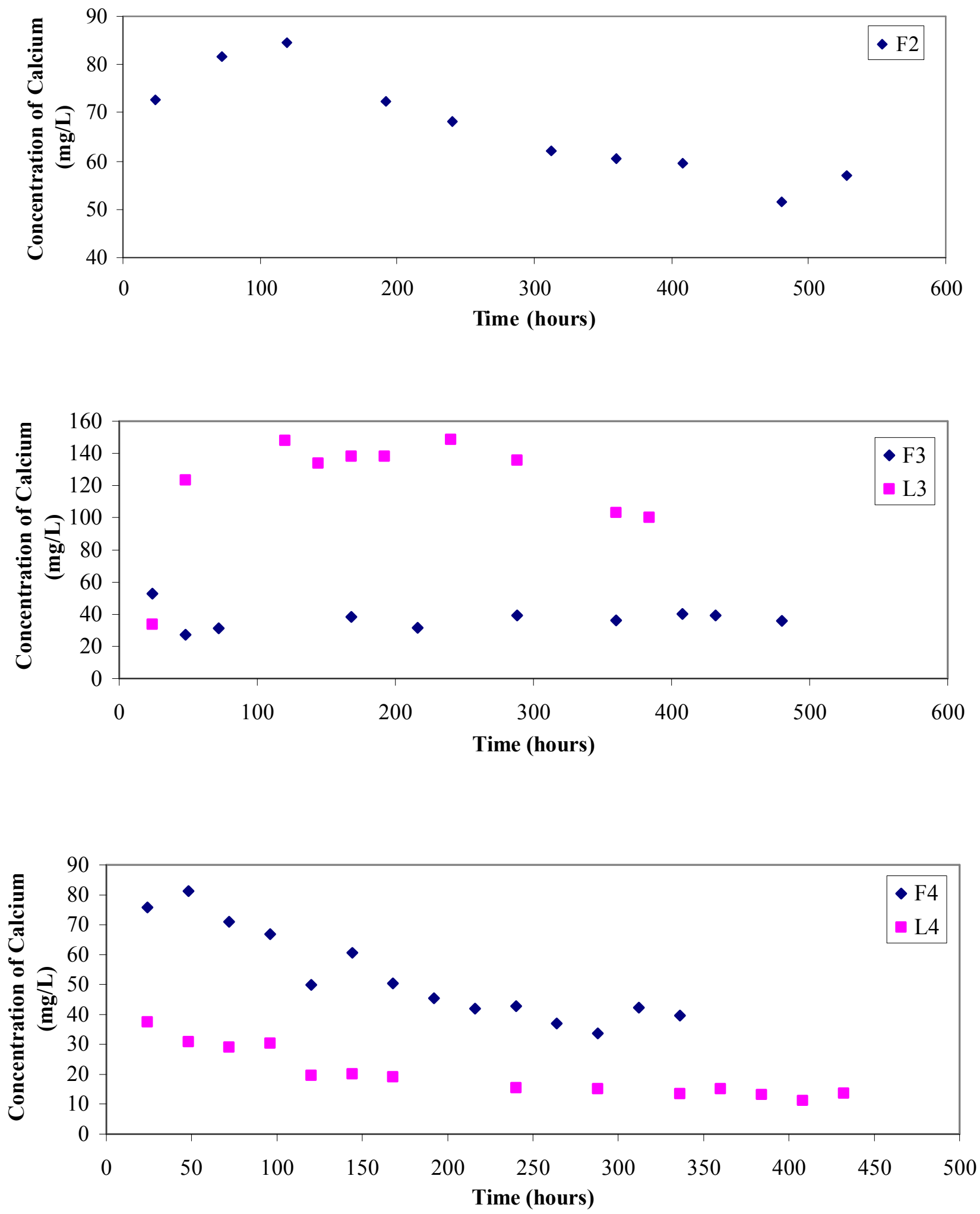

Figure 5.15. Concentration of Calcium versus time for different pyrite/grout mixtures 

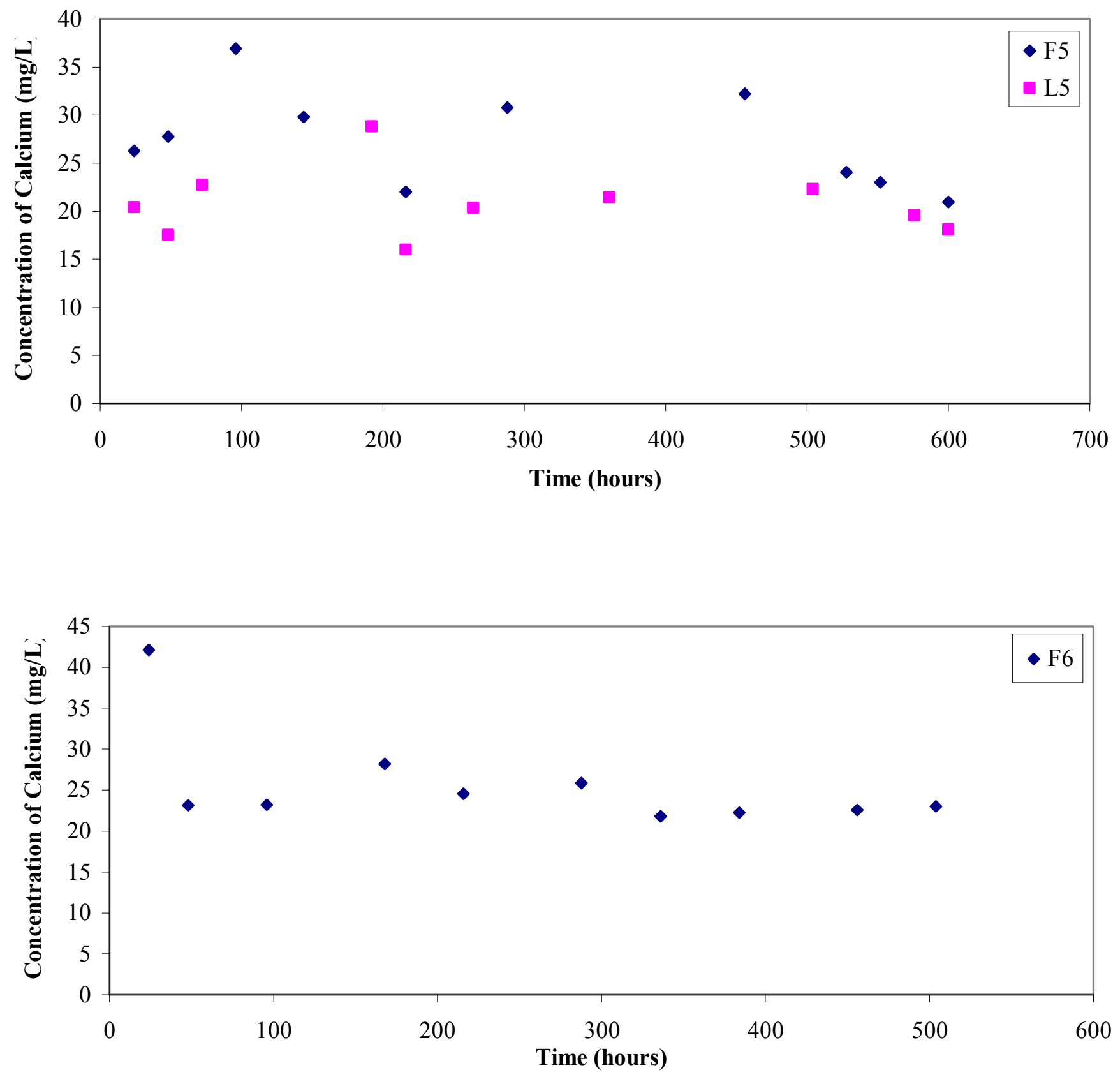

Figure 5.15 (Cont'd). Concentration of Calcium versus time for different pyrite/grout mixtures 

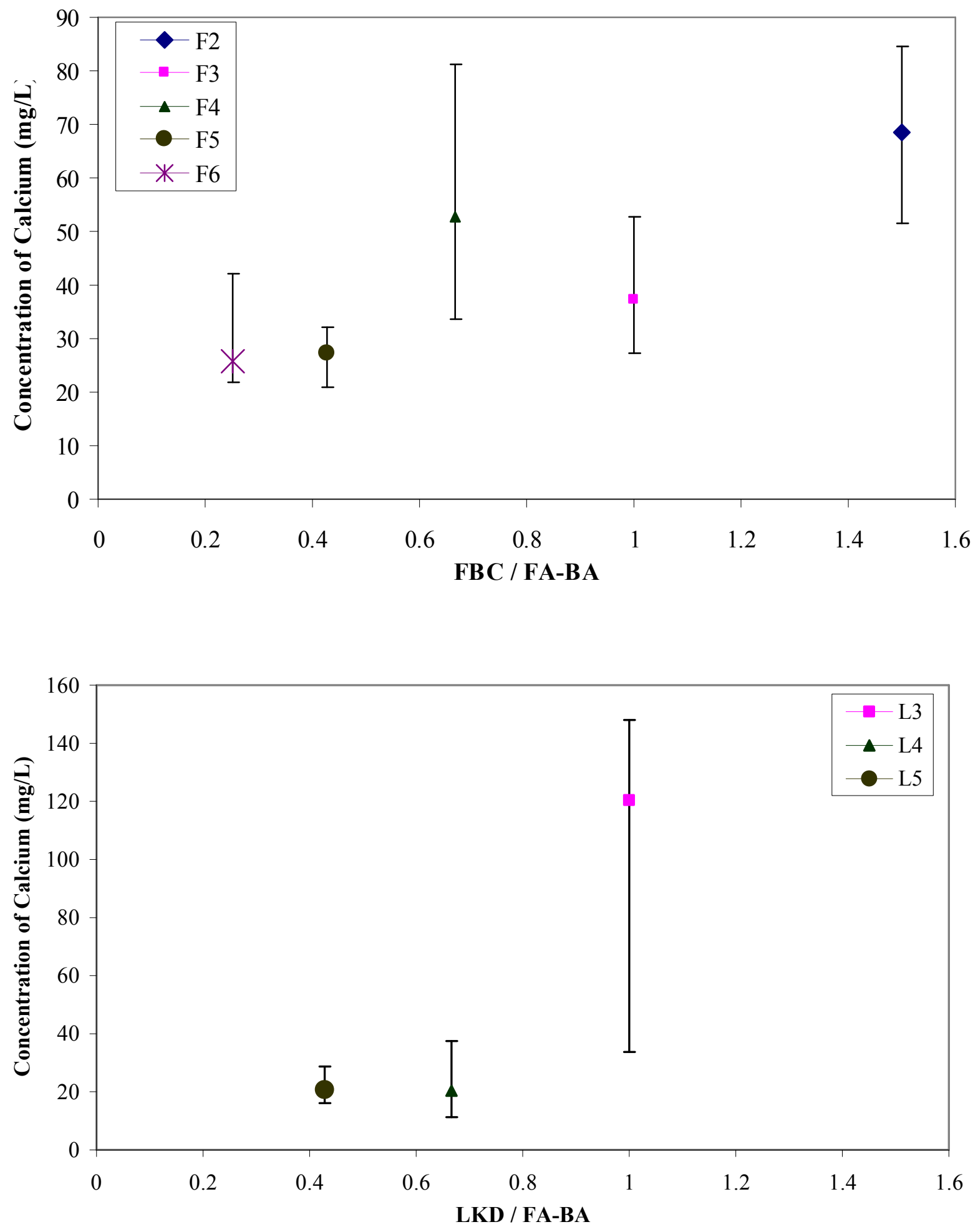

Figure 5.16. Concentration of Calcium versus (a) FBC / FA-BA, and (b) LKD / FA-BA 
however, there is some scatter in the plot for low concentrations of sulfate (Figure $5.17 b)$. 

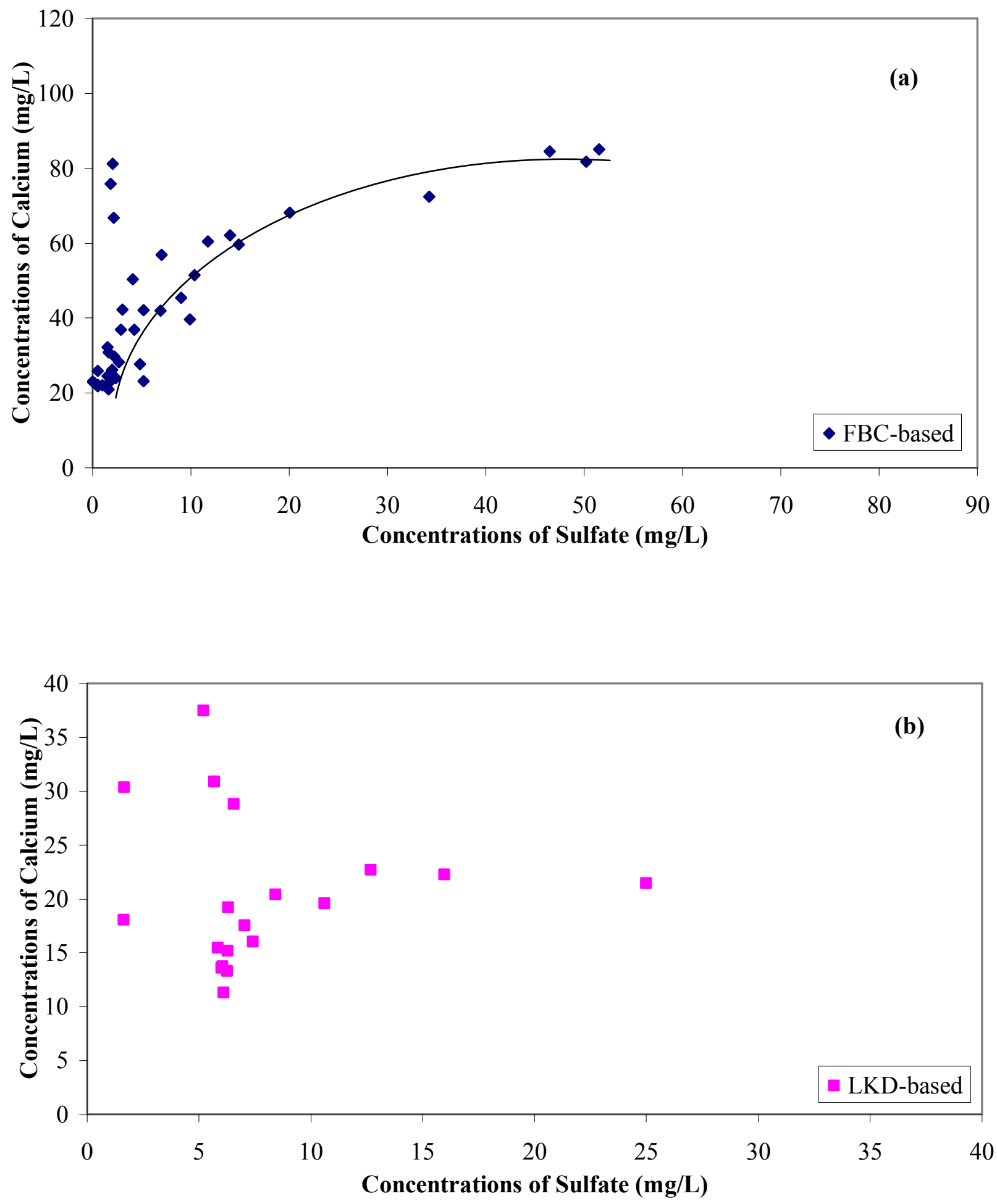

Figure 5.17. Concentrations of Calcium versus Concentrations of Sulfate for (a) FBCbased, and (b) LKD-based grout mixtures 


\section{SECTION 6}

\section{CONCLUSIONS AND RECOMMENDATIONS}

\subsection{SUMMARY AND CONCLUSIONS}

Acid mine drainage (AMD) is a commonly encountered problem in areas where abandoned coal mines exist. A study was conducted to investigate the effectiveness of CCBs to abate the acid mine drainage by studying the encapsulation of pyrite. Grouts prepared with various ratios of CCBs, and LKD were tested for geomechanical properties such as spread, slump, bleed, and strength. Eight "optimal" grout mixtures were selected and evaluated for their ability to encapsulate pyrite and neutralize AMD. Hydraulic conductivity of pyrite-grout columns was measured. Leachate collected from the columns was tested for various AMD-related parameters such as $\mathrm{pH}$, and concentrations of iron, aluminum, calcium, and sulfate. As part of the study, the data collected from the Frazee mine, a four hectare abandoned underground coal mine in Western Maryland remediated using CCBs, was analyzed to evaluate the long-term effectiveness of the encapsulation process.

The following conclusions are advanced from the current work:

1. Based on laboratory flowability and strength tests, an FBC-based mixture was selected for grouting an abandoned deep coal mine located in Western Maryland, as a part of the Winding Ridge Demonstration Project. A detailed cost analysis indicated that using $\mathrm{FBC}$ in a mine grouting application has a clear advantage over other free lime sources. 
2. It can be concluded from the constant flow rates encountered after grouting of the Frazee mine that entire filling of mine voids has not occurred, as was first intended. However, eight years of post-injection water quality monitoring shows that there has been a significant decrease in concentrations of major ions and trace elements in the mine water other than the short-term concentration fluctuations observed during injection. There was a significant decrease in total acidity. The acidity decreased to levels below pre injection conditions and the $\mathrm{pH}$ showed a subtle upward trend. The groundwater and surface water showed no adverse impacts of AMD in the pre or post-injection period.

3. Laboratory geomechanical testing of grout mixtures using FA-BA, and FBC or LKD indicated that all materials are highly sensitive to water contents and slight variation in water content has a considerable effect on the flow (spread) of the grout. Mechanical properties of the grout such as spread, slump, bleed and strength are dependent on the FA-BA mix and free lime contents. In general, increase in free lime content / FA-BA ratio increases the strength and decreases spread, slump, and bleed of the grout.

4. Laboratory tests showed that strength of grout increases with curing time. The rate of strength gain increased after 14 days for grout mixtures high in FA-BA content since fly ashes have slow reactive nature and gain strength only after sufficient curing. Rate of strength gain of FBC-based specimens is relatively lower after 14 days as compared to the strength gain in 7 days of curing. For LKD-based specimens with relatively higher lime contents, the 7-day 
strengths are low, and appreciable strength is gained after 14 days. Therefore, high lime contents can cause a rapid gain in the strength of grout, but the rate of strength gain decreases with curing time.

5. Based on the observed trends in the geomechanical properties, eight "optimal" grout mixtures were selected and tested for their ability to properly encapsulate pyrite and reduce the formation of AMD. Hydraulic conductivities of pyrite-grout columns are relatively higher than expected, mainly due to coating of the pyrite rock with the grout rather than filling of all the void spaces, even though volume of grout used was nearly equal to the volume of voids present in the pyrite. Therefore, the columns represented pyrite rock present on the mine pavement and walls of the mine shaft that has been "properly" encapsulated by grout.

6. The average $\mathrm{pH}$ of leachate from the columns increased with increasing free lime content of the grout. Iron and aluminum concentrations followed a decreasing trend with time. The rate of decrease of iron was slower for grouts with relatively higher free lime contents, due to rapid hardening and low dissolution rates of the grouts. An initial increase in aluminum concentrations was observed for grout mixtures with high FBC contents. This may be due to leaching of aluminum from the FBC.

7. Sulfate concentrations were highly dependent on the free lime content of the grout mixtures. Concentration of sulfate increased with increase in free lime content / FA-BA up to a ratio of 1.00 and then decreased indicating that high free lime content caused lower dissolution of grout due to hardening. 


\subsection{RECOMMENDATIONS}

1. From the observations made from the Winding Ridge Demonstration Project, and Taerakul et al. (2004) it is seen that complete filling of mine voids is usually not possible due to unknown voids that may be present in the mine, and/or limited penetration of grout into deeper mine voids. Therefore, encapsulation of pyrite should be targeted in field remediation projects.

2. From the results of leaching behavior of grout-encapsulated pyrite it can be observed that high free lime content of grouts is alone not sufficient to improve the quality of AMD since the rate of dissolution of high free lime content grouts may be slow due to rapid hardening. On the other hand, low free lime content may not provide sufficient strength to the grout to efficiently encapsulate pyrite. Also, the low free lime content may deplete quickly thus not providing alkalinity to the AMD in the long-run. Therefore, an optimum between the two has to be achieved.

3. Further research may be conducted on a large number of grouts with varying free lime contents in order to recommend this optimum free lime content grout mixture. 


\section{REFERENCES}

Adriano, D.C., Page, A.L., Elseewi, A.A., Chang, A.C., and Straughan, I. (1980). "Utilization and disposal of fly ash and other coal residues in terrestrial ecosystems: A review”, Journal of Environmental Quality, Vol. 9, No. 3, pp. 333344.

Aljoe, W. W. (1999). "Hydrologic and water quality changes resulting from injection of CCB grout into a Maryland underground mine", Presented at the $13^{\text {th }}$ International Symposium on Use and Management of Coal Combustion Products (CCPs), Orlando, Fl, pp. 66.1-66.12.

American Concrete Institute (1999). "Controlled low-strength materials", Report No. 229R-99, ACI Committee 229, Detroit, Michigan.

Ayers, M. E., Wong, S. Z., and Zaman, W. (1994). "Optimization of flowable fill mix proportions", ACI Committee 229, Controlled low-strength materials, SP-150, pp. $15-37$.

Barton, C. D. and Karathanasis, A. D. (1999). "Renovation of a failed constructed wetland treating acid mine drainage", Environmental Geology, Vol. 39, No. 1, pp. $39-50$.

Butalia, T. S., Wolfe, W. E., and Lee, J. W. (2001). "Evaluation of dry FGD material as a flowable fill”, Fuel, Vol. 80, No. 6, pp. 845-850.

Caruccio, F.T., G. Geidel, and Williams, R. (1984). "Induced alkaline recharge zones to mitigate acid seeps", Proceedings of the National Symposium on Surface Mining, Hydrology, Sedimentology and Reclamation, University of Kentucky, Lexington, KY, pp. 43-47. 
Conner, J. R. (1990). "Chemical fixation and solidification of hazardous wastes", Van Nostrald Reinhold, pp. 280-427.

Cravotta, C. A., III, K.B.C, Brady, M. W. Smith, and Beam, R. L. (1990). Effectiveness of the addition of alkaline materials at surface coal mines in preventing or abating acid mine drainage - Part I, Geochemical considerations", Proceedings of the 1990 Mining and Reclamation Conference, Charleston, West Virginia, Vol. 1, pp. 221-223.

Cravotta, C.A. (2003). "Size and Performance of Anoxic Limestone Drains to Neutralize Acidic Mine Drainage”, Journal of Environmental Quality, Vol. 32, pp. $1277-1289$

Department of the Army (1983). "Soil stabilization for pavements", online document (http://www.army.mil/usapa/eng/).

Dolence, R. C. and Giovannitti, E. (1997). "Utilization of coal ash / coal combustion products for mine reclamation", Proceedings of the American Power Conference, Vol. 59, No. 2, pp. 837-840.

Federal Highway Administration. (1986). "Fly Ash Facts for Highway Engineers", U.S. Department of Transportation, FHWA-DP-59-8, Demonstration Projects Program, July 1986.

Gabr, M. A., Boury, E., and Butler, C. (1996). "Fly ash-based mixtures for low permeability grouts", Geotechnical News, March Issue, pp. 26-30.

Gabr, M. A. and Bowders, J. J. (2000). "Controlled low-strength material using fly ash and AMD sludge", Journal of Hazardous Materials, Vol. 76, No. 2, pp. 251263. 
Gray, D. D., Reddy, T. P., Black, D. C., and Ziemkiewicz, P. F. (1998). "Filling abandoned mines with fluidized bed combustion ash grout", Design and Application of Controlled Low-Strength Materials (Flowable Fill), ASTM STP 1331, A. K. Howard and J. L. Hitch, eds., Philadelphia, Pennsylvania, pp. 180193.

Haefner, R. J. (2002). "Environmental tracers of leachate derived from pressurized fluidized bed combustion by-products in an abandoned coal mine setting", Proceedings of Coal Combustion By-products and Western Coal Mines: A Technical Interactive Forum, Golden, Colorado, pp. 89-96.

Han, S. H., Kim, J. K., and Park, Y. D. (2003). "Prediction of compressive strength of fly ash concrete by new apparent activation energy function", Cement and Concrete Research, Vol. 33, No. 7, pp. 965-971.

Harshberger, K. L. and Bowders, J. J. (1991). "Acid mine drainage control utilizing fly ash", Proc., ASCE Energy Division Specialty Conf. on Energy in the 90's, 300-305.

Hausmann, M. R. (1990, “Engineering principles of ground modification", McGrawHill, New York.

Hedin, R. S., Watzlaf, G. R., and Nairn, R. W. (1994). "Passive treatment of acid mine drainage with limestone", Journal of Environmental Quality, Vol. 23, pp. 1338-1345.

Herr, J. W., Chen, C. W., Goldstein, R. A., Herd, R., and Brown J. M. (2003). "Modeling acid mine drainage on a watershed scale for TMDL calculations", Journal of the American Water Resources Association, Vol. 39, No. 2, pp. 289300. 
Hodges W. K. and Keating, R. W. (1999). "Maryland power plant research program promotes the beneficial use of CCPs as a means to protect Maryland's Natural Rseources", Proceedings of International Ash Utilization Symposium, Lexington, Ky, p. 9.

Huang, W. H. (2001). "Improving the properties of cement - fly ash grout using fiber and superplasticizer", Cement and Concrete Research, Vol. 31, No. 7, pp. 10331041.

Indraratna, B. (1996). "Utilization of lime, slag and fly ash for improvement of colluvial soil in New South Wales, Australia", Geotechnical and Geological Engineering, Vol. 14, No. 3, pp. 169-191.

Johnson, D.B and Hallberg, K.B. (2005). "Acid Mine Drainage Remediation Options: A Review", Science of the Total Environment, Vol. 338, pp. 3-14.

Laperche, V. and Traina, S. J. (1999). "Flue gas desulfurization by-product weathering by acidic mine drainage", Journal of Environmental Quality, Vol. 28, pp. 1733-1741.

Lee, T., Park J., and Lee, J. (2004). "Waste Green Sands as Reactive Media for the Removal of Zinc from Water", Chemosphere, Vol. 56, pp 571-581.

Loop, C. (2004). "Lessons learned from full-scale, non-traditional placement of fly ash", Presented at State Regulation of CCB Placement at Mine Sites: A Technical Interactive Forum, Harrisburg, Pennsylvania.

Majizadeh, Kamran, Gary Bokowski, and Rashad El-Mitiny. (1979). "Material Characteristics of Power Plant Bottom Ashes and Their Performance in Bituminous Mixtures: A Laboratory Investigation," Proceedings of the Fifth 
International Ash Utilization Symposium, U.S. Department of Energy, Report No. METC/SP-79/10, Part 2, Morgantown, West Virginia.

Mehling P.E., Day, S.J., and Sexsmith, K.S. (1997). "Blending and layering waste rock to delay, mitigate or prevent acid generation: a case review study", Proceedings of the Fourth International Conference on Acid Rock Drainage, Vancouver, BC, Vol. II, pp. 953-70.

Mirza, J., Mirza, M.S., Roy, V., and Saleh, K. (2002). "Basic rheological and mechanical properties of high-volume fly ash grouts", Construction and Building Materials, Vol. 16, No. 6, pp. 353-363.

Moulton, L. K. (1973). "Bottom Ash and Boiler Slag", Proceedings of the Third International Ash Utilization Symposium. U.S. Bureau of Mines, Information Circular No. 8640, Washington, DC.

Murarka, I., Bailey, T. E, and Meiers, J. R. (2002). "Water quality at coal ash filled surface coal mine pit in Indiana", Proceedings of Coal Combustion By-products and Western Coal Mines: A Technical Interactive Forum, Golden, Colorado, pp. 197-221.

Naik, T. R. and Ramme, B. W. (1994). "Low-strength concrete and controlled lowstrength material (CLSM) produced with class F fly ash", ACI Committee 229, Controlled low-strength materials, SP-150, pp. 1-13.

Petzrick, P. (1997). "Ash utilization for elimination of acid mine drainage", Proceedings of the American Power Conference, Vol. 59, No. 2, pp. 834-836, Chicago, Illinois. 
Petzrick, P. (1999). "The coal combustion by-product/acid mine drainage partnership", Proceedings of the International Ash Utilization Symposium, Paper \#75, Lexington, Kentucky, 7 p.

Petzrick, P. (2001). "The use power plant coal combustion products in Maryland", Proceedings of the International Ash Utilization Symposium, Paper \#51, Lexington, Kentucky, 7 p.

Rafalko, L. G. and Petzrick, P. (2000). "Report of findings for the Winding Ridge demonstration project", Prepared for Power Plant Research Program, Maryland Department of Natural Resources, ERM, Inc., Annapolis, Maryland, 112 p.

Rose, A. W. and Cravotta, C. A., III (1998). "Geochemistry of coal mine drainage", Chapter 1, Coal mine drainage prediction and pollution prevention in Pennsylvania, The Pennsylvania Department of Environmental Protection, online document (http://www.dep.state.pa.us/dep/deputate/minres/districts/cmdp/chap01.html).

Rudisell, M. T., Stuart, B. J., Novak, G., Payne, H., and Togny, C. S. (2001). "Use of flue gas desulfurization by-product for mine sealing and abatement of acid mine drainage", Fuel, Vol. 80, No. 6, pp. 837-843.

Schueck, J., Tarantino, J., Kania, T., and Scheetz, B. (2001). "The use of FBC ash for alkaline addition at surface coal mines", Proceedings of the International Ash Utilization Symposium, Paper No. 49, Lexington, Ky., 16 p.

Sharma, H. D. and Lewis, S.P. (1994). "Waste containment systems, waste stabilization, and landfills-design and evaluation", John Wiley and Sons, Inc.

Singer, P. C. and Stumm, W. (1970). "Acid mine drainage: Rate-determining step", Science, Vol. 167, pp. 1121-1123. 
Siriwardane, H. J., Kannan, R. S. S., and Ziemkiewicz, P. F. (2003). "Use of waste materials for control of acid mine drainage and subsidence", Journal of Environmental Engineering, ASCE, Vol. 129, No. 10, pp. 910-915.

Skousen, J. and Ziemkiewicz, P. (1996). "Acid mine drainage control and treatment", 2nd Edit, National Mine Land Reclamation Center, WVU, Morgantown, WV, 362 p.

Smith, M. W. and Brady, K. B. C. (1998). "Alkaline addition”, Chapter 13, Coal mine drainage prediction and pollution prevention in Pennsylvania, The Pennsylvania Department of Environmental Protection, online document (http://www.dep.state.pa.us/dep/deputate/minres/districts/cmdp/chap13.html).

Stumm, W. and Morgan, J. J. (1996). "Aquatic chemistry: chemical equilibria and rates in natural waters", John Wiley and Sons, Inc., 1022 p.

Stump, D. E. (1998). "Grouting to control coal mine subsidence", Proceedings of the Geo-Congress, Geotechnical Special Publication, No. 40, pp. 128-138.

Taerakul, P., Lamminen, M., He, Y., Walker, H., Triana, S. J., and Whitlatch, E. (2004). "Long-term behavior of fixated flue gas desulfurization material grout in mine drainage environments", Journal of Environmental Engineering, ASCE, Vol. 130, No. 7, pp. 816-823.

Tolle, D. A., Arthur, M. F., and Pomeroy, S. E. (1982). "Fly ash use for agriculture and land reclamation: A critical literature review and identification of additional research needs", RP-1224-5, Battelle Columbus Laboratories. Columbus. Ohio.

Tuncan, A., Tuncan, M., and Koyuncu, H. (2000). "Use of Petroleum Contaminated Drilling Wastes as Subbase Material for Road Construction”, Waste Management and Research, Vol. 18, pp. 489-505. 
Turner, D., and McCoy, D. (1990). “Anoxic alkaline drain treatment system, a low cost acid mine drainage treatment alternative", Proceedings, 1990 National Symposium on Mining, University of Kentucky, Lexington, KY.

United Kingdom Quality Ash Association (2002). "Pulverized fuel ash for grouting", online document (http://www.ukqaa.org.uk/DSheet03/Datasheet3GroutsJune2002.htm).

U.S. EPA. (2004). "National Recommended Water Quality Criteria", online document (http://www.epa.gov/waterscience/criteria/nrwqc-2004.pdf).

Wattenbach, H. L., Rafalko, L. G., and Petzrick, P. (1999). “An evaluation of freelime containing by-products to produce CCB grouts for use in AMD abatement", Proceedings of the International Ash Utilization Symposium, Paper \#20, Lexington, Kentucky, 8 p.

Whitehead, P.G., Cosby, B.J., and Prior, H. (2005a). "The Wheal Jane wetlands model for bioremediation of acid mine drainage", Science of the Total Environment, Vol. 338, pp. 125-135.

Whitehead, P.G., Hall, G., Neal, C., and Prior, H. (2005b). "Chemical behavior of the Wheal Jane bioremediation system", Science of the Total Environment, Vol. 338, pp. 41-51.

Wilbert, K. L. (1997). "Displacement grouting used in abandoned mine lands", Proceedings of the First National Conference of the ASCE Geo-Institute, GeoLogan, Logan, UT, USA, pp. 434-440 
Ziemkiewicz, P.F., Skousen, J.G., and Lovett, R. (1994). "Open limestone channels for treating acid mine drainage: a new look at an old idea", Green Lands, Vol. 24, No. 4, pp. 36-41

Ziemkiewicz, P. F., Skousen, J.G., Brant, D.L., Sterner, P.L., and Lovett, R.J. (1997). "Acid mine drainage treatment with armored limestone in open limestone channels", Journal of Environmental Quality, Vol. 26, pp. 1017-102

Zurbuch, P.E. (1984). "Neutralization of acidified streams in West Virginia", Fisheries, Vol. 9, pp. 42-47.

Zurbuch, P.E. (1996). "Early results from calcium carbonate neutralization of two West Virginia rivers acidified by mine drainage", Proceedings of the Seventeenth West Virginia Surface Mine Drainage Task Force Symposium, Morgantown, WV, p L1-L9. 